\title{
Disability, Education and Development: Perspectives from Tokelau
}

\author{
Kathryn Meredith \\ A thesis submitted in partial fulfilment \\ of the Master of Development Studies Degree
}

Victoria University of Wellington

New Zealand

March 2009 

"We have to be determined to bring disabled people out of the shadowy world in which they are typically confined. ... Disabled people want what we all want - the chance to get educated, find rewarding work, lead worthwhile lives and be valued members of their community and in the world at large. These desires need not be just idle dreams, since much can be achieved if we are ready to give this extensive problem the attention and commitment it demands. We need to mobilize the determination to do just exactly that."

Amartya Sen \& John Wolfensohn, 2004 


\section{Abstract}

This thesis is concerned with the issue of people with disability accessing education. The contemporary international dialogue about how best to include people with disability in education recommends developing regular education systems to cater for the full diverse range of learners' needs and abilities. This approach is part of an Inclusive Education philosophy and is designed as a response to all populations who experience exclusion from education, including people with disability.

By examining people's opinions, experiences, attitudes, aspirations, perceptions, knowledge, and understanding about disability, education and development, this thesis aims to identify the challenges of including people with disability in education and society in the context of a small Pacific Island developng nation, and the ways in which these challenges can be addressed. In doing so, it contributes to the growing body of literature which raises awareness of the experiences of exclusion faced by people with impairments; as well as the literature exploring disability issues from a social and rights-based perspective in developing countries.

Semi-formal interviews were conducted with ten participants from Tokelau, New Zealand and Samoa to garner traditional, modern and personal perspectives about disability, education and development.

The main findings of the research are that although disability is still predominantly understood within a medical, religious or deficit-model paradigm in Tokelau, some historical attitudinal barriers to inclusion may be shifting. This is occurring as people become better informed about disability through education, personal experiences and awareness of the causes of disability. Consequently, there is some indication that the younger generation are less likely to stigmatise the cause of disability because of their exposure to scientific explanations and increased familiarity and comfort with human rights concepts. People in Tokelau called for raising public awareness about disability causes and issues.

Another finding of the research is that although there is a perception from some that the rhetoric of human rights is demanding and antithetical to the culture, responsibility is more easily accepted because it is considered in line with traditional 
communal values and social systems of support like inati (sharing of resources). Terminology aside, the concepts involved in Inclusive Education reflect traditional Tokelauan beliefs about treating people equally and with fakaaloalo (respect), alofa (love) and poupouaki (support).

Although the inclusion of disability issues into the international human rights framework through the UN 2006 Convention on the Rights of Persons with Disabilities is not yet widely known in Tokelau, human rights concepts are beginning to be introduced and understood at the community level, and they are seen in the constitutional documents and education policies of Tokelau. Support and partnership from New Zealand is welcomed in enabling locally developed inclusive services in Tokelau.

Overall, the research suggested that inclusive philosophies and approaches within the education system in Tokelau are emerging, and that it is an opportune time to develop capacity and services for ensuring that people with impairments can access education. Despite material and human resourcing difficulties, there is a general willingness to include people with impairments in society and a strong preference for a collaborative community wide approach. 


\section{Acknowledgements}

I would like to express my gratitude to the many people who have helped me while doing this research.

\section{In New Zealand}

Thanks to my supervisor Peggy Fairbairn-Dunlop, for her enthusiasm and wisdom, and for being inspiring! Thanks to my parents Noel and Pieta Meredith for their encouragement and support. Thanks to my friend Mary for her excellent and meticulous editing and to Clare and Anna for their proof-reading contributions also. Thanks to my colleagues at Group Special Education, particularly my manager Jane. Thanks to the Tokelau Team: Colleen, Ezra, Isopo, Jesse, Louella, Murray Rose, and Tim. Thanks to people who I've met through this research who have contributed along the way - Andrew Perez, Hayden Montgomerie, Tony Johns, Tessa Buchanan, Nila Lemisio-Poasa and Rebekah McCullough.

Arohanui to my friends and family.

\section{In Tokelau}

Fakafetai lava to everyone in Tokelau who has contributed to this research and to making my experiences in Tokelau so enjoyable. Thanks to the staff of the Tokelau Department of Education, and all the staff and students at Tialenui, Matiti and Matauala Preschools and Schools.

\section{In Samoa}

My gratitude goes to the staff at the Tokelau office and to those people who contributed to this research in Apia. 


\section{Glossary of Terms}

Atiakega

Aumaga

Inati

Faipule

Fatupaepae

Fono

General Fono

Lakehe

Maopopo

Motu

Nuku

Pulenuku

Taupulega

Ulu development

men's workforce organisation on each atoll

centralised sharing of the daily catch of fish and other

resources

village head, responsible for relationship and affairs with New

Zealand

women's workforce organisation on each atoll

meeting

Tokelau's parliament or national representative body, comprised of representatives from each atoll

preferential sharing of resources to support the needy

unity of being and spirit, togetherness

islet

village

village mayor, responsible for internal affairs of own atoll

village council of elders

head of state, during a three year tenure of government the position of Ulu is rotated annually between the three Faipule

Other Tokelauan words which occur with less frequency are explained as they arise in the text for ease of readability. 


\section{Acronyms}

ACYA Action for Children and Youth Aotearoa, NZ.

ADB Asian Development Bank

AUSAID Australian Agency for International Development

BMF Biwako Millenium Framework

CBR Community-Based Rehabilitation

CEDAW Convention on the Elimination of Discrimination Against Women

CIA Central Intelligence Agency

COG Council for the Ongoing Government of Tokelau

CRPD The Convention on the Rights of Persons with Disabilities

DFID Department for International Development; UK

DPO Disabled Persons Organisations

EFA Education For All

ESD Education for Sustainable Development

GDP Gross Domestic Product

GSE Group Special Education

HDI Human Development Index

IDA International Disability Alliance

IEP Individual Education Plan

MDG Millennium Development Goals

MFAT Ministry of Foreign Affairs and Trade

MHT Modern House of Tokelau

MOE Ministry of Education

NGO Non-Government Organisations

NOLA Nuanua O Le Alofa

NUS National University of Samoa

NZAID New Zealand Agency for International Development

PDF Pacific Development Forum 
PIFS Pacific Islands Forum Secretariat

PRG Pacific Research Guide

PRIDE Pacific Regional Initiatives for the Delivery of (basic) Education

SPC Secretariat of the Pacific Community

TALO Tokelau Apia Liaison Office

TPS Tokelau Public Service

TVET Technical and Vocational Education Training

UDHR Universal Declaration of Human Rights

UN United Nations

UNCROC United Nations Convention on the Rights of the Child

UNDP United Nations Development Programme

UNESCAP United Nations Economic and Social Council Asian-Pacific

UNESCO United Nations Educational, Scientific and Cultural Organisation

UNFPA United Nations Population Fund

UNGA United Nations General Assembly

UNICEF United Nations Children's Fund

UNOHCHR United Nations Office of the High Commissioner of Human Rights

VSA Volunteer Services Abroad

WHO World Health Organisation

WHOICF World Health Organisation International Classification of Functioning, Disability and Health 


\section{Contents}

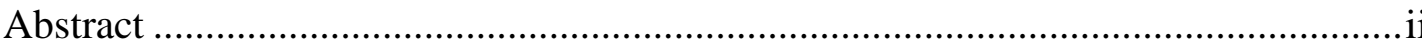

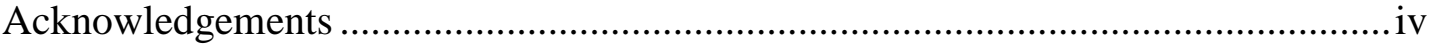

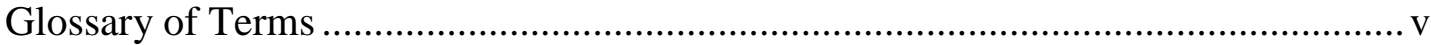

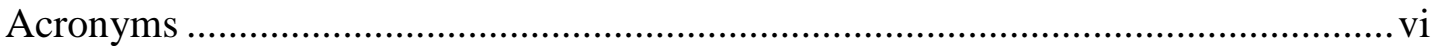

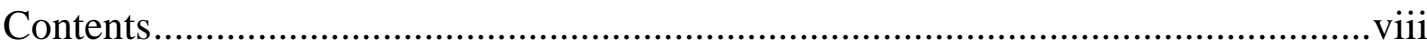

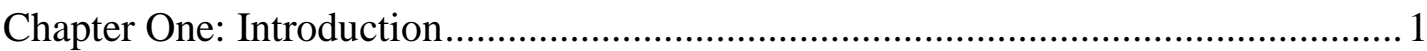

The link between Disability, Development and Education.................................... 1

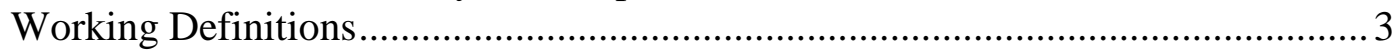

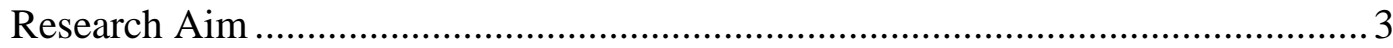

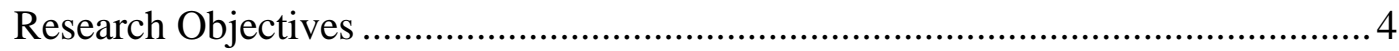

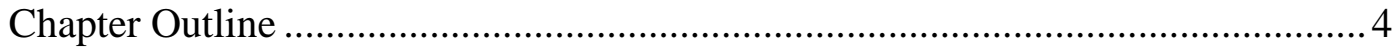

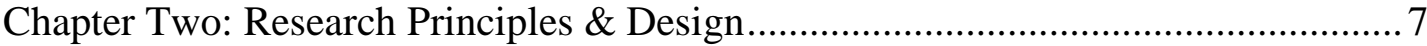

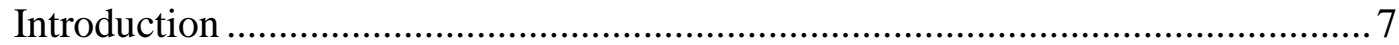

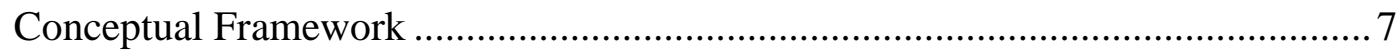

Qualitative Research Methodologies ................................................................... 8

Research with Indigenous Pacific Cultures \& Indigenous Research

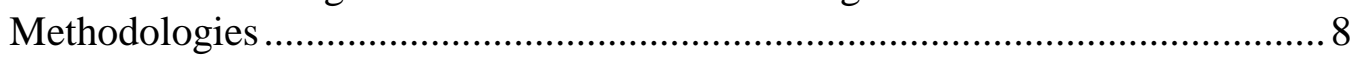

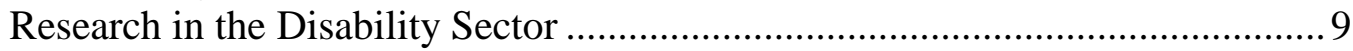

Disability Research in the Development Sector............................................. 10

Researcher's Own Philosophies and Place in the Research .............................. 10

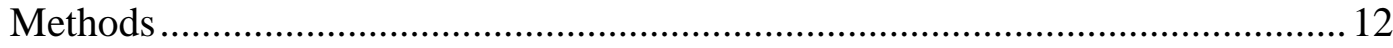

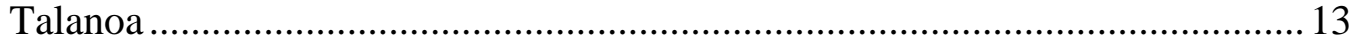

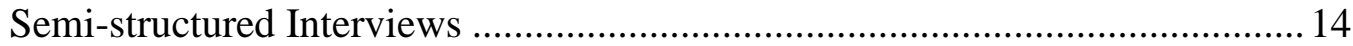

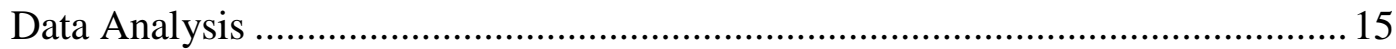

Grounded Theory Principles and a General Inductive Approach ..................... 15

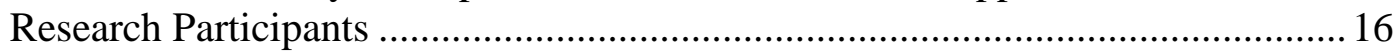

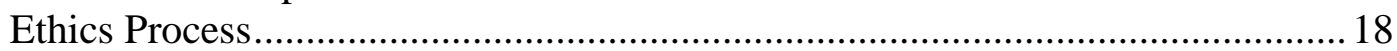

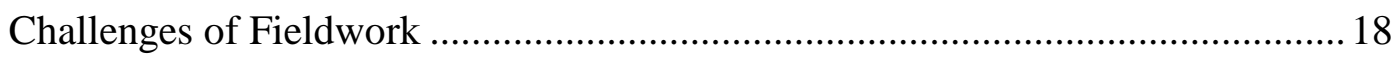

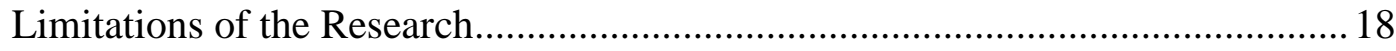

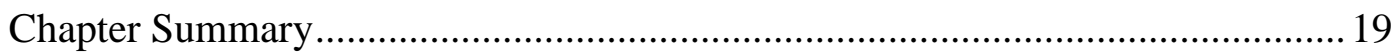

Chapter Three: Disability, Development and Education ........................................20

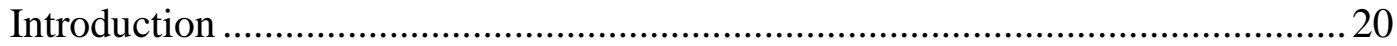

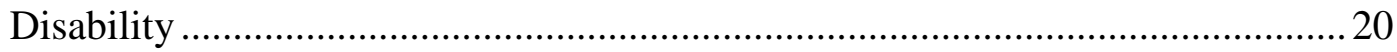

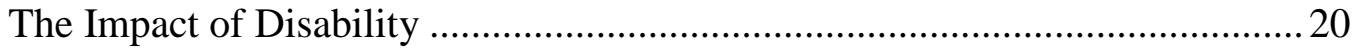

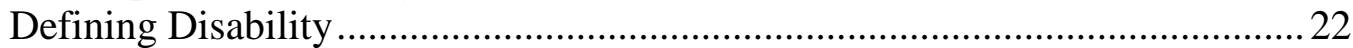

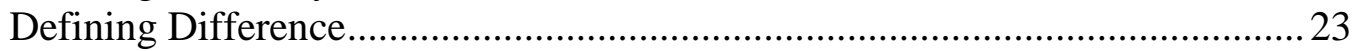

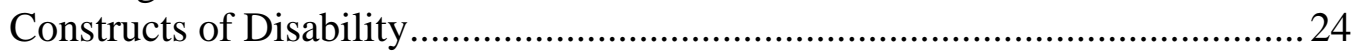

Considerations of Language and Terminology ............................................... 27

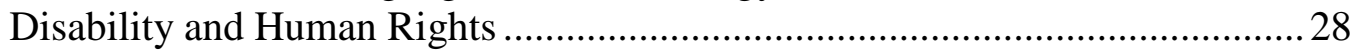

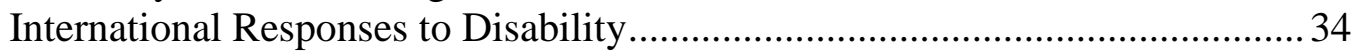

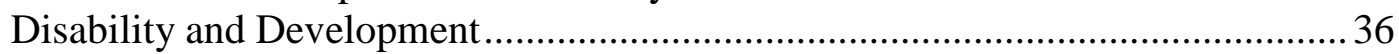

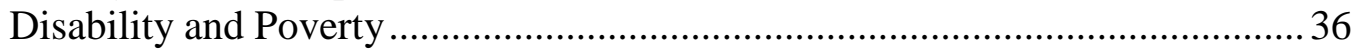

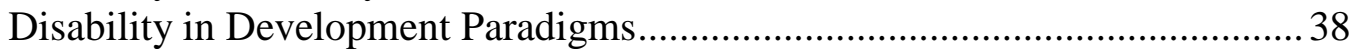

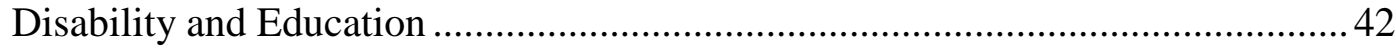

Disability, Development and Education in the Pacific .......................................48

Attitudes to disability in the Pacific ................................................................. 48

Pacific Regional Disability Initiatives ........................................................ 49 


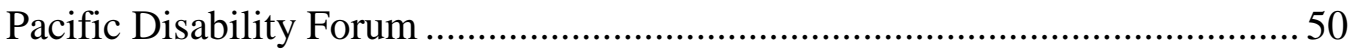

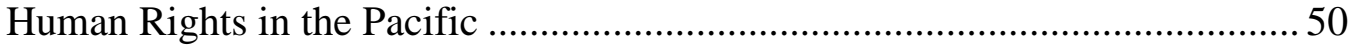

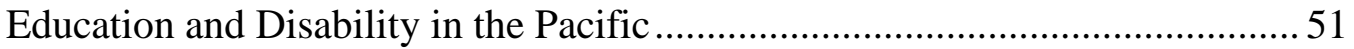

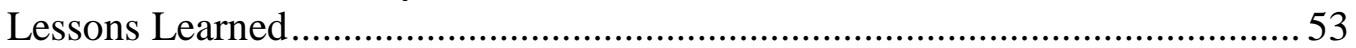

The National Experience of Inclusive Education in Samoa.............................. 53

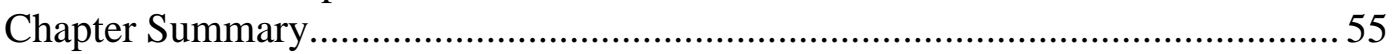

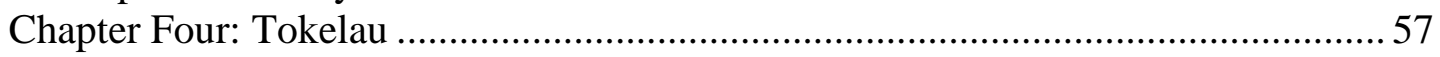

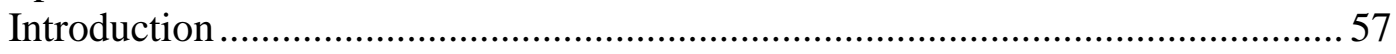

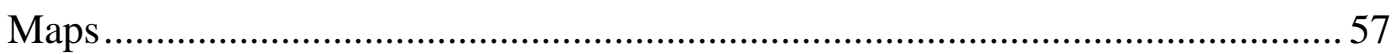

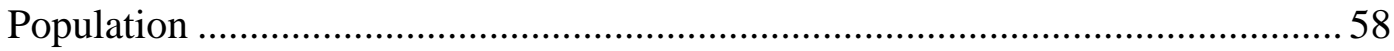

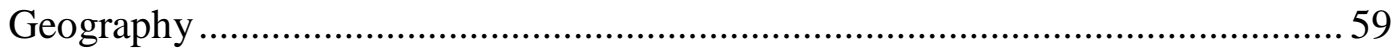

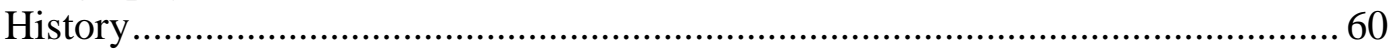

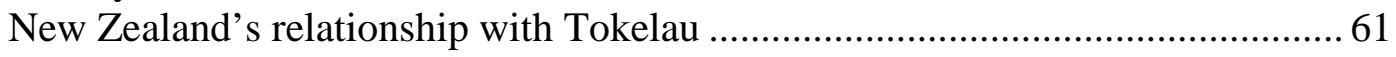

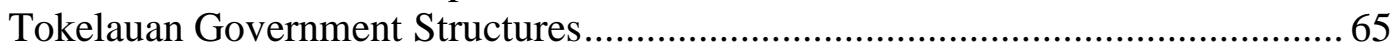

Tokelau Public Service \& the Modern House of Tokelau ................................... 66

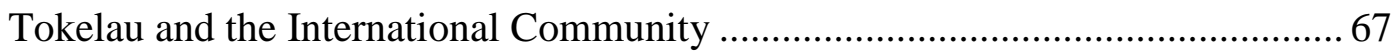

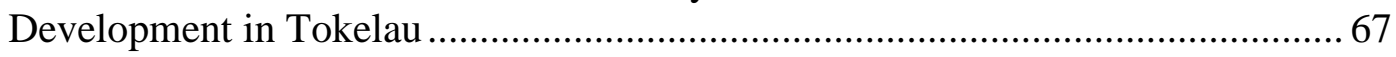

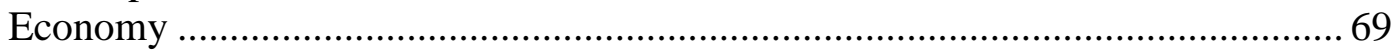

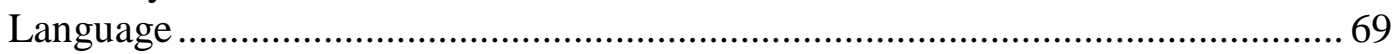

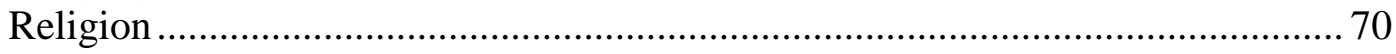

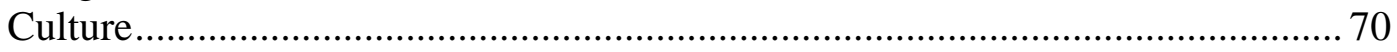

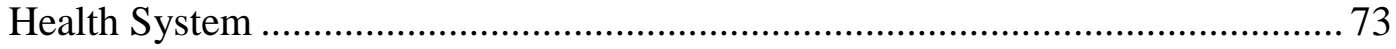

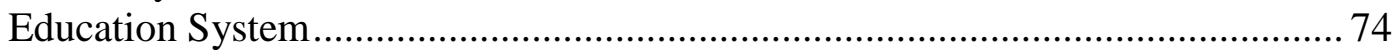

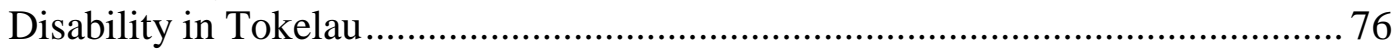

Inclusion International / NZAID Survey 2002 _.............................................. 76

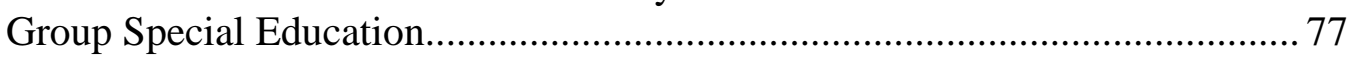

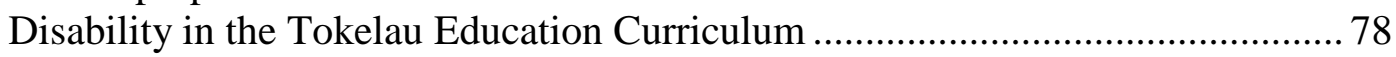

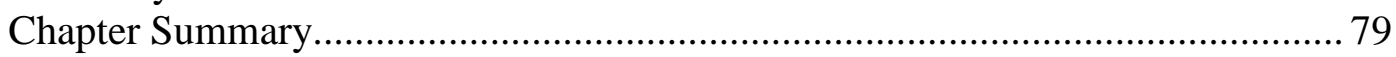

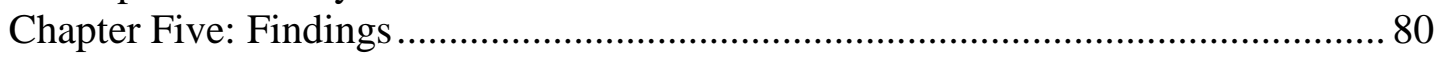

Part One: Knowledge and Understanding, Attitudes and Beliefs ........................ 80

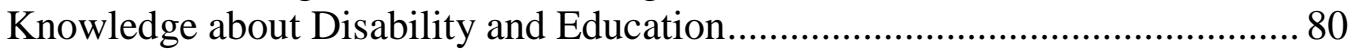

Attitudes to People with Disability and their Family........................................ 84

Part Two: Resources \& Provision of Support ....................................................... 97

Part Three: The Human Rights Framework \& Tokelau's participation in regional

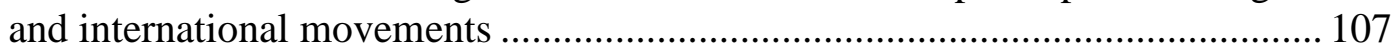

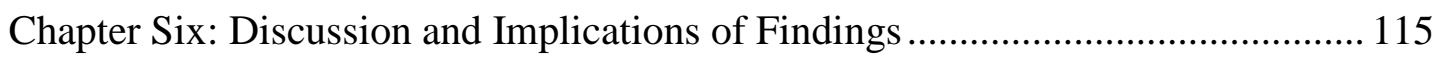

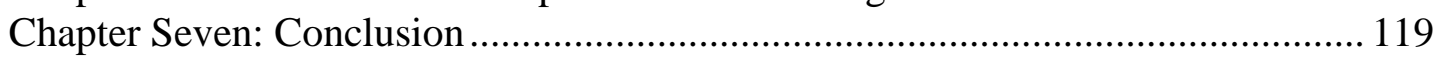

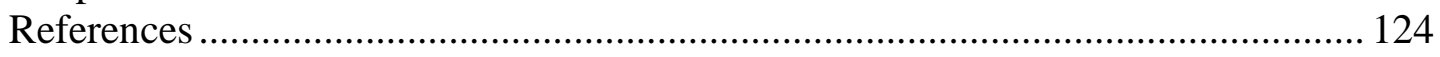

Appendix One: Principles which underpin the International Human Rights

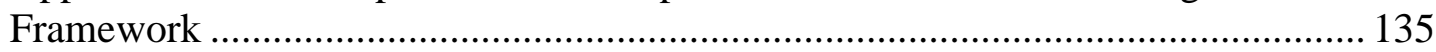

Appendix Two: Obligations of State Parties to International Human Rights Law .. 136 Appendix Three: Outline of International Frameworks relating to Disability,

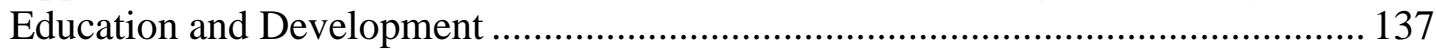

Appendix Four: UN Asian-Pacific Regional Disability Initiatives.......................... 140

Appendix Five: The Cycle of Poverty and Impairment .......................................... 142

Appendix Six: Bronfenbrenner's Ecological Model of Child Development ............ 143

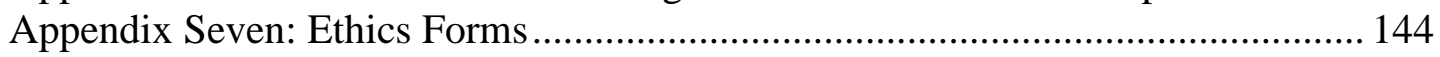

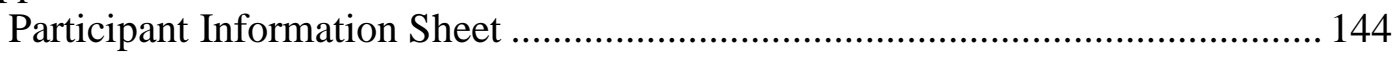

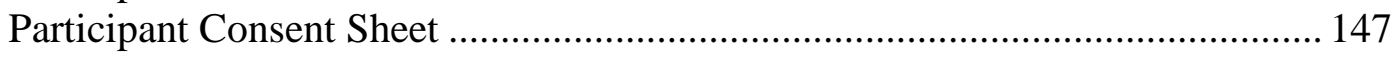

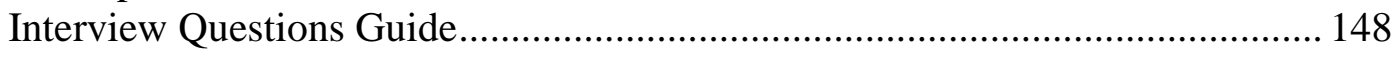


List of Figures and Tables

Figure 1: An Integrated Approach to Overcoming Obstacles..................................26

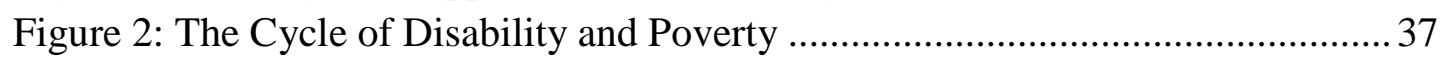

Figure 3: The Twin-Track Approach to Disability ...................................................39

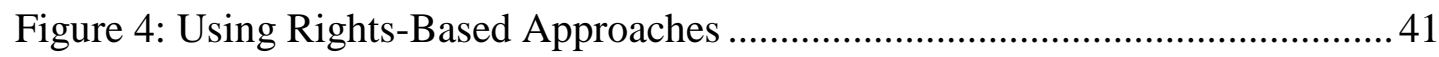

Figure 5: Map One: The Pacific Region ............................................................5

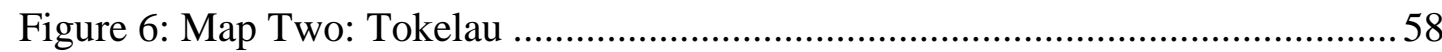

Table 1: The Coding Process in Inductive Analysis ................................................ 16

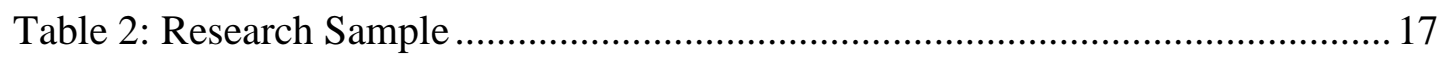

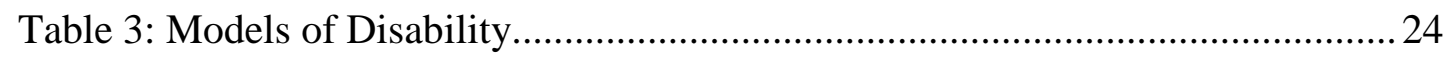

Table 4: International Mandates Relating to Disability and Education .....................29

Table 5: Tokelau 2006 / 2007 Population Data.........................................................5

Table 6: Human Development Indicators for Tokelau..............................................6 68

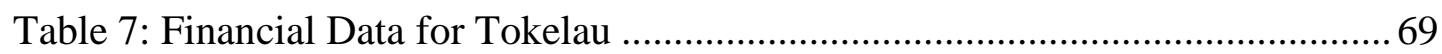

Table 8: Religious Affiliation in Tokelau by Atoll ................................................. 70

Table 9: Religious Affiliation in Tokelau by Percentage............................................ 70

Table 10: Number of Students on each Atoll in Tokelau........................................... 74

Table 11: Tokelau Disability Identification Survey 2002 ......................................76 


\section{Chapter One: Introduction}

\section{The link between Disability, Development and Education.}

Full participation in a community is central to the realisation of every person's human rights (UDHR, 1948; UNOHCHR, 2006). Yet for many people with disability, social, economic, political and cultural participation in daily life is limited by society's systemic preferential bias toward the majority (Katsui, 2005; Minnow, 1990; Smith; 2004). Discrimination towards people with disability occurs in all cultures. Attitudinal, political, social and cultural barriers result in a continuum of subtle to overt marginalisation of over 650 million people living with disability, the majority of whom live in the developing world (Miles, 2003; UN Enable, n.d.; AusAID, 2008). Disability is both a cause and a consequence of poverty, which is interpreted in this thesis in its broadest sense as defined by Mikkelsen (2005):

"Someone, for whom a number of human rights remain unfulfilled, such as the right to food, health, education, information, participation, etc., is a poor person. Poverty is thus more than lack of resources - it is the manifestation of exclusion and powerlessness" (p. 204).

Disability issues cannot be resolved without an increase in committed action because the population of people living with disability is predicted to rise (because of population growth, ageing, lifestyle diseases such as diabetes, accidents, conflict, malnutrition, injuries, HIV and advances in medicine which preserve and prolong life) (AusAID, 2009; Thomas, 2005). To successfully alleviate poverty and progress the realisation of human rights and equality, development must therefore include disability issues (DFID, 2000).

Education is the platform on which many development initiatives are founded and is the key to human development (AusAID, 2008; Jonsson \& Wiman, 2001; Lene, 2005; Price, 2003; Sen, 1990; Yeo \& Moore, 2005). The denial of education to people with disability is detrimental to their own, and society's development. Yet, despite a strong global commitment to international targets like Education For All ${ }^{1}$

\footnotetext{
${ }^{1}$ At successive World Conferences on Education for All (EFA) in 1990 and World Education Forum in 2000, 155 countries and 150 international organisations pledged a commitment to providing basic education for all children, youth and adults by 2000, then 2015. For more information see: http://www.unesco.org/education/efa/ed_for_all/
} 
and Universal Primary Education ${ }^{2}$, education continues to be denied to most children with disability in the developing world (DFID, 2000; Price, 2003, UNESCO; 1994). The link between disability and education and the realisation of human rights is thus critical to the field of development (Katsui, 2005; Yeo \& Moore, 2003).

The most recent United Nations (UN) addition to the international human rights framework is the Convention on the Rights of Persons with Disabilities (CRPD). It came into force on the $3^{\text {rd }}$ May 2008, signalling a strengthened commitment by the international community to fostering inclusive and enabling societies (UN, 2006). This convention has reinforced the paradigm shift of disability from a care and welfare issue to a human rights issue. The topic of this research is therefore in line with current international priorities.

This research seeks to explore the relationship between disability, development and education at the global and regional Pacific level. It then centres on the case study of Tokelau, a small Pacific Island nation which is New Zealand's last remaining dependent colony. In 2006 the Tokelauan government requested support in developing its capacity in Special Education from the New Zealand Ministry of Education (MOE)'s Group Special Education (GSE).

Practical, political, environmental and attitudinal adaptations are needed when developing inclusive societies. While commitment and guidance at the government level is critical, change at the community level is ultimately dependent on the will and actions of members of the community. This research thus seeks to explore people's opinions, experiences, attitudes, aspirations, perceptions, knowledge, and understanding about disability, education and development in Tokelau.

\footnotetext{
${ }^{2}$ Universal Primary Education is the second of eight Millennium Development Goals (MDGs), a series of internationally agreed upon development targets to be achieved by 2015 . The MDGs derived from the UN Millennium Declaration which was adopted by 189 nations and signed by 147 heads of state and governments at the Millennium Summit in 2000. For more information see: http://www.undp.org/mdg/goal2.shtml
} 


\section{Working Definitions}

For the purpose of this thesis, the following definitions are given:

The definition of a 'child' is taken from the United Nations Convention on the Rights of the Child (UNCROC), and refers to any person less than 18 years old ${ }^{3}$ (UN, 1989).

The definition of 'culture' will be taken from Thaman (2000) - "a shared way of living of a group of people which includes their accumulated knowledge and understandings, skills and values, and which is perceived by then to be unique and meaningful" (p. 1).

The definition of 'disability' is taken from the United Nations (UN) Convention on the Rights of Persons with Disabilities (CRPD) - "persons with disabilities include those who have long-term physical, mental, intellectual or sensory impairments which in interaction with various barriers may hinder their full and effective participation in society on an equal basis with others." (Article 1, UNCRPD, 2006). The definition of disability is discussed thoroughly in Chapter 3.

The definition of 'development' is taken from Sen (1999) - "a process of expanding the real freedoms that people enjoy" (p. 3). This definition includes economic growth, social and economic arrangements, and access to political and civil rights. It also includes the removal of obstacles to participation in daily life and fundamental human freedoms.

'Poverty' is defined by Mikkelsen (2005) above.

\section{Research Aim}

By examining people's opinions, experiences, attitudes, aspirations, perceptions, knowledge, and understanding about disability, education and development, this thesis aims to identify the challenges of including people with disability in education

\footnotetext{
${ }^{3}$ UNCROC recognises legal differences in some countries of the definition of a 'child'. There is variance in the definition of a child in the Pacific - for example, Huffer (2006) notes that many Pacific countries consider that the childhood of a girl ends upon her first menstruation, which can be between $10-15$ years old.
} 
and society in the context of a small Pacific Island developng nation, and the ways in which these challenges can be addressed.

In doing so, it contributes to the growing body of literature which raises awareness of the experiences of exclusion faced by people with impairments; as well as the literature exploring disability issues from a social and rights-based perspective in developing countries, an area which has previously been dominated by medical model studies (Shakespeare \& Watson, 2002; Yeo \& Moore, 2003).

\section{Research Objectives}

In order to achieve the research aim, the following objectives have been formulated:

1. To understand what disability is and why it is important to include disability planning in development work at a global and Pacific regional level.

2. To understand historical and modern paradigms about education for children with disability at a global and Pacific regional level.

3. To understand the local context of Tokelau where the fieldwork was undertaken, so that considerations about the practical application of the global ideas about disability, development and education can be better understood.

4. To document traditional and modern Tokelauan perceptions and knowledge about disability, and aspirations for educating people with disability in Tokelau.

5. To explore opinions about New Zealand's role and responsibilities in ensuring education for children with disability and building capabilities in Tokelau, considering Tokelau's status as a dependent territory of New Zealand.

6. To find out the practical impact and significance of regional and international initiatives and mandates concerning disability issues at the local level.

\section{Chapter Outline}

This introductory chapter is the first of seven chapters.

Chapter Two presents the research design and process involved in meeting the research aim. It outlines the chosen conceptual framework - social constructivism, and research methods and methodologies, and explains why they are suited to this 
research. The ethics process and limitations of the research are discussed in this chapter.

Chapter Three focuses on objectives one and two by exploring three interconnected topics: disability, development and education, at the global and Pacific regional level. The chapter first explores how the definitions and constructs of disability have changed to reflect a social model which recognises the human rights of people with disability; it also considers the international human rights framework and the international response to disability. The second section of the chapter illustrates why incorporating disability issues into development is important, and looks at two development paradigms, rights-based development perspectives and approaches and participatory development, which are well suited to the contemporary realisation of inclusion and participation in society and empowerment for people with disability. The third section of the chapter looks at historical and contemporary ideas of how best to include people with disability in education. All three components are then localised to the context of the Pacific, where governments, aid donors and NGOs work together to respond to the needs of their disabled citizens. This section looks at attitudes about disability in the Pacific, some of the regional and international initiatives and mandates about disability, development and education, and the relevance of human rights-based approaches. Lastly it outlines some disability initiatives in Samoa, Tokelau's closest neighbour, to give an example of some national and grass roots applications of the global and regional ideas.

Chapter Four meets objective three by giving an historical and present day illustration of Tokelau, and provides the contextual background for objectives four to six. This chapter describes the contemporary administration which incorporates elements of Western governance and traditional authoritative structures, and considers some of the implications and challenges Tokelau faces as a small developing island nation. It also explores the special relationship between Tokelau and New Zealand.

Chapter Five addresses objectives four to six; it presents the data from the interviews thematically in accordance with three broad themes: Attitudes \& Knowledge, Resources \& Support, and Regional \& International Initiatives.

Chapter Six discusses the findings and considers their implications. 
Chapter Seven concludes the thesis with a summary of the research findings including suggestions for future research topics. 


\section{Chapter Two: Research Principles \& Design}

\section{Introduction}

This chapter presents the research principles and design. It starts with a discussion of the conceptual framework which underpins the research and the research methodologies used. This research is undertaken from the perspective of development studies research, which is both action and policy-oriented, and highly practical (Mikkelsen, 2005). Like most ethnographic development studies research, this thesis is interdisciplinary and participatory in nature in that it seeks to contribute to dialogue amongst people impacted by the topic. Consideration is given to undertaking development research with Pacific participants, as well as within the disability sector. The chapter outlines the methods used and the ethics process, and concludes by giving some of the constraints of the research.

\section{Conceptual Framework}

In terms of research philosophy, I employ a social constructivist approach in which meaning is constructed and influenced by lived experiences, cultures, polities, societal norms and histories (Mikkelsen, 2005). Social constructivism is evident when looking at the variance in constructs of disability between cultures and over time, and therefore naturally follows as the appropriate choice for research methodology. As mentioned earlier, the aim of this reseach is to explore people's opinions, experiences, attitudes, aspirations, perceptions, knowledge and understanding about disability, development and inclusive education in Tokelau. Social constructivism is therefore the most appropriate epistemology for the content and context of the research; and is aligned to my own beliefs. Like social constructivism, indigenous research in the Pacific holds that the researcher and research recipients, methodology, framework and context are all influenced by values (Sanga, 2004). I acknowledge that research is a subjective exercise that neither the participants nor the researcher can, nor should, be removed from. Cultural and societal norms interplay in research and in the context in which research is situated. 


\section{Qualitative Research Methodologies}

Like social constructivism, qualitative research methodologies have been chosen because they hold that meanings should be taken from people's perspectives and also disclaim that everything can be measured scientifically and objectively (Mikkelsen, 2005). Qualitative research aims to obtain contextual details, insider perspectives and particularities (Sanga, 2004). Qualitative methodologies are considered appropriate to meet the research aim of garnering opinions and experiences, as they offer:

- "The ability to obtain rich contextual details;

- The ability to capture realities as they unfold;

- Multiple realities to be captured;

- Particularities to be spotlighted;

- Each voice to be heard" (Sanga, 2004, p. 44).

The chosen qualitative research methods (such as semi-structured interviews and Talanoa ${ }^{4}$ ), and data analysis approaches (such as using grounded theory principles and a general inductive approach) are also appropriate for this research, given its social constructivist conceptual framework (Vaioleti, 2006; Charmez, 2006).

\section{Research with Indigenous Pacific Cultures \& Indigenous Research Methodologies}

As Sanga (2004) notes, Pacific research sees knowledge as relativist and inseparable from the context and social realities of Pacific peoples. Before beginning the field research, the Pacific Research Guide (PRG) developed by the Ministry of Education (MOE) in 2001 was referred to for guidance in terms of protocols and the operational side of conducting research with Pacific participants.

For many indigenous cultures research has historically been used as a tool of oppression to further the gap between the powerful and the less powerful, i.e. the researcher and the subjects of research (Baba, 2004; Smith, 2004). There are accounts of research fatigue amongst Pacific peoples because past participation in research has not always led to beneficial outcomes, resulting in a lack of enthusiasm for more of the same kinds of research (Vaioleti, 2006).

\footnotetext{
${ }^{4}$ Talanoa is explained further on page 12.
} 
However, Baba (2004) states that there is now a change in the perception that research is a further tool of neo-colonialism as indigenous cultures are now taking on the role of advocacy for their rights in order to "reclaim their knowledge, systems and processes" (p. 97). Indigenous scholars, including those from the Pacific, are engaging more with debates about research methodologies and research undertaken with indigenous communities (Smith, 2004, p. 5). Research is increasingly seen as a useful tool for development and self-determination (Baba, 2004; Williams, 2004; Smith, 2004). For research to serve these goals, the relationship between the researchers, the recipients of the research and the actual data must be as directed by the recipients of the research as possible. At the minimum a partnership must exist in order for research to be symbiotic and not merely an extractive process (Baba, 2004; Smith, 1999, Vaioleti, 2006).

In this instance, I am picking up a topic which has already been defined collaboratively by the education departments in New Zealand and Tokelau. It cannot be said that this research follows the participatory planning ideal in which development researchers give up their right to define what the problem is, whose problem it is, how to solve it and why it must be solved, nor the Talanoa ideal that places the power to define Pacific issues between researcher and participant (Mikkelsen, 2005; Vaioleti, 2006). However, in the greater scheme of initiatives underway in Tokelau, it is hoped that this research can offer insight into an issue which has already been identified: the challenges of including children with disability in meaningful education.

\section{Research in the Disability Sector}

Research into disability has historically been dominated by a medical model perspective, although there is a growing body of literature into the experiences of people with disability from the social model perspective ${ }^{5}$ (Lene, 2005; Yeo \& Moore, 2003). Knox, Mok \& Parmenter (2000) state that ideally research depicting the experiences of people with disability is done with participants as active coresearchers. This avoids characterising people with impairments as passive recipients of research and allows them to vouch for the authenticity of the information and not

\footnotetext{
${ }^{5}$ A medical model of disability considers only anatomical or physiological deviances from the ablebodied population whereas the social model considers impairment of function and therefore incorporates the social elements of disability (discussed further on pages $24-25$ ).
} 
leave it to be interpreted by a non-disabled person (Knox, Mok \& Parmenter, 2000). Disability studies refer to 'emancipatory research' which is research used to effect beneficial social change for people with disability, their families and societies (Katsui, 2005; Lene, 2005).

\section{Disability Research in the Development Sector}

Yeo \& Moore (2003) searched 44 development journals between the years 1997 2002 for keywords such as 'handicap' 'disability' and 'impairment' and reported a "dearth" of research into development, poverty and disability (their search returned 24 articles in 13 journals). It has been suggested that development research is guilty of marginalisation of disability issues, or more moderately of briefly acknowledging people with disability as included in the 'most vulnerable' or 'poorest' groups and then forgetting them (Yeo \& Moore, 2003; Katsui \& Kumpuvuori, 2008). While there is a growing body of research into disability and development (e.g. Katsui, 2005; Lene, 2005) there are still a number of gaps to be filled in this field. This research contributes to the literature which considers the relationship between disability as a process of social, cultural, political and economic exclusion, human rights, poverty and development.

\section{Researcher's Own Philosophies and Place in the Research}

The primary influence for my selection of this topic is my work as a Speech and Language Therapist working in the Wellington and Porirua Early Intervention Team for Group Special Education (GSE), Ministry of Education (MOE), New Zealand. In this job I work with preschool children with impairments and their whanau to support their communication, development and access to education. An opportunity arose within GSE to travel as part of a delegation to Tokelau in 2007 following a request from the Tokelau government for assistance in implementing a disability strategy. The work in Tokelau in 2007 sparked my interest in exploring some of the cultural, ethical, political and practical difficulties implicit in implementing the GSE project. Shortly after the completion of that trip I decided on the thesis topic, and decided to use Tokelau as a case study. The timing of the project and selection of the thesis topic coincided with a strong international climate of advocacy and rights for people with disability. 
I was fortunate to be part of the second phase of the GSE project, and to return for a second time to Tokelau in 2008. These opportunities shaped the focus of my research in that I was able to include the voices of people I have met and worked with in Tokelau, as well as in New Zealand.

Given the social constructivist paradigm it is important to explore and outline my own philosophies about including children with impairments in all forms of education and in society. My view is that all human society at any given time has a group of people who have needs that may differ from the majority of the population. I believe that including all citizens in society and education as early as possible will ultimately benefit the entire society. I identify with a human rights based approach that all people should be included in society and that it is a duty of the state to ensure that opportunities for equality are available to all citizens, as a matter of course, rather than a burden for the state or a privilege for the recipient. In addition to the state's duties, I believe all rights-holders have a humanitarian responsibility to act in a way which protects and promotes human rights.

I see an interesting tension between a social constructivist and a positivist paradigm. A positivist approach seeks to discover natural laws and fundamental logics which are independent of the social actors they apply to. In order to ethically be involved in cross-cultural work, to some degree I identify with positivism, that there are universal truths about child development, and that therefore knowledge can have some value across contexts. The positivist element of my own beliefs is that children are social actors who develop through interaction, communication and relationships with people and their environment which is why I see inclusive education and inclusive societies as vital. Smidt (2006) captures the essence of child development which spans cultural variance; the idea that children are social constructivists operating within a positivist paradigm of child development is expanded below. 


\begin{abstract}
A Child in the 21st Century
Smidt (2006), images a child in the $21^{\text {st }}$ century as: "engaged in building a relationship with the world and intent on experiencing it so that she develops a complex system of abilities, strategies for learning and ways of organising relationship. So she is able to make her own personal maps for her own development and orientation - social, cognitive, emotional and symbolic. She is making meaning from events from very early on and she will share her meanings through representations and language. She will make and take and share meanings through stories. She is a competent and active and critical child...challenging because she can produce change and movements in the various systems with which she is involved. These include the family, the setting, the school, the society. She is a player in her society. The child makes cultures, values and rights and is competent in learning and in living. This child can explore a range of realities; can construct metaphors, seeing what it is like and why that matters. She can make and explore paradoxes, seeing what is different and why that matters. She can invent symbols and codes and use these to help her learn to decode the conventional means of symbolisation prevalent in her culture and community. Living within a community she will learn from all those around her through interaction, watching, listening, being an apprentice and being a teacher" (p. 14-15).
\end{abstract}

\title{
Methods
}

I use a combination of primary and secondary research sources. A literature review of peer reviewed journal articles, books and other literary sources in the fields of disability, development and education, at the international and regional Pacific level was conducted to inform the primary field-research component. A combination of qualitative methods, grounded theory principles, a general inductive approach and a Talanoa method have been used to gather and analyse the primary research data. Focusing the study on Tokelau provides the chance to explore whole of village and community considerations and is aligned to the goal of obtaining detailed contextualised data. Qualitative methods require the researcher to form relationships with the recipients of the research and to find the meanings which people attach to everyday interactions and objects. The qualitative methods of Talanoa and semistructured interviews are used because of their suitability to finding out people's opinions, experiences, attitudes, aspirations, perceptions, knowledge, and understanding about including people with disability in education. 


\section{Talanoa}

Pacific cultures continue to value oral tradition and Talanoa, "a personal encounter where people story their issues, their realities and aspirations" is seen to be a theoretical framework and research methodology which is natural to Pacific peoples and therefore appropriate for undertaking research in the Pacific (Smith 2004; Vaioleti 1999 - 2003 as cited in Vaioleti, 2006, p. 23). The essence of Talanoa is that it is a face to face exchange of ideas, relaying of experiences or conversation carried out either formally or informally and without a rigid framework (Otsuka, 2006; Vaioleti, 2006). Tala literally means to inform, tell, relate, command, ask and apply. Noa literally means any kind, ordinary, nothing-in-particular, purely imaginary or void. The literal translation of Talanoa is having a face to face chat about nothing in particular, and interacting without a rigid framework (Otsuka, 2006, p. 3; Vaioleti, 2006, p. 24).

Conducting research with Pacific participants means that Pacific values and world views must underpin the research, at the expense of traditionally dominant Western research paradigms (MOE, 2001). As a non-Pacific researcher, developing my understanding of and incorporating elements of Talanoa was intended as a way to elicit and respect the authentic and valuable information from participants.

A criticism of traditional research is that it is typically based on the philosophies and ideas upheld by a Western institution, which does not require any interpersonal relationship between researcher and participant. This is in contrast to a Pacific way of thinking where variables such as age, gender, or community standing of the researcher are likely to impact on the results (Smith, 2004; Vaioleti, 2006).

The personal connection between researcher and participant is critical in Talanoa because culturally, relationships are the foundations for many Pacific activities (Vaioleti, 2006). For the researcher to have credibility research must be undertaken for the advancement of the community rather than solely for personal academic achievement or commercial interests (Vaioleti, 2006). I had established some rapport with all of my research participants through being part of the previous GSE team in 2007 which was an advantage. Being part of a team advocating for inclusion in education for all children meant that my position and personal philosophies were 
transparent and probably already known to the participants. Doing research while simultaneously working in a community was also a privileged position to be in.

Talanoa differs most notably from more traditional research methodologies in that the researcher and participant enter the exchange on equal footing in terms of engagement with the process, and potential knowledge creation. The researcher does not sit back, question and analyse, so even though it can be literally translated as talking "about nothing in particular" Talanoa interactions can contain complex and multi-layered levels of content (Vaioleti, 2006, p. 24). Talanoa is flexible and creates opportunities for challenging, probing and clarifying information within the shared space of the conversation.

"In this methodology, the social, political, intellectual and cultural legitimacy of Pacific peoples are taken for granted, and Pacific cultures, knowledge and values are accepted in their own right" (Vaioleti, 2006, p. 31).

This methodology best suits this research, which seeks to document and gain insight from opinions, knowledge and aspirations of people.

A potential limitation of Talanoa, according to Vaioleti (2006), may be that it is unlikely to be reliable over time since both the researcher and participant are in fact generating as well as documenting knowledge. This lack of consistency means that it is unlikely to reproduce similar results if replicated. From a social constructivist viewpoint and given that the community are currently developing their disability and education systems, which in turn are developing and fluid concepts, it is expected that the results from these interactions will be relevant for the current time, but certainly not timeless.

\section{Semi-structured Interviews}

I prepared a set of questions to ask people. This departs from Talanoa, which suggests introducing the topic at the start of the encounter and letting the introduction guide the discussion from that point. However within interviews I was often able to employ Talanoa, and explore topics which came up, as well as to cover my intended questions with participants where appropriate. The pragmatics of the discussions was dependent on many factors, the most obvious of which was my relationship with the participant. The strength of using semi-formal interviews is that they allow flexibility 
to explore the topic and allow participants to raise issues and comment freely. They also make the data comparable between participants (Mikkelsen, 2005). Later interviews were influenced by prior interviews in probing answers and guiding topics which may have been raised by other participants, in order to gain a depth of perspectives.

\section{Data Analysis}

Once back from the field, interviews were transcribed, read over repeatedly, and key recurrent or powerful points were grouped into themes, in accordance with a naturalistic process of data inquiry. Therefore, data analysis was steered by my research aim of exploring people's opinions, experiences, attitudes, aspirations, perceptions, knowledge and understanding about disability, development and inclusive education in Tokelau. Frequent, dominant and significant concepts which evolved through iterative readings and analysis of the data are presented thematically in chapter five.

\section{Grounded Theory Principles and a General Inductive Approach}

Grounded theory is based on the idea that patterns emerge from the data collected and are not imposed on the data before it is gathered (Dick, 2002; Charmaz, 2006). The idea is to discover the theory which is implicit in the data and which will emerge rather than be forced out. Grounded theory departs from more traditional research methods which require value free objectivity. Instead, as with social-constructivism, the researcher's political and ideological influence over the iterative process of observation, exploration and data analysis in the research and creation of theory is acknowledged (Charmez, 2006; Mikkelsen, 2005).

A general inductive approach, inherent in grounded theory principles, has been employed as the method for data analysis (Charmez, 2006). An inductive approach is a systematic way of analysing qualitative data, where specific evaluation objectives guide the analysis (this contrasts with a deductive approach where data is analysed to prove or disprove pre-supposed hypotheses) (Thomas, 2006). As in grounded theory, the researcher begins with the raw data from an area of study and allows theory to emerge. The general inductive approach has three main purposes:

1. To condense data into a brief summary format; 
2. To establish clear links between the research objectives and summary findings, and to ensure these links are both transparent (able to be shown to others) and defensible (justifiable given the research objectives);

3. To develop a model or theory about the underlying structure of experiences or processes evident in the data;

(Thomas, 2006, p. 238).

The general inductive approach differs from grounded theory in that the data is not explicitly coded into axial and open coding (Thomas, 2006, p. 241).

Table 1: The Coding Process in Inductive Analysis

\begin{tabular}{|c|c|c|c|c|}
\hline $\begin{array}{l}\text { Initial } \\
\text { reading } \\
\text { of text } \\
\text { data }\end{array}$ & $\begin{array}{l}\text { Identify } \\
\text { specific text } \\
\text { segments } \\
\text { related to } \\
\text { objectives }\end{array}$ & $\begin{array}{l}\text { Label the } \\
\text { segments of } \\
\text { text to } \\
\text { create } \\
\text { categories }\end{array}$ & $\begin{array}{l}\text { Reduce } \\
\text { overlap and } \\
\text { redundancy } \\
\text { among the } \\
\text { categories }\end{array}$ & $\begin{array}{l}\text { Create a model } \\
\text { incorporating } \\
\text { most important } \\
\text { categories }\end{array}$ \\
\hline $\begin{array}{l}\text { Many } \\
\text { pages of } \\
\text { text }\end{array}$ & $\begin{array}{l}\text { Many } \\
\text { segments of } \\
\text { text }\end{array}$ & $\begin{array}{l}30 \text { to } 40 \\
\text { categories }\end{array}$ & $\begin{array}{l}15 \text { to } 20 \\
\text { categories }\end{array}$ & 3 to 8 categories \\
\hline
\end{tabular}

\section{Research Participants}

Employing a social constructivist approach to research means that I do not hope to uncover a unified viewpoint, or single truth, but rather to investigate several experiences which may provide insight into some of the realities experienced by people.

All participants were approached individually and asked to take part in this research. Many participants offered their assistance in linking the researcher up with other people to interview, but in most cases time constraints precluded this snowball effect from happening.

Qualitative research typically focuses on fewer information-rich samples. A total of ten individual interviews were conducted which provided a range and depth of insight and data. Most of the participants were professionals in education or government, and all were involved with education in some capacity at the time of the data collection. Therefore, this sample cannot be considered representative of the population. Nevertheless, participants also represented the views of parents of 
children with disability, school staff, community members, a range of ages, male, female, Tokelau based Tokelauans, members of the Tokelau community in New Zealand and government officials. The two participants who live in New Zealand both work for the New Zealand Ministry of Education and one was involved in the GSE project.

Of the non-Tokelauan participants, two are Samoan nationals who work for the Tokelau Education Department. Including Samoan participants meant that perspectives and information from Tokelau's closest neighbour in the Pacific could be incorporated into the data. Their perspectives are also interesting considering they work in the Education Department of Tokelau. The third is an Australian woman who lives in Samoa and is involved in regional and national initiatives in disability and education, and has been instrumental in establishing an Inclusive Education School in Apia. It was felt that these participants would enrich the data with their familiar perspectives of Inclusive Education in a Pacific setting.

All participants have travelled to New Zealand and Samoa and therefore are more likely to have had exposure to other disability service and education models than those available in Tokelau.

Table 2: Research Sample

\begin{tabular}{|c|c|c|c|c|c|}
\hline Participant & Male & Female & Usual Place of Residence & Location of Interview & Nationality \\
\hline 1. & $\sqrt{ }$ & & Fakaofo & Fakaofo & Tokelauan \\
\hline 2. & & $\sqrt{ }$ & Atafu & Nukunonu & Tokelauan \\
\hline 3. & $\sqrt{ }$ & & Atafu & Apia & Tokelauan \\
\hline 4. & & $\sqrt{ }$ & New Zealand & New Zealand & Tokelauan \\
\hline 5. & $\sqrt{ }$ & & New Zealand & Apia & Tokelauan \\
\hline 6. & $\sqrt{ }$ & & Nukunonu & Nukunonu & Tokelauan \\
\hline 7. & $\sqrt{ }$ & & Nukunonu & Nukunonu & Tokelauan \\
\hline 8. & $\sqrt{ }$ & & Apia & Apia & Samoan \\
\hline 9. & & $\mathrm{~V}$ & Apia & Apia & Samoan \\
\hline 10. & & $\sqrt{ }$ & Apia & Apia & Australian \\
\hline TOTAL & 6 & 4 & & & \\
\hline
\end{tabular}




\section{Ethics Process}

The Victoria University of Wellington Human Ethics Committee granted ethics approval for the research prior to any fieldwork undertaken. Participants were provided with an information sheet which detailed the research aims and purpose. If they agreed to take part in the research, participants were required to sign an informed consent form which outlined their rights as participants in the research, including the right to withdraw themselves and their comments from the research at any stage prior to publication of the thesis. The participant information sheet and consent form were both approved by the Victoria University of Wellington Human Ethics Committee. Participants' comments have not been attributed to them throughout the body of the text for ease of readability. However, some of the background information given to the quotes is likely to make the participants identifiable. All participants were happy for their responses to be attributed to them, and waivered confidentiality.

\section{Challenges of Fieldwork}

Time constraints were experienced while undertaking the research because the time spent in Tokelau was slightly less than originally intended. Travel to Tokelau is dependent on the boat schedule which was altered several times during the trip. The first delay occurred as a result of inclement weather which meant the boat arrived in Apia later than anticipated. It then had to return to Tokelau on an emergency run to get a patient to bring back to hospital in Apia. Fortunately, at the behest of the Faipule from Fakaofo, the boat schedule was renegotiated and we were able to spend an even amount of time on each atoll. On the first atoll, a village elder passed away so village activities were suspended as people paid respects and readied for the funeral. I was able to conduct one interview on the first atoll and several on the second but none on the third, again due to time constraints. I was fortunately able to interview some people in Apia in the Tokelau office, so the sample included representatives from each atoll.

\section{Limitations of the Research}

- Due to the sensitive and complex nature of the topic, the Talanoa tended to be quite lengthy, typically lasting between forty minutes to an hour, and occasionally longer. As a result, fewer participants were able to be 
interviewed than hoped for but the information gleaned in each interaction provides insight into people's ideas and opinions.

- A potential risk was that because the participants are all highly educated they do not necessarily represent the views of the wider community. I tried to counter this by encouraging participants to not only give their own views about disability and education, but to convey the prevalent attitudes of the community. Nevertheless, it is acknowledged that the sample is limited by its size and tendency toward highly educated people. Future research of this kind would benefit from including youth, members of the extended community, and particularly from people who are directly impacted by disability.

- Another potential limitation relates to the use of a digital voice recorder; some participants stated their aversion to the device, although all consented to its being used. Other recent research in Tokelau noted that a recording device was probably not appropriate, as participants will find it uncomfortable even though they may tolerate it for the sake of politeness (Buchanan, 2007).

- Although I was in Tokelau with GSE, I undertook research independently outside of project time as agreed with the managers of the GSE project. In reality there was very little time outside project time in which it was appropriate to pursue research. It was probably difficult for me to completely step outside of my role as an employee of GSE to assume the role of an independent researcher. Therefore, there is a risk that participants' perceptions of me and my role may have led them to tailor their responses in a way in which they felt they ought to. This aside it is hoped that the overall research benefitted from the opportunity of building on existing relationships so allowing for candidness and comfort in participation.

\section{Chapter Summary}

In order to explore people's ideas and opinions and obtain rich detailed perspectives, qualitative methodologies and methods have been chosen. Therefore this thesis tends towards an interpretive and descriptive nature (Charmez, 2006). Qualitative methodologies and methods are also comfortably positioned within a social constructivist epistemology in which historical, social, cultural and political influences on both the participants and the researcher are considered. 


\section{Chapter Three: Disability, Development and Education}

\section{Introduction}

This chapter explores three interconnected issues - disability, development and education. It starts at the global level, and then looks at all three issues in the context of the Pacific. There are four sections to this chapter. The first draws on available international literature to discuss how disability is defined, attitudes toward people with disability, and how disability and education paradigms sit within the international human-rights framework. The second explains the relationship between disability, development and poverty, and presents two contemporary development paradigms which are well suited to respond to disability issues from a human rights perspective. The third section shows how education has historically and currently included students with impairments, including the relatively recent progression from Special Education to Inclusive Education approaches. The final section of this chapter ties together disability, development and education at the Pacific regional level. It looks at some regional and multilateral dialogues on Special and Inclusive Education as well as the Samoan national experience of establishing disability services and strategies, particularly in Inclusive Education.

\section{Disability}

\section{The Impact of Disability}

People living with disability are the world's largest minority. Exact numbers are hard to quantify due to suspected under-reporting and differences in the definition of disability between cultures. Also, earlier research typically followed a medical model construct of disability ${ }^{6}$ which did not consider or measure functional impairment and social aspects of disability (Yeo \& Moore, 2003).

It is estimated that the global population of people living with disability is approximately 650 million people, or ten percent of the total population, but that in a developing country the figure is more likely to be twenty percent (UN, 2008). The majority of people with a disability live in poverty; some figures estimate that approximately $80 \%$ of the global population living with disability live in the developing world ( Eklindh \& Brule-Balescut, 2005; Price, 2003; UN, 2006; Yeo \&

\footnotetext{
${ }^{6}$ Constructs of disability are discussed further on pages $24-25$.
} 
Moore, 2003). The Asian-Pacific region is home to two-thirds of people living with disability in the developing world (ADB, 2005). The Pacific Islands Forum Secretariat give the figure of approximately 800,000 people living with disability in the Pacific Islands, which approximately equates to between six and ten percent of the total population (PIFS, 2008; Price et al., 1999). The global incidence of impairments and disability is expected to increase due to factors such as population growth, ageing, lifestyle diseases (like diabetes), conflict, malnutrition, accidents, injuries, HIV and medical advances which preserve and prolong life (Thomas, 2005).

People with disability are amongst the most marginalised in the world and are seen negatively by almost every culture, religion and ethnic group (Pfeiffer, Sam, Guinan, Ratcliffe, Robinson \& Stodden, 2004). More than alcoholism, criminalist behaviour, depression, or sexual orientation, research shows that the social stigma from disability is the most debilitating (Smith, 2004, p. 10).

The experience of children and women with disability varies depending on their personal circumstances, as with all people with disability. Nevertheless data indicates there are severe consequences of disability for children and women (DFID, 2000).

\section{Children with Disability in the Developing World}

Estimates are that a third of the global population with disability are children, most of who live with preventable impairments ${ }^{7}$ (ADB, 2005; Yeo \& Moore, 2003). Children with disability are arguably the world's most vulnerable population. Underfive mortality rates for infants with disability can be as high as $80 \%$, even in countries where the total under-five mortality rate has decreased to under $20 \%$ (DFID, 2000). Children are particularly at risk of living in poverty because of the perpetuating ramifications of exclusion, for example exclusion from education leads to exclusion from participation in vocational training, employment, and society in general ( McKinstry et. al, 2004; Price, 2003). For families living in abject poverty, giving a child with disability (who may be unlikely to survive, or less able to provide

\footnotetext{
${ }^{7}$ For example, lathyrism, a motor-neuron disease which affects mobility and coordination is caused by toxins in the cheapest form of lentils; people who consume these lentils are aware of the risk but have no alternative option. Similarly in Cambodia, over $70 \%$ of landmine survivors were aware of the risk of the prevalence of landmines in the area where they were farming or foraging (both examples from Action on Disability and Development (ADD), 1997, cited in Yeo \& Moore, 2003). Childhood blindness and hearing impairments in developing countries are often preventable or treatable (WHO, 1992 cited in Yeo \& Moore, 2003).
} 
for the family in adulthood) last access to education, food and other scarce resources can be a rational economic measure, albeit a desperate circumstance (Yeo \& Moore, 2003). In addition to resources, children often experience marginalisation and oppression because they are at the bottom of their cultural social hierarchy (McMurray, 2006).

\section{Women with Disability in the Developing World}

Women with disability face multiple forms of discrimination (DFID, 2000; Lene, 2004). They have less access to essential services and less access to opportunity to gain income (McKinstry et al, 2004; UN Enable). All women are more impacted by disability than men, as women are often entrusted to care for people with disability in a community (UN Enable). Women with disability are also more at risk of certain forms of abuse and harmful practices directed against them such as being beaten, sexually assaulted and forcibly sterilised ${ }^{8}$ (UN Enable; Yeo \& Moore, 2003).

\section{Defining Disability}

Defining disability is complex, dynamic and controversial (DFID, 2000). Some see classification of disability is motivated more by social management than the best interests of people with disability (Smith, 2004). Classification of impairments is a useful way to establish eligibility criteria when justifying the allocation of resources, but on the other hand it may isolate and stigmatise people by emphasising their difference from a socially constructed norm (Minnow, 1990; Hardman \& Nagle, 2004).

Recently, the terminology used has tried to convey the conceptual difference between physiological or anatomical impairments, and socially constructed exclusionary practices (Katsui, 2005; Shakespeare \& Watson, 2002; Smith, 2004; WHOICF, 2001). In the World Health Organisation's 2001 International Classification of Functioning, Disability and Health (WHOICF), defects, anomalies, losses or significant deviation in functions from the general population are known as impairments. These impairments can be either physiological (to do with body processes) or anatomical (to do with body structures). The WHOICF identifies 9 broad areas of functioning which can be affected: learning and applying knowledge;

\footnotetext{
${ }^{8}$ It is estimated that in 28 countries in Africa over a hundred million girls and women are disabled as a result of female genital mutilation (Lwanga Ntale, 2002 as cited in Yeo \& Moore, 2003).
} 
general tasks and demands; communication; mobility; self-care; domestic life; interpersonal interactions and relationships; major life areas and community, social and civic life (WHO, 2001).

Disability is distinguished from impairment. It is an umbrella term; disability encompasses impairment but impairment does not automatically lead to disability if inclusive policies and philosophies are implemented ${ }^{9}$ (Lene, 2005; Yeo \& Moore, 2003). As stated earlier, for the purpose of this thesis, the definition of disability is taken from the United Nations (UN) Convention on the Rights of Persons with Disabilities (CRPD):

"Persons with disabilities include those who have long-term physical, mental, intellectual or sensory impairments which in interaction with various barriers may hinder their full and effective participation in society on an equal basis with others."

Article 1, UNCRPD, 2006

The social and rights-based models of disability are reflected in the definitions of disability given by the WHOICF and CRPD and they are also the models in which this thesis is framed.

\section{Defining Difference}

The concept and definition of disability is inherently bound within the broader concept of difference. Minnow (1990) has argued strongly about the need to question and change dominant hegemonic viewpoints and classifications of difference. Exclusionary practices that result from difference have often been seen to occur as a natural consequence of difference, rather than from assumed social arrangements into which people must fit. Minnow's work on what she called the "social-relations" approach to difference contends that difference is socially constructed on the basis of incontestable (and often unstated) norms such as: the ability to see, hear, walk, talk, and read; adulthood; maleness and whiteness (1990, p. 56). While the social-

\footnotetext{
${ }^{9}$ As an example, if a person has a double lower limb amputation that would be considered an impairment but not a disability if inclusive policies: a). allow the person to access a wheelchair and other resources, b). his or her society has wheelchair access to its buildings and public spheres and c). the person is not discriminated against on the basis of being in a wheelchair. However a person with a double lower limb amputation would be considered disabled if the impairment immobilises or restricts him or her physically, socially, politically, economically and culturally.
} 
relations approach is relatively easy to understand and accept, changes in automatic assumptions about what is 'true', and associated changes in behaviour are harder to apply (Bartlett, 1992). In her response to Minnow's work, Bartlett states that "familiar truths are reinforced through habitual action" (1992, p. 452), but that this does not excuse a lack of action. Rather, Bartlett contends that once there is understanding that difference is socially constructed, it demands social responsibility to redress exclusionary practices; society must reflect on its actions and act on its reflections (Bartlett, 1992; Freire, 1970). Managing diversity well creates a paradox of difference described succinctly by Martha Minnow (1990):

"When does treating people differently emphasize their differences and stigmatize or hinder them on that basis? When does treating people the same become insensitive to their difference and likely to stigmatize or hinder them on that basis? ...The stigma of difference may be recreated by both ignoring and focusing on it."

(p. 2)

\section{Constructs of Disability}

As with the definition, the construct and conceptualisation of disability has evolved over time. There are several models and the evolution of constructs of disability continues. The three most dominant constructs, the medical, social, and political models of disability are depicted Table 3 and discussed in the following paragraphs.

Table 3: Models of Disability

\begin{tabular}{|l|l|l|l|}
\hline Models & Medical & Social & Political (Rights-based) \\
\hline Paradigm & Positivist & Interpretive & Emancipatory \\
\hline Problem & Individual & Social & Political \\
\hline Disabled Persons as & Patients & Clients & Citizens \\
\hline Focus & Impairment & Disability & All personal experiences \\
\hline Vis a vis mainstream & Exclusion & Inclusion & Participation \\
\hline Position & Object & Subject & Subject in action \\
\hline Solution & Medical Care & Accessibility & Human Rights \\
\hline Sphere & Health & Society & Human Beings \\
\hline
\end{tabular}

(Katsui, 2005, p. 16) 
Disability has historically been considered from the viewpoint of a 'medical model'. This model holds that a disability is something which an individual is considered to be afflicted with, which reduces them as individuals, and is thus known as a deficit perspective. As such, intervention is focused on the rehabilitation and amelioration ${ }^{10}$ of individuals with impairments in order to assist them to function as closely to the majority of the population as possible (Price, Radio, \& Toga, 1999; Terzi, 2007; UN, 1993).

By way of contrast, in the social model, 'disability' is not seen as a 'thing', but rather as a process or description of exclusion within a society. As discussed earlier, recent international definitions of disability highlight how the social and physical barriers faced by a person with one or multiple impairments impacts on their participation in society. By defining disability and health with a reference to impairment of function, rather than medical or biological dysfunction, or deviation from a norm, the WHOICF considers the social aspects of disability (WHO, 2001). The social model acknowledges that the collective experience of people with disability goes beyond diagnoses and medical facts (Katsui, 2005). As a result, interventions to support persons with impairments must occur at the societal level by focusing on collective change to move towards developing communities which cater for all their members (Price, Radio, \& Toga, 1999; Shakespeare \& Watson, 2002). This is not to completely disregard the medical model; it is still necessary to have a clinical component so as to identify how to support people to manage and alleviate their impairment where realistic to do so, but it must go hand in hand with attitudinal and systemic change as depicted by the illustration below (Katsui, 2005; Shakespeare \& Watson, 2002).

\footnotetext{
${ }^{10}$ It is beyond the scope of this thesis to enter into a philosophical debate about the frequently raised issue in disability of eugenics, but it is acknowledged here that advances in medicine and science pose ethical questions about whether impairments are conditions to be prevented or part of the spectrum of human difference (Smith, 2004). Shakespeare \& Watson (2002) put forth the view that where impairments are preventable (see footnote 4 on page 20) it is reasonable to do so without damaging respect for and the rights of people with disability.
} 


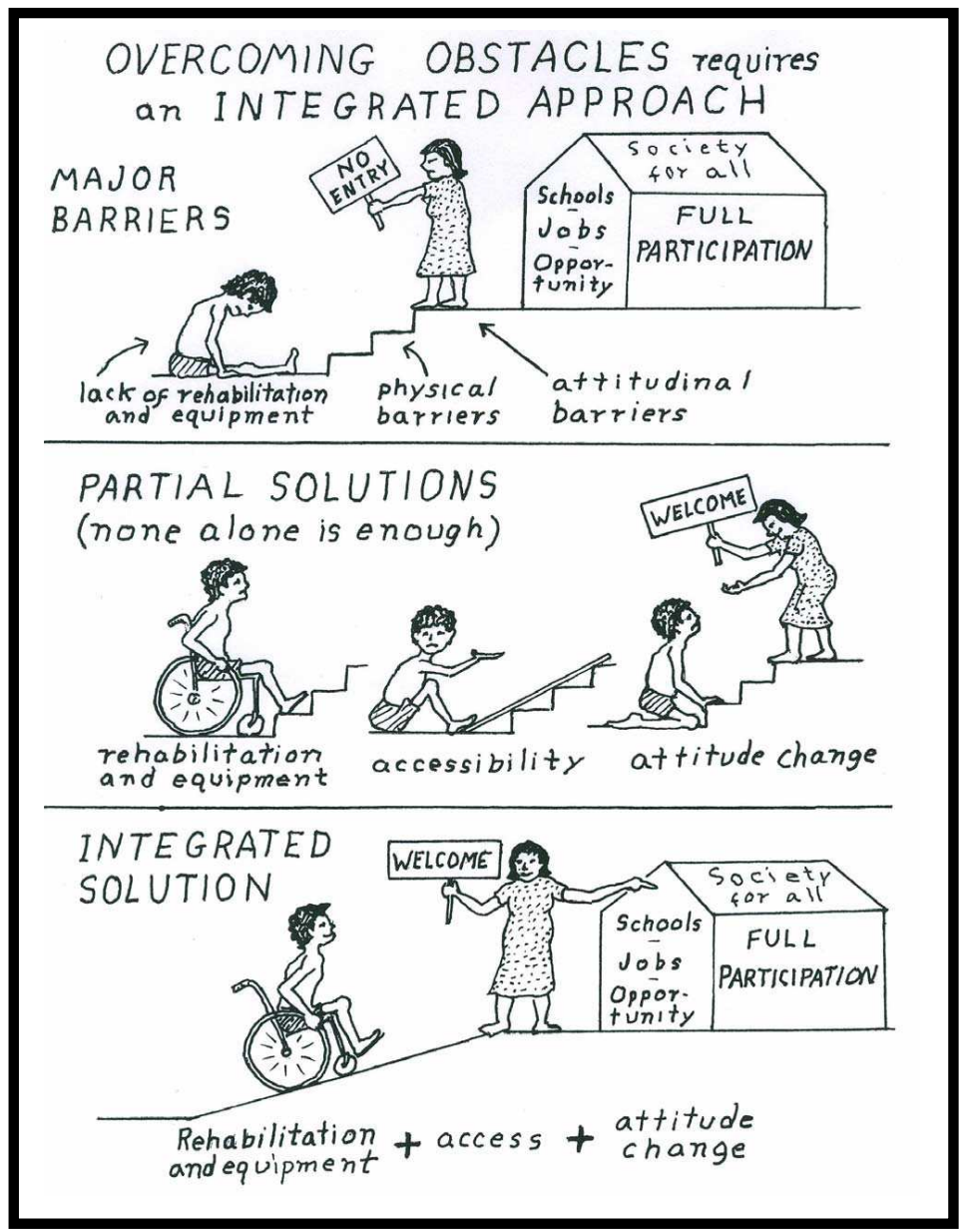

(Source: Dr. David Werner at a UN Health Rights Expert Meeting in

Vienna, 1995 cited by Wiman, 1996, p. 126, cited in Katsui, 2005, p. 18).

The political or rights-based model encompasses the social model and builds on its strong relationship with the international human rights framework. The aims of the political model are that people with disability must be empowered to be able to advocate for themselves and be involved in changing the exclusionary practices of their society (Katsui, 2005; Terzi, 2007).

In addition to these three models it is recognised that throughout the world, disability tends to be regarded as a tragedy, a disgrace, a punishment from God, an ancestor or an evil spirit for sins; and that these conceptualisations are known as the charity, and the moral or religious models of disability respectively (Miles, 2003; Pfeiffer et al., 2004). 
Pfeiffer (2001) suggests that all dominant paradigms of disability are accounted for and bound by intolerance towards people with disability; disadvantages experienced by disabled people come from social infrastructure, stigma from a constructed collective identity, and political oppression. How we view and perceive people is extremely important; believing that people with disability are piteous is likely to be prophetic because people with disability internalise negative feelings directed toward them (Katsui, 2005).

\section{Considerations of Language and Terminology}

The language used to describe people is powerful and political and must be carefully considered. It is through language that we construct identity and can perpetuate or challenge negative stereotypes. For instance the connotation of the terms 'mongolism' 'idiocy' 'Down Syndrome' and 'Trisomy-21' are very different, although they all refer to the same condition (Shakespeare \& Watson, 2002). Within the goal of establishing a common understanding of terminology, there has been a strong international movement towards what is called People First Language, where defining a child or person by their impairment is rejected as discriminatory (Snow, 2008). As an example a child may be considered "a boy who is blind" rather than "a blind boy". A debate about extending the same consideration to the terms impairment and disability has ensued in the disability sector, particularly in the UK. Some contest the term 'people with disabilities' because it can be interpreted to mean that the disability is caused by the person with an impairment; this position prefers 'disabled persons', arguing that it is the more appropriate term in a social model because it gives room to be explained further as 'persons disabled by society'. For the purpose of this thesis, the term 'people with disability' is chosen to mean people with impairments who experience disability; the use of the singular is deliberate to reflect that disability is a social process of exclusion. Shakespeare \& Watson (2002) feel that rigidity of terminology has been and continues to be helpful for activism but can also be immobilizing and polarising in debate. It is in the spirit of these 'moving forward' type sentiments that I state my choice of phrasing and align my viewpoint philosophically to a social and rights-based model. 


\section{Disability and Human Rights}

The social and rights-based (or political) models of disability are well positioned in the contemporary climate of global participation in and commitment to the international human rights framework ${ }^{11}$ - a set of UN treaties and declarations which protect individuals and groups against abuses of universally agreed upon freedoms and entitlements (UNOHCHR, 2006). The 1948 Universal Declaration of Human Rights (UDHR) is the seminal human rights document and although it is not legally binding, it holds position as customary international law. When States agree to an international human rights treaty ${ }^{12}$ they are the principal duty-bearer for the respect, protection and fulfilment of human rights for all their citizens ${ }^{13}$ (Mikkelsen, 2005). Human rights are based on the premise that all people have the right to full and equal participation in, and contribution to the political, economic, social and cultural life of their community (Mikkelsen, 2005; UNOHCHR, 2006). Human rights are moral and legal entitlements which are fundamental to people's well-being, dignity and the pursuit of their full potential (Mikkelsen, 2005, p. 201). Smith states that the greatest challenge for people with disability in today's society is having their lives understood within a framework of civil rights such as freedom, justice and equality (2004, p. 13).

Disability rights activism began in the 1960s and gained momentum in the 1970s, an era which represented a time of identity politics where issues of equality of opportunity despite race, gender and disability were brought to the fore, and many activist movements gained momentum (Shakespeare \& Watson, 2002; Smith, 2004; Yeo \& Moore, 2003). The 1970s saw the emergence of international disabilityspecific declarations (Yeo \& Moore, 2003). Prevention of the causes of disability, rehabilitation of disabled persons and equalisation of opportunities of persons with disability became key international directions (McKinstry et al., 2004). As the construct of disability shifted from a medical to a social model, disability issues shifted from care and welfare to human rights and the new paradigm began to be

\footnotetext{
${ }^{11}$ See Appendix One: Principles which underlie the International Human Rights Framework.

${ }^{12}$ Treaties can either be signed, which does not legally bind the state but does oblige it to act in a way which does not undermine the obligations of the treaty; or acceded to, which allows a state to be bound to the principles of a treaty despite not signing it when the treaty was originally adopted. After a state has signed or acceded to a treaty, the obligations of the treaty should be formally incorporated into domestic law, a process known as ratification (MFAT, 2003; UN, 2002).

${ }^{13}$ See Appendix Two: Obligations of State Parties to International Human Rights Law
} 
reflected in international literature and the international human rights framework, as shown in the table below: (Nowland-Foreman and Stubbs, 2005; McKinstry et al., 2004; Price et al., 1999).

Table 4: International Mandates Relating to Disability and Education

\begin{tabular}{|l|l|}
\hline Year & International Human Rights Movements relating to Disability and Education \\
\hline 1948 & Universal Declaration of Human Rights \\
\hline 1981 & UN International Year of Disabled Persons \\
\hline $1983-1992$ & United Nations World Programme of Action Concerning Disabled Persons \\
\hline 1989 & UN Convention on the Rights of the Child \\
\hline 1990 & The World Declaration on Education For All \\
\hline 1993 & The UN Standard Rules on the Equalisation of Opportunities for Persons with Disability \\
\hline 1994 & Salamanca Statement \& Framework for Action on Special Needs Education \\
\hline 2000 & World Education Forum Framework for Action, Dakar (EFA) \\
\hline 2000 & Millennium Development Goals \\
\hline 2006 & UN Convention on the Rights of Persons with Disability \\
\hline
\end{tabular}

(Eklindh \& Brule-Balescut, 2005; McKinstry et al., 2004)

Two of the most recent and significant frameworks with regard to disability and education, the Salamanca Statement and the Convention on the Rights of Persons with Disability are discussed below ${ }^{14}$.

\section{Salamanca Statement and Framework for Action 1994}

A significant international framework on disability, education and development arose from the 1994 United Nations Education Science \& Culture Organisation (UNESCO) World Conference on Special Needs Education: Access and Quality, held in Salamanca (henceforth known as the Salamanca Statement). The Salamanca Statement was the first international document to cite the direct connection between education for children with special needs and human rights (Eklindh \& BruleBalescut, 2005). At the time of its formation, less than one per cent of the global population of children and young people with disability attended school in

\footnotetext{
${ }^{14}$ For further information, a brief outline of some of the international and Asian-Pacific regional UN driven documents, conventions and frameworks relevant to the rights of people with disability to access education is given in Appendix Three and Appendix Four.
} 
developing countries and the international community recognised the need to redress this inequality, particularly given the climate of the Education For All movement (Price et al., 1999). The Salamanca Statement signified a change in the direction of international thinking about education for children with special educational needs. It affirmed the need for government commitment to provide education for people with special educational needs and advocated that the best way to do this is within existing regular education systems (Eklindh \& Brule-Balescut, 2005; Price et al., 1999; UNESCO, 1994). The Salamanca Statement encouraged creative problem solving about educational difficulties and anticipated that the creative solutions could ultimately benefit all of the students in the form of a richer learning environment based on child-centred learning (Eklindh \& Brule-Balescut, 2005). It put respect for differences and diversity at the centre of debates about education, society and culture and proposed that schools implement philosophical, practical and strategic changes (Eklindh \& Brule-Balescut, 2005). The practices and philosophies recommended by the Salamanca Statement are known as an Inclusive Education philosophy (discussed further on page 43).

\section{The Convention on the Rights of People with Disabilities}

Although all international human rights documents and frameworks extend to people with disability and their families they continue to face discrimination, marginalisation and exclusion. The Convention of the Rights of Persons with Disability (CRPD) ${ }^{15}$ is the first convention which explicitly accords all human rights to people with disability. The CRPD is the most recent United Nations convention; it has been in development since 2001, was adopted in 2006 and came into force on $3^{\text {rd }}$ May 2008 (UN, 2008). The CRPD has been signed by 137 countries and ratified by $46(\mathrm{UN}, 2008)^{16}$. The purpose of the convention is "to promote, protect and ensure

\footnotetext{
15 There are eight guiding principles which underlie the CRPD: "respect for inherent dignity, individual autonomy including the freedom to make one's own choices, and independence of persons; non-discrimination; full and effective participation and inclusion in society; respect for the difference and acceptance of persons with disabilities as part of human diversity and humanity; equality of opportunity; accessibility; equality between men and women; and respect for the evolving capacities of children with disability and respect for the right of children with disability to preserve their identities" (CRPD, 2006; UN Enable, n.d.).
}

\footnotetext{
${ }^{16}$ New Zealand signed the convention on $30^{\text {th }}$ March 2007 and ratified it on $25^{\text {th }}$ September 2008. A full list of countries who have signed and ratified the CRPD and its optional protocol is available at www.un.org/disabilities/countries.asp?id=166
} 
the full and equal enjoyment of all human rights and fundamental freedoms by all persons with disability and to promote respect for their inherent dignity" (Article 1).

The main aims of the CPRD are to ensure that:

"Persons with disability and their family members should receive the necessary protection and assistance to enable families to contribute towards the full and equal enjoyment of the rights of persons with disability". (Preamble, section x.)

and:

"To make a significant contribution to redress the profound social disadvantage of persons with disability and promote their participation in the civil, political, economic, social and cultural spheres with equal opportunities, in both developing and developed countries" (Preamble, section y.)

The obligations of the State outlined in the Convention include:

- developing appropriate legislation to address disability issues as human rights issues

- raising public awareness

- providing access to the physical public environment

- not excluding its citizens from the general education system or highest standard of health care

- providing adequate living standards

- providing social protection

- allowing persons with disability to participate in political, public, cultural, and recreational life.

(UN, 2006).

Through becoming signatories to the CRPD, states acknowledge the right to education that people with disability have and their own obligation in providing an inclusive education system (UN, 2006). The provision of education to children with disability alongside their peers is necessary in order to fully realise their abilities, talents, creativity and personality out of respect for diversity and for the greater recognition of human rights (UN, 2006). Article 7 of the CRPD focuses on children with disability and states that they must be supported to enjoy their full human rights and fundamental freedoms on an even basis with other children. It upholds acting only in the best interests of the child and advocates for child participation in its support of giving children with disability (as with all children) the right and means to 
express their views freely on all matters concerning them bearing in mind the child's age and maturity, and to have those views considered (UNCRPD, 2006).

There are no new rights in the CRPD, but the idea of redressing the social disadvantage faced by people with disability introduces the idea of providing extra support (positive discrimination) in enabling people with disability to access the same rights as everyone else. The CRPD is the first convention in the international human rights framework which includes reference to international cooperation (Article 32) thereby obligating duty bearers at a trans-national level (Katsui, 2008).

\section{Criticisms of the International Human Rights Framework}

The omission of specific reference to disability within key international initiatives based on the international human rights framework such as the Millennium Development Goals and Education For All has been criticised (McKinstry et al., 2004). The development of the CRPD is one response to that concern. However, although the CRPD is a powerful progressive step towards human rights for persons with impairments, inclusion in the human rights framework does not automatically guarantee their provision.

Accountability is the first of two criticisms of the international human rights movement discussed here ${ }^{17}$. This position holds that without any assigned person, system or agency to hold accountable for the provision of rights they are essentially invalid, or "imperfect obligations" (Kant 1788, as cited in Sen, 1999). Certainly, considering the plentiful number of signatories to various international human rights treaties and conventions there seems to be wide international concurrence with the human rights framework, and yet human rights and fundamental freedoms continue to be denied to the majority of the world's population (Mikkelsen, 2005; Price, 2003; Sen, 1999). Sen (1999) suggests that human rights can be both valued and unfulfilled without necessarily being considered void; and since human rights transcend citizenship, we can look at unfulfilled human rights claims as being directed generally to anyone who is in a position to assist (p. 230).

\footnotetext{
${ }^{17} \mathrm{~A}$ third criticism is the issue of whether there is any legitimacy to pre-legal moral claims; this thesis adopts Sen's (1999) suggestion to consider as human rights ethical claims rather than legal claims (p. 228).
} 
The second criticism deals with the issue of cultural relativism; are there any universal truths and universal rights? Cultural relativists contest that human rights cannot be universal for two reasons. Firstly, because the human rights movement developed from a specific period of Western history, the eighteenth century Enlightenment, there is an ongoing debate about the ethics and relevance of largely Western constructs of human rights being imposed on indigenous cultures (Bell, Nathan \& Peleg, 2001; Miles, 2003). Secondly, cultural relativists contend that the individualistic nature of human rights is incongruous in societies in which individual wellbeing comes from communal values and group harmony (Sen, 1998). Individual human rights therefore have a tenuous position in cultures where collective consciousness is emphasised and individuals are required to contribute to the group. The UDHR itself declares respect for different cultures and provides for group rights; Article 29 emphasises the responsibilities of the individual to their community (UDHR, 1948). The argument that human rights promote the interests of the individual above the group tends to come from non-Western cultures (sometimes as a defence against allegations of human rights law breaches) but there are also criticisms from Western perspectives who consider that the focus on individualistic rights is neo-imperialistic (Merry, 2001). The cultural relativist position is countered by the normative, and the formative position. The normative position states that human rights are derived from the inherent dignity of humanity, and therefore accorded to all humans irrespective of culture (UDHR, 1948). The formalist position acknowledges that human rights approaches did originate in the West, but are widely accepted, as evidenced by the fact that most states have signed and ratified the UDHR and other subsequent human rights conventions (Steiner \&Alston, 2000).

A response to the discourse about universalism and cultural relativism is eloquently framed by Higgins (1994):

"It is sometimes suggested that there can be no fully universal concept of human rights, it is necessary to take into account the diverse cultures and political systems of the world. In my view this is a point advanced mostly by states, and by liberal scholars anxious not to impose the Western view of things on others. It is rarely advanced by the oppressed, who are only too anxious to benefit from perceived universal standards. The non-universal, relativist view of human rights is in fact a very state-centred view and loses sight of the fact that human rights are human rights and not dependent on the fact that 
states, or groupings of states, may behave differently from each other as far as their politics, economic policy and culture are concerned ... Individuals everywhere want the same essential things: To have sufficient food and shelter; to be able to speak freely; to practise their own religion or to abstain from religious belief; to feel that their person is not threatened by the state; to know that they will not be tortured, or detained without charge, and that, if charged, they will have a fair trial."

(As quoted by Steiner \& Alston, 2000, p. 397 - 398).

Recently human rights discourse has found a middle ground between universalism and cultural relativism. Anthropology and social constructivism have been major influences on these new interpretations which argue that since the international human rights framework has evolved over the past 61 years in response to emerging moral, political and social issues it is inherently adaptive to global and local contexts and priorities (Merry, 2001). It is now coming to be accepted that rights and rules about morality are interpretable in different cultural contexts but not at the expense of fundamental freedoms (Wilson, 2000).

\section{International Responses to Disability}

\section{Disabled Persons Organisations}

The internationally heard maxim from people with disability is "nothing about us, without us'. The current rights-based approach is reflected in the call for leadership by disabled persons in all areas of their lives, and the subsequent formation throughout the world of Disabled Persons Organisations (DPOs) as a forum to hear those voices (Barnes \& Mercer, 1995; Katsui \& Kumpuvuori, 2008; McKinstry et al., 2004). Single focus organisations such as the World Federation of the Deaf have formed since the 1950s (Barnes \& Mercer, 1995). At a global level, the International Disability Alliance (IDA), which represents seven disability organisations ${ }^{18}$, acts as a consultant to the UN and advises agencies such as the World Bank (McKinstry et al., 2004). There are many grass roots examples of local disability self-advocacy groups showcasing their voices and abilities; for example, one advocacy project in Nepal supported children with disability to share their stories about their experiences in education to raise public awareness, and offer themselves as role models to the

\footnotetext{
${ }^{18}$ The World Blind Union, the World Federation of the Deaf, Disabled Peoples International, Inclusion International, World Federation of the Deaf-Blind, the Association of the Users and Survivors of Psychiatry, and Rehabilitation.
} 
community (Smidt, 2006). DPOs contribute to alleviating exclusion and isolation by acting as a contact point for people with disability to interact with other people impacted by disability, and recently have begun engaging in more political purposes such as lobbying and advocacy which is often done in liaison with international organisations and Non-Government Organisations (NGOs) (Barnes \& Mercer, 1995; Yeo \& Moore, 2003).

Because the membership of DPOs is often dominated by males with physical impairment, there is some question whether DPOs are themselves guilty of exclusionary practices since women and people with forms of impairment such as learning difficulties, leprosy, epilepsy, sensory impairments, mental and emotional illness are typically less involved (Yeo \& Moore, 2003). Additionally, Katsui (2005) notes her concern that DPOs seem to have had minimal input into policy development, despite their aim to do so.

\section{Community-Based Rehabilitation}

Community-Based Rehabilitation (CBR) is an ecological model of service provision to people with disability developed by the World Health Organisation in the 1970s. It is estimated that 80 percent of people with disability could have their rehabilitation needs met at the community level (DFID, 2000). CBR is designed to foster the relationship between the wider community and persons with disability within any community (Kuipers, Kendall, \& Hancock, 2001). The defining features of the CBR model are community participation and partnerships, supporting and developing initiatives driven by people with disability and their families and community, integration into the local context and maximisation of formal and informal service provision (Kuipers et al., 2001). CBR has evolved since its initial conceptualisation and its practical implementation must be tailored to local contexts, making writing operational guidelines for this model an elusive goal (Barnes \& Mercer, 1995; Kuipers et al., 2001).

It can be argued that disability service provision is clarified through the CBR process whereby the local community is empowered to hold the responsibility for service provision, as well as identify existing resources within the local community which can be utilised in service provision. CBR is also credited with generally raising the awareness of the community about the needs of people with disability, promoting the 
visibility of people with disability participating in community life and fostering a greater sense of civic conscious and community responsibility for all members (Kuipers et al., 2001). For example, in one rural project, some successful outcomes of a combined CBR conceptual framework and participatory development ${ }^{19}$ implementation approach have included: the generation of a sustainable service model to respond to the needs of people with disability, greater community awareness of disability issues, more community support for people with disability and their carers, more effective networking and communication in the community, and greater informal community support for people with disability (Kuipers et al., 2001).

\section{Disability and Development}

"Because disability and poverty are inextricably linked, poverty can never be eradicated until disabled people enjoy equal rights with nondisabled people."

(Lee, 1999, p. 13 as quoted in Yeo \& Moore, 2003, p. 571)

\section{Disability and Poverty}

Disability advocacy in developed countries tends to focus on supporting people with disability in independent living. This is a very different experience from people with disability in a developing country whose focuses are concerned with survival and the opportunity to participate in everyday community life (Barnes \& Mercer, 1995). The cyclic link between impairment, disability and poverty ${ }^{20}$ is depicted below:

\footnotetext{
${ }^{19}$ Participatory Development is explained further on page 41 .

${ }^{20}$ For an expanded interpretation of the relationship between poverty and impairment see Appendix Five.
} 


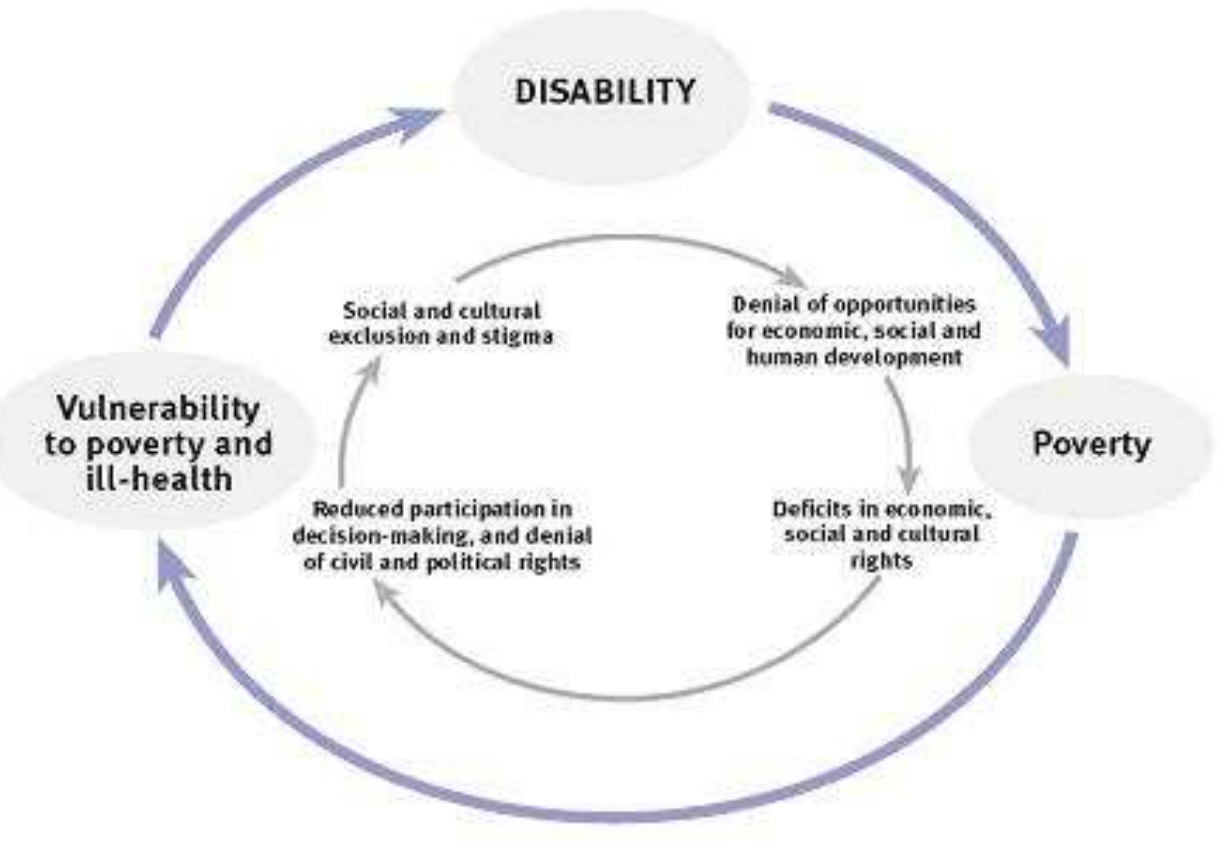

(Source: DFID, 2000, p. 4)

This diagram illustrates how the social-model paradigm of disability reflects the contemporary paradigm of poverty; both are concerned with limitation of social, cultural, political and economic participation. Yeo \& Moore state "if disabled people were able to achieve equal rights and opportunities, this would contribute to poverty reduction for society as a whole" (2003, p. 581). Sen's capabilities approach holds that poverty perpetuates unless development is targeted at giving people freedom to pursue the benefits of equal opportunities (1999). He emphasises that people with disability are often doubly disadvantaged in society. Sen (1999) gives the example of accessing services to participate in the productive work force - people with disability have a reduced ability to earn an income combined with the need for extra income to achieve the chance to participate in employment.

The link between poverty alleviation and education is well established (DFID, 2000; Katsui, 2005; Sen, 1999; UN, 2008; Yeo \& Moore, 2003). Inclusion in education for children with disability also has benefits in post-school outcomes (Hardman \& Nagle, 2004; Jonsson and Wiman, 2001; Terzi, 2007). Education provides the technical, academic and social skills necessary for employment. It also reduces the likelihood of people with impairments who are looking for inclusion in the workplace being discriminated against by employers who have had no personal 
experience of interacting with people with impairments (Price, 2003). Enabling disabled people to achieve employment benefits society in terms of increased economic productivity and reduced time constraints on carers (AusAID, 2008). Jonsson \& Wiman (2001) give an economic analysis of including children with disability in education and find that there is an economic component which argues that the incremental benefits of educating children with disability outweigh the incremental costs. This was earlier suggested by Lynch (1994) as shown in the table below:

\section{Table 5: Economic Benefits of Inclusive Primary Education}

\section{Economic Benefits from Inclusive Primary Education}

- Reduction of social welfare costs and future dependence

- Increased potential productivity and wealth creation provided by education of those children with impairments and disadvantages

- Through concomitant overall improvement of the quality of primary education, reduction in school repetition and drop-out rates

- Increased government revenue from taxes paid, which can in part be used to recoup the costs of initial education

- Reduction of administrative and other recurrent overheads associated with special and regular education, and

- Reduced costs for transportation and institutional provision typically associated with segregated service.

\section{Disability in Development Paradigms}

International literature acknowledges that disability issues require a "twin-track" approach; while they must be fully integrated into all development planning and projects, it is also appropriate to have disability as a separate thematic issue at times (DFID, 2000; Nowland-Foreman \& Stubbs, 2005; McKinstry et al., 2004; Tiroler, 2003; UN, 2008). 
Figure 3: The Twin-Track Approach to Disability

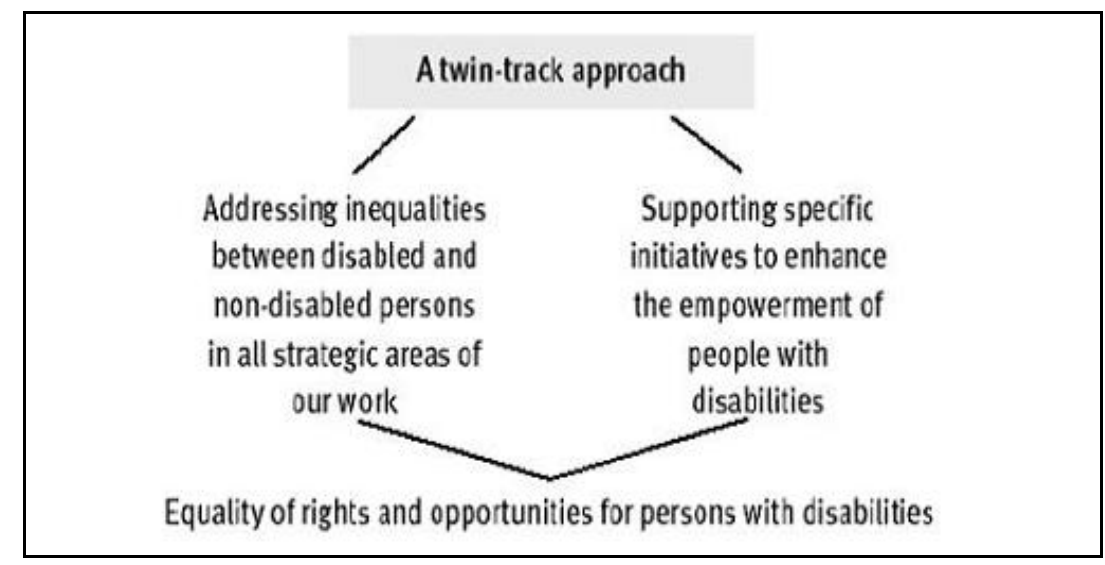

(Source: DFID, 2000, p. 11)

An example of an international organisation demonstrating a twin-track approach is the WHO which acknowledges that disability is not something that only happens to a minority - all human beings may experience a decline in health and experience some degree of temporary or permanent disability (WHO, 2001; UN, 1993). Very few mainstream projects have a disability component to them; it is estimated that less than two percent of global development funding includes planning for people with disability (Tiroler, 2003; Katsui, 2005). An increase in demand for disability considerations to be considered at all levels of development planning has been heard in the international literature (AusAID, 2008; Tiroler, 2003; Yeo \& Moore, 2003). Finland provides an example of where successful disability activism has resulted in an increase of development aid funding; now five percent is targeted toward disability specific projects (Katsui, 2005). Development planning for an inclusive and enabling society does not only benefit the disabled population; infrastructure and access adaptations also benefit others such as the frail, temporarily injured, unwell and elderly (AusAID, 2008).

Two contemporary development paradigms well suited to promoting the inclusion of disability in development, Right-Based Approaches and Participatory Development, are discussed below.

\section{Rights-based Development Perspectives and Approaches}

Rights-based approaches are currently replacing the traditional needs based approaches in development. Internationally, many government and nongovernmental development activities are required to centre their practice in a human 
rights framework as a basis of sustainable development (Eklindh \& Brule-Balescut, 2005). The link between sustainability and the human rights tenets of participation, ownership and accountability is crucial to successful development (Eklindh \& BruleBalescut, 2005; Miles, 2003; Sanga, 2004). A rights-based approach requires using a conceptual framework based on international human rights standards, principles and norms, and means that development plans, policies and processes include the promotion and protection of human rights (Mikkelsen, 2005). Human rights-based approaches to development include as key components: express linkage to rights, accountability, empowerment, participation, non-discrimination and specific attention to vulnerable groups (Katsui \& Kumpuvuori, 2008).

Rights-based approaches are grounded in social justice theory:

"A rights-based approach to development describes situations not simply in terms of human needs, or out of development requirements, but in terms of society's obligations to respond to the inalienable rights of individuals, empowers people to demand justice as a right, not a charity, and gives communities a moral basis from which to claim international assistance when needed." (UN Secretary General Kofi Annan 1998, as quoted in Mikkelsen, 2005, p. 205)

The relationship between development and the fulfilment of human rights can be seen as mutually implicit; development is in itself a human right (Mikkelsen, 2005).

Applied to disability issues, ideally disability should be included in all development and thus realisation of human rights naturally follows. Rights-based approaches to development are designed to simultaneously empower rights holders to claim their rights and strengthen the ability of duty-bearers to fulfil their obligations (Alston, 2005; Mikkelsen, 2005).

The way in which this occurs is illustrated below: 


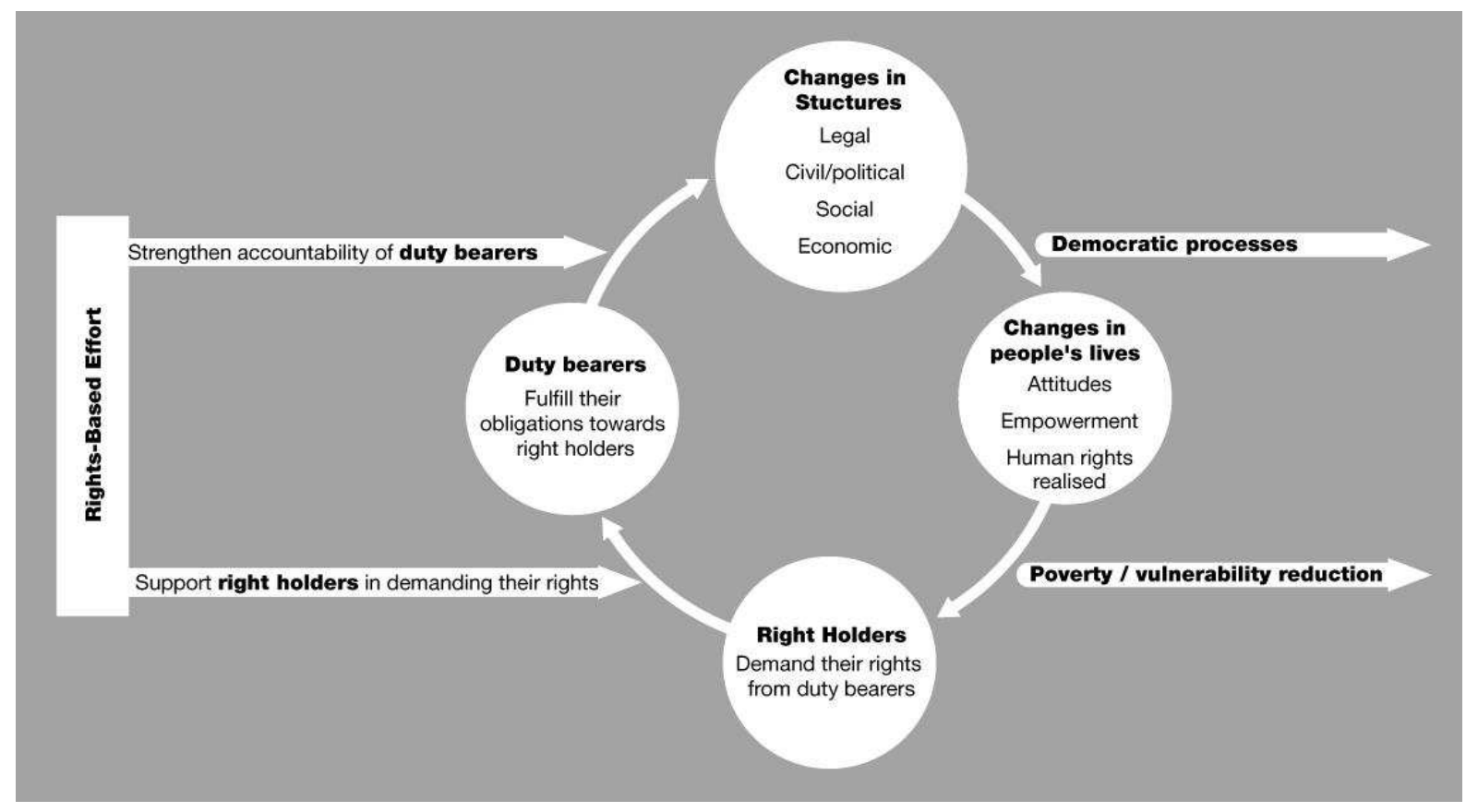

(Source: Ljungman, 2005, p. 8)

\section{Participatory Development}

Participatory development is the dominant approach to redressing social inequalities in development work. Ideologically, participatory development is a belief in selfdetermination (Chambers, 1995; Jennings, 2004). It aims to address social issues such as poverty, inequality and social exclusion by giving a voice to local people, especially poor, vulnerable and weak groups or individuals, empowering them to participate in determining their own development goals and plans (Hayward, Simpson and Wood, 2004). Ultimately, participatory development aims for social change; the redistribution of power in a societal relationship, enabling typically marginalised and excluded individuals and groups to be systematically included in social, political and economic processes (Chambers, 1995). Therefore, participatory development has a strong political stance and potentially contradicts many of the existing social structures of a community or society. 
Participatory development approaches offer insights into priorities and wants that other needs assessments cannot offer (Blackburn, Chambers and Gaventa, 2000; Chambers, 2005). Projects that are developed in this way are in a sense 'owned' by the local people and are thus likely to be sustained (Blackburn et al., 2000). The process of participatory development is undertaken in partnership and is empowering; completion is indicated when the process has resulted in skill development and human capital accumulation (Briggs, 2005; Chambers, 1995).

However, while participatory development has many benefits, Platteau \& Abraham (2002) caution that it may not be the best approach in societies without a functioning democracy at a localised level. They propose that poor people are more likely to benefit from a centralised state distribution system than a participatory approach which may ultimately fall prey to the familiar hegemonic structure of society (Platteau \& Abraham, 2002).

One of the applications of participatory development is the movement toward facilitating child participation which involves encouraging and enabling children to make their views known on the issues that affect them. In child participation, adults elicit and consider children's opinions, ideas and contributions when making decisions that impact them (UNICEF, 2003). As noted earlier, children with disability are often the most vulnerable in populations so child participation approaches are likely to significantly benefit them.

Another application of a participatory development approach is in its combination with a CBR approach to provide an effective disability service delivery model in developing countries (Kuipers et al., 2001; Wirz \& Thomas, 2002). A benefit of this combined framework is in improved cooperation between government sectors such as education and health which optimises services for the whole community (Kuipers, et al., 2001).

\section{Disability and Education}

Like other social institutions, schools have a history of excluding people with disability (Hick, 2009; Smith, 2004). Smith (2004) gives the example of a court case in early twentieth century America where a child with cerebral palsy who had the academic capacity to learn was excluded from school because of his impaired 
speech, drooling and facial-muscle contractions; in this case the judge ruled the school could exclude the child on the basis that he "produces a depressing and nauseating effect on the teachers and school children" (p. 4).

It is estimated that out of more than 100 million children who do not attend school, 40 million are disabled (Sen \& Wolfensohn, 2004). Currently, most children with disability in developed countries do attend school. However, there is a massive discrepancy between children's access to education in developing and developed countries (Price, 2003; Yeo \& Moore, 2003). For example, in the Asian and Pacific region less than ten percent of children with disability access any form of education despite a net enrolment rate of 70 percent for the region and fewer girls with disability attend school than boys (DFID, 2000; Price, 2003; Yeo \& Moore, 2003). There are many reasons why children with disability may not be sent to school including fear they will not cope, their education is not a good investment and that their public existence will shame the family and potentially jeopardise marriage opportunities of siblings (Yeo \& Moore, 2003). Documents report that all children with disability who are included in education are likely to receive "inferior treatment" (Yeo \& Moore, 2003, p. 574).

\section{The Shift from Special Education to Inclusive Education}

\section{Special Education}

The New Zealand Ministry of Education gives the definition of Special Education as: "the provision of extra help, adapted programmes, learning environments, or specialised equipment or materials to support children and young people with their learning and help them participate in education" (MOE, 1996). Special education is characterised by the provision of extra arrangements for students with impairments so they can be integrated into a mainstream or regular school system (Hick, Kershner \& Farrell, 2009; Farrell, 2005). Special Education is targeted towards children and young people with learning difficulties, communication, emotional or behaviour difficulties, or intellectual, sensory or physical impairments. Public policy in special education originally focused on ensuring equal access to education in terms of children with disability being present at school, which it has achieved with some success in the developed world (Farrell, 2005). Today, accountability for educational achievement and outcomes for all students is prioritised, including those with 
disability. The focus on participation and quality of learning signal a change in the previously accepted low educational expectations (and subsequent low achievements) of children with impairments (Hardman \& Nagle, 2004; Eklindh \& Brule-Balescut, 2005).

\section{Individual Education Plans}

One of the ways in which learning goals have been planned for in the Special Education system has been through Individual Education Plans (IEPs). An IEP is a specific education program for an individual student where academic and functional goals are set depending on the child's level of ability (MOE, 1999; Hamill \& Everington, 2002). IEPs are designed in collaboration with all people involved in a student's education; they have an holistic focus and consider all factors which enable a child to learn, for example a nurse may be included if the child has health needs. A typical IEP team includes parents, teachers and other relevant school personnel and relevant specialists, and sometimes the student. Hamill \& Everington (2002) advocate for always including the student in his or her own IEP, regardless of their level of functioning so that the team are reminded that the child is to be worked with rather than 'done to'. Collaboration is a core component of an IEP; each team member contributes equally to the information sharing and goal setting process, and responsibility for implementation of the plan is shared amongst the team (Spedding, 2005). The IEP follows a strengths-based model; it focuses on the student's current achievements and next steps to be met. For this reason IEPs occur quite frequently and monitoring, assessment, goal setting and collaboration continue in a dynamic process to ensure a student's meaningful inclusion in education (MOE, 1999).

\section{Critiques of Special Education}

Some people have raised concerns that a special education approach can only have limited success because it does not focus on systemic change - for example, students' educational difficulties are measured in a clinical and medical way and reflection about the school's inability to teach the student are rarely considered (Eklindh \& Brule-Balescut, 2005). Other concerns indicate that special education reinforces social prejudice. As a matter of course, education must cater to a diverse range of students' learning styles and academic ability. Schools' acceptance of these differences tacitly benefits one group and disadvantages children who are labelled as having 'special' educational needs (Minnow, 1990). From a social model of 
disability, the term and concept of 'special' accommodation needed for some students to participate in education further perpetuates their disability (Minnow, 1990). There are some strong opponents of the term 'Special Needs' who see it as a "pejorative descriptor that creates a powerful attitudinal barrier to the inclusion of individuals who are so described" (Snow, 2008, para. 2).

Critics of Special Education feel the approach has been insufficient to meet the educational and social requirements of many students with impairments. Some say it has been detrimental to social inclusion, and places students with impairments further at risk of marginalisation and exclusion (Eklindh \& Brule-Balescut, 2005; Hardmand \& Nagel, 2004).

\section{Special Schools}

There is a continued debate about whether special schools or regular schools are the best option for educating children with additional needs. Vygotsky ${ }^{21}$ (in Rieber \& Carton, 1993, p. 85-6) believes that all children, regardless of ability, can be educated through existing educational pedagogies and asserts that special schools are inherently antisocial and isolating. Lynch (1994) and Jonsson \& Wiman (2001) state that as well as social benefits, it is economically more viable to include children with disability in regular education. Inclusive Education advocates for children with disability to be included in regular or mainstream schools. This is seen as the best way of "combating discriminatory attitudes, building an inclusive society and achieving education for all" (UNESCO, 1994). Farrell (2005) believes that an inclusive orientation can also be characteristic of special schools and that parents ought to be able to choose their preferred option.

\section{Inclusive Education}

Inclusive Education departs from Special Education by focusing on the transformation of education systems to increase their ability to respond to the diversity of all learners in both formal and non-formal education. The basis of inclusive education philosophy is threefold; firstly it is based on the premise that

\footnotetext{
${ }^{21}$ Vygotsky is a developmental psychologist whose work has influenced many educational theorists in the field of child development, including Bronfenbrenner (see Appendix Six). It is important to note that Vygotsky's work is posited in Marxist theory, and as such Vygotsky placed great emphasis on the social aspects of child development. For more information see 'Is Vygotsky Relevant? Vygotsky's Marxist Psychology' by Martin Packer (2008) available from: http://pdfserve.informaworld.com/20489 789629617.pdf
} 
exclusion is a social process; secondly, that each student must be viewed holistically; and thirdly on the principle of non-segregation (UNESCO, 1994).

\begin{abstract}
"Inclusion is seen as a process of addressing and responding to the diversity of needs of all learners through increasing participation in learning, cultures and communities, and reducing exclusion within and from education. It involves changes and modifications in content, approaches, structures and strategies, with a common vision which covers all children of the appropriate age range and a conviction that it is the responsibility of the regular system to educate all children" (UNESCO, 1994).
\end{abstract}

As discussed earlier, Inclusive Education has explicit links to the international human rights framework. The right to education was established in the initial inception of the international human rights framework in the 1948 UDHR and was reiterated in the 2006 CRPD. The conceptualisation of Inclusive Education is that it is a rights-based process of decreasing exclusion from, and increasing participation in, the culture, curriculum and community of mainstream schools (Florian, 2009). Therefore, Inclusive Education is a vital tool for mainstreaming a human rights approach to development (Mikkelsen, 2005).

\title{
Inclusive Schools
}

Inclusive schools are founded on the belief that all children within a community learn together (SENESE, 2008). Inclusion in education reflects a school culture where all the students' individual educational needs are met, schools are flexible in teaching styles and structure and community partnership is fostered (Farrell, 2005; SENESE, 2008). The individualising of all students' educational programs (e.g. through IEPs or other mechanisms) benefits all children, and reduces the stigmatisation of difference, since all the individual differences between the students in the school will be apparent; all students will be seen as different, and therefore the same (Minnow, 1990; Vygotsky, in Rieber \& Carton, 1993). Opportunities for participation in education ought to be created at all times (but not to the exclusion of personal preferences for specialist assistance for those who need it) (Eklindh \& BruleBalescut, 2005).

Imperative to inclusive education is the importance of building a school culture which is welcoming and respectful to everyone; barriers to learning and participation are identified and removed through a commitment to inclusive philosophies (Eklindh 
$\&$ Brule-Balescut, 2005). The attitudes of teachers and the culture of the school (and wider community in which it exists) are seen as the most pertinent features of successful inclusion (Wong, Peason, Ip \& Lo., 1999). While many other education initiatives recognise the importance of including the wider school community, inclusive education aims to foster the community's comfort with diversity (MOE, 1996; Wong et. al., 1999).

A consideration which is gaining prevalence in the international literature is that of the emotional benefits of inclusion in education and society, for people with and without disability (Urquhart, 2009). An emotional component to learning dispositions is often taken for granted (Urquhart, 2009); none of us are as available to learn if anxious, distracted, upset, unwell or excited as we are if calm, focused, satiated etc. Yet if it is to be judged by the current prevalence of children's mental health disorders, level of exclusion from education and perceived pressures on children's well being, the emotional component of learning must be seen to have been neglected (Urquhart, 2009). Miles (2003) questions whether it is helpful for a child with disability to be included in a less than efficacious mainstream education system whereas others (Kershner, 2009; Lene, 2008; and Tiroler, 2003) see that inclusion, even in an imperfect mainstream system, when done properly, can benefit the system and all its pupils simultaneously.

\section{Critiques of Inclusive Education}

Inclusive Education is not a panacea; it is a philosophy which requires commitment and deliberate action to meet its goals (UNESCO, 2009). Two critiques of the movement are given here. The first is that although the international community acknowledges inclusive education as the way to achieving the fullest educational objectives for children with disability, educational practice frequently belies the rhetoric of equality of opportunity it purports (Smith, 2004; Wong et. al, 1999). Legislature, policies, conceptual changes and practical educational changes are all needed to move towards inclusive education and there are often gaps between policy and practice (Eklindh \& Brule-Balescut, 2005). In response to this critique, Wong et al. (1999) reminds that anti-discrimination law tends to precede public attitudinal change rather than respond to it. 
The second critique discussed here is the fear that this will place further strain on the workload of teachers, thereby weakening the education system, and holding back the potential academic success of some students (UNESCO, n.d.). Broadening teacher training in catering for diverse populations is an important consideration when looking at educational reforms (Hardman \& Nagle, 2004). However, like Vygotsky, Florian (2009) believes that teachers need not learn any new inclusive pedagogy, but rather can learn how to include all children into existing education pedagogies. Furthermore, there is strong anecdotal evidence that the benefits of Inclusive Education practices (such as flexible teaching styles, and the ability to individualise learning where appropriate to meet the students' level of ability) are accessed by the wider school population (AusAID, 2008; UNESCO, n.d.).

\section{Disability, Development and Education in the Pacific}

This section of this chapter situates the main discussion points from the previous sections about disability, development and education into the regional context of the Pacific.

\section{Attitudes to disability in the Pacific}

Just as at the global level, disability is recognised as both a cause and consequence of poverty in the Pacific (PIFS, 2005). Pacific Island communities have a history of isolating and excluding their disabled members from education, community participation, and from self-expression (McKinstry et. al., 2004). The Pacific Islands Forum Secretariat (2008) recognises that barriers to participation in societies stem primarily from underlying harmful attitudes and prejudices towards people with disability, including stereotyping and misunderstanding. Information about disability is scarce in the Pacific and social prejudice is often borne from the belief that an impairment is a punishment for wrong-doing, caused by an evil spirit (as in the religious model of disability) (McKinstry et al., 2004; PIFS, 2002; Yeo \& Moore, 2003). Some of the negative attitudes toward disability are reflected in the legislature of Pacific Island Countries, which persist in using outdated terminology adopted from previous colonial legislation. McKinstry et al. (2004) found fourteen examples $^{22}$ of demeaning terms in Pacific Island countries' laws and recommend that this be redressed to reflect people's inherent dignity and human rights.

\footnotetext{
${ }^{22}$ The examples of denigrating language found in legislation in the South Pacific include: "idiot or imbecile"; "unlawful carnal knowledge"; "persons of unsound mind"; "mentally defective";
} 
Negative attitudes toward and consequent neglect of people with disability in the Pacific have often stemmed from a lack of knowledge, rather than a lack of compassion (Price, 1994; Mead, 1928 as cited in Smith, 2005). Price (1994) describes passive acceptance of a child with disability by some families, who feel that they must deserve a disabled child for some reason and are often not aware of potential services, or ways of managing the child's impairment.

\section{Pacific Regional Disability Initiatives ${ }^{23}$}

Due to the strength of social networks and subsistence lifestyles, income poverty has not historically been a major concern for the Pacific (Lameta, 2005). However, poverty of opportunity is acknowledged in the Pacific as a "multi-dimensional concept embracing a lack of education and health, lack of economic assets, employment opportunities, social exclusion and political marginalisation" (Lameta, 2005, p. 10). Many countries in the Pacific have either not known about or not attended to disability issues until recently, and so have been unaware of the prevalence, causes or nature of disability within their community (McKinstry et. al, 2004). Ownership of disability issues has historically been held by NGOs and early disability services in the Pacific were established in an ad hoc manner dependent on whoever had the interest, impetus and resources necessary to drive the movement (Price et al., 1999). In the last ten years, Pacific governments have been gradually taking over responsibility for their disabled citizens; disability was first included as an agenda item at the Pacific Islands Forum and the Secretariat of the Pacific Community (SPC) in 2002 (McKinstry et. al., 2004; PIFS, 2002; Price et al., 1999). Although many Pacific Island countries have signed international and regional documents to do so, there is variance in the degree to which countries in the Pacific have started to address disability issues in their development (McKinstry et al., 2004). ${ }^{24}$

\footnotetext{
"incompetent"; "natural mental infirmity"; "severely subnormal"; "natural imbecility"; "disadvantaged"; "mentally defective persons whose cases call for segregation"; "insanity"; "retarded class of persons"; "mental handicap"; and "feeble minded" (McKinstry et al., 2004, Annex 2).

${ }^{23}$ An outline of some UN driven Asian and Pacific Regional Disability initiatives is given in Appendix Four.

${ }^{24}$ See also the Pacific Islands Forum Secretariat for a disability profile for the following countries: Cook Islands, Federated States of Micronesia, Fiji, Kirabati, Nauru, Niue, Palau, Papua New Guinea, Samoa, Solomon Islands, Tonga, Tuvalu and Vanuatu; www.forumsec.org/pages.cfm/sustainabledevelopment/social-policy/disability/country-profiles
} 


\section{Pacific Disability Forum}

The Pacific Disability Forum (PDF) is a collective of 20 mostly small, regional DPOs, and several international organisations. The PDF, now funded by NZAID began in 2002 and was officially inaugurated in 2004 (PDF, 2009, para 1.). It faces problems of isolation and distance between its members, but is developing capacity and beginning to work on disability issues (Hunt, 2008). At their meeting in Apia in 2008, the forum raised goals for people with disability in the Pacific including freedom from violence, abuse and neglect, support for families, early intervention services, and access to quality health services and education (Hunt, 2008). The PDF focuses on advocacy and awareness, capacity and training and promoting the equal rights of women with disability (PDF, 2009).

\section{Human Rights in the Pacific}

Negative attitudes and discrimination towards people with disability prevail in the Pacific and results in exclusion from accessing human rights (PIFS, 2008). The debate over the universalism of human rights is pertinent in the Pacific context because Pacific cultures tend to emphasise collective consciousness (Thaman, 2000). They place value on belonging rather than rights; collective wellbeing is traditionally paramount and individual wellbeing ensues; emphasis on individual rights is thought by some to undermine traditional Pacific cultural values (Huffer, 2006; Thaman, 2000). The idea of children's rights is particularly contentious for many in the Pacific because of the strong stratification of societies by age; children are expected to be respectful to their elders by listening and are socialised against self-expression of their opinions, ideas and needs (McMurray, 2006). Also, Pacific countries are often not involved in contributing to the development of international treaties and covenants to which they are expected to adhere (Angelo, 1992; Thaman, 2000).

As discussed earlier, Sen (1999) counters the viewpoint that the international human rights framework undermines culture and asserts that cultures are more resilient than this credits them with. Indeed, Pacific cultures are not static; they have been changing, adapting, and evolving due to both external and internal influences without being overwhelmed (Price, 1994; Sen, 1999; Thaman, 2000). However, there are some who contend that modernisation in the Pacific is unique in that rather than being a gradual process of change from traditional to modern, Pacific cultures have 
adopted modern beliefs, ideas and values which sit alongside their traditional beliefs (Hooper, 2000 as cited in UNICEF, 2008). As discussed earlier, recent discourses on human rights sit between universalism and relativism and this approach was favoured at the 2000 Collective Human Rights of Pacific Peoples Conference in $2000^{25}$ who agreed that all human rights were interpretable in the context of Pacific cultures (Wickliffe, 2000). This position reinforces the validity of both cultural protection, and the progression of human rights-based approaches in development in the Pacific while not excusing human rights violations. As Thaman (2000) puts it:

"Human rights... were and continue to be attractive to Pacific Islanders because there was, and is dissatisfaction with the old order" (p. 8).

\section{Education and Disability in the Pacific}

Education is highly valued in the Pacific and is seen as the pathway to modernisation of countries with skilful, law abiding citizens, indispensable to economic and social development, and a way to protect and maintain indigenous cultures and human rights ( PIFS, 2004; PIFS, 2006; Sanga, 2002; Taafaki, 2000; Taufe'ulungaki, 2002). At consecutive Pacific Island Forum Secretariat (PIFS) Education Ministers meetings it has been acknowledged both that education is the fundamental building block for society (2001) and that education for people with disability is the greatest challenge facing Pacific governments (2002).

Education systems in the Pacific have typically been inherited from the colonial or religious powers who first introduced formalised education meaning that each Pacific country's education system reflects different internal and external influences (Kalolo, 2002; Sanga, 2002). It has been said that in general the quality of education in the Pacific needs improvement as much of it is imported, inflexible, academic and irrelevant to its targeted audience (McMurray, 2006; Taufe'ulungaki, 2002). Problematic issues such as a lack of resources, untrained teachers, inadequate funding, poor management and non-participating parents pervade all countries in the Pacific (Sanga, 2002).

As discussed, including children with disability in education was first tabled as an agenda item at a regional level for the PIFS Education Ministers meeting in 2002. At

\footnotetext{
${ }^{25}$ Indigenous participants from Tonga, Samoa, Fiji, Hawaii, Niue, Tokelau, Australia and Aotearoa / New Zealand were present at this conference.
} 
these meetings many Pacific governments ${ }^{26}$ have stated their recognition that education is a basic human right for all children and many have signed various international treaties to this effect; however in 2003 only seven governments out of the 23 in the Asian and Pacific region had included specific mention to children with disabilities in their education for all planning (Price, 2003). Policy implementation joins the list of barriers to inclusive education in the Pacific, alongside a lack of knowledge at the grass roots level - for example, many parents may not know their child is capable of learning, and negative attitudinal barriers at all levels of society frequently hinder attempts to garner education for children with disability (McKinstry et al., 2004; Price, 2003; SENESE, 2008). In addition, the PIF Forum Education Ministers meeting listed the following concerns which need to be developed to support inclusive education systems and services for people with impairments in the Pacific:

"lack of early identification and intervention services; inadequate teacher training, particularly training of all regular teachers to teach children with diverse abilities; inflexible curriculum and assessment procedures; inadequate specialist support staff to assist regular class teachers; lack of appropriate teaching equipment and devices; unmodified school environment to make it fully accessible; lack of political commitment to legislative protection, policy development and implementation" (PIFS, 2002).

Since 2002, Pacific initiatives in basic education, inclusive education, special education and non-formal education have been regularly discussed at the Education Ministers meetings as part of the regional drive toward implementing the Biwako Millennium Framework (BMF) ${ }^{27}$ and EFA goals (PIFS 2002 - 2007). The main tool for implementing the Forum's Basic Education Action Plan is the Pacific Regional Initiatives for the Delivery of basic Education (PRIDE) project whose priorities are

\footnotetext{
${ }^{26}$ The PIFS Education Ministers meetings have been represented by the following members: Australia, Cook Islands, Federated States of Micronesia, Fiji, Kirabati, Nauru, New Zealand, Niue, Palau, Papua New Guinea, Republic of the Marshall Islands, Samoa, Solomon Islands, Tonga, Tuvalu and Vanuatu. Representatives from other countries and international organisations which have had representatives granted observer status include: Tokelau, New Caledonia, ADB, the Australian Sports Commission, the Secretariat for the South Pacific Community (SPC), UNICEF, UNDP, UNESCO, UN ESCAP-EPOC, UNFPA, the World Bank, DFID, the University of the South Pacific, the University of Fiji, the PRIDE project, the Pacific Association of Technical and Vocational Education and Training (TVET), the European Union, the Commonwealth of Learning and the South Pacific Board for Educational Assessment. (Taken from Forum Basic Education Action Plan Meeting Minutes: 2001, 2002, 2004, 2005, 2006, and 2007. Not all parties were present at all meetings.). ${ }^{27}$ The BMF is an operational guideline which partners the Millenium Development Goals. For further explanation see Appendix Four.
} 
the provision of quality basic formal and non-formal education in the early childhood, elementary, primary and secondary sectors, and TVET (PRIDE, 2004; PIFS 2006). Disability was specifically discussed again in 2007 at the PIFS Education Ministers Meeting where Pacific Governments supported the change in the paradigm of disability from a medical and deficit model a social and rights-based model.

\section{Lessons Learned}

There is no single solution to providing education for children with disability. Pacific governments differ on many important historical, social, geographical, economic, educational, political and cultural influencing factors (Price, 1994). However there are now some valuable lessons which have been learned in Pacific contexts which other disability initiatives can draw from. Some examples are given here. Early identification and intervention is critical so that families can begin to support their children as soon as possible, develop advocacy and other pertinent skills, and because early identification decreases the likelihood of secondary disability (Price, 2003). Also, data collection to identify children with disability is imperative because if children are not identified as having additional needs it is difficult to plan for their inclusion into school (Price, 2003). Advocacy campaigns targeted toward specific issues are more effective than general public awareness campaigns about disability issues (Nowland-Foreman \& Stubbs, 2004).

\section{The National Experience of Inclusive Education in Samoa}

A comprehensive presentation of historical and current aid, NGO, and government initiatives in the field of disability and education for each country in the Pacific is beyond the scope of this thesis. However, the Samoan experience of Inclusive Education is depicted here briefly, as an example of a Pacific model. The experiences of Samoa are given here in the interests of gathering information which may be helpful for Tokelau, but are not critically appraised. Samoa is illustrated because of its political and geographical links to Tokelau and subsequent familiarity to Tokelauan people.

In 1998 Samoa signed the United Nations Economic Social Committee Asian-Pacific (UNESCAP) Proclamation on the Full Participation and Equality of People with Disabilities in the Asian and Pacific Region (PIFS, 2009). As seen in the regional 
experience, disability initiatives were historically driven by the NGO sector in Samoa until 2000 when a child identification survey signalled the beginning of a strong national focus on disability and education (Lene, personal communication, $15^{\text {th }}$ October 2008). This was followed by an adult identification survey conducted in 2002 (PIFS, 2009). Samoa has a national disability committee and there is a high level of strategic collaboration involving the ministries of education and health, NGOs and bilateral donors such as AusAID and NZAID (Lene, personal communication, $15^{\text {th }}$ October 2008; PIFS, 2009). There is also a DPO - Nuanua O Le Alofa (NOLA) which is a member of the Pacific Regional Forum and the Disabled Persons International organisation. In 2008 NOLA held a forum to establish a committee for women with disability (Hunt, 2008). At the government level there are policies on inclusion, a national vision plan and a national hearing plan which targets infant screening (Lene, personal communication, $15^{\text {th }}$ October 2008).

Originally the Samoan educational priority for children with disability was to establish special education units in pilot schools. However this did not result in inclusion because students with impairments stayed in their special needs units (Lene, personal communication, $15^{\text {th }}$ October 2008). Learning from these initial experiences has provided the impetus for establishing Inclusive Education Schools:

\footnotetext{
"There were lessons we learned there so now we're steering towards all classrooms being inclusive and able to cater for children with diverse range of needs and abilities." (Lene, personal communication, $15^{\text {th }}$ October 2008).
}

The PRIDE project has supported Samoa to develop sustainable education systems (Lene, personal communication, $15^{\text {th }}$ October 2008). Samoa has adapted the UNESCO Toolkit for Inclusion, a resource manual for teachers on how to facilitate a more inclusive school environment, so it is more suitable to the local environment (UNESCO, n.d.). Professional development has been offered in specific disciplines like deaf and blind education, and on developing and using individual education plans. Other key areas of focus include empowering parents through parent support groups, training parents as teacher aides so they can continue to support their child at home as well as in school, and establishing early intervention services. The strong national and NGO commitment to establishing rights-based disability initiatives in Samoa, coupled with inclusive policies and public awareness-raising through 
campaigns shown on TV and in newspapers, has yielded a change in attitudes toward people with disabilities (Lene, personal communication, $15^{\text {th }}$ October 2008; Lameta, personal communication, $10^{\text {th }}$ November 2008).

"There are good stories for every child involved in inclusive programming here. We trialled having teacher aides this year ... one parent of a deaf child went into her neighbouring village where she'd heard of another deaf child and taught that village signs in the school holidays." (Lene, personal communication, 2008).

\section{Chapter Summary}

Disability, a process of social exclusion of people with impairments, is inextricably linked to the denial of fundamental human rights and freedoms, and therefore inseparable from poverty. Consequently, if development is to be efficacious there is a pragmatic responsibility and rationale to include disability in all planning, policy and practice. This has been recognised in the UN Convention on the Rights of Persons with Disability (2006), and can be seen in some aid programmes such as AusAID's "Development For All: Towards a disability-inclusive Australian Aid Program, 2009-2014" (2008). The evolution of disability and development paradigms to rightsbased models and approaches is reflected in the education sector's conceptual change from Special Education to Inclusive Education philosophies and approaches. The practical applications of these human rights-based ideas are starting to be reflected at the regional Pacific level through the Pacific Disability Forum, the Pacific Islands Forum Education Ministers meetings, and the PRIDE project. Taking Samoa to illustrate this further at a national level, we can see a progressive example of collaboration between government, NGO and aid sectors which has led to the development of inclusive policies, a national disability committee, national data collection, public awareness raising through TV and newspapers, and the formation of DPOs, including a women's committee on the DPO, and Inclusive Schools. While Inclusive Education is still in the early stages in Samoa, we can already see that this affords more people the opportunity to access education, and can reasonably project that the combined impact of these initiatives will benefit Samoa's economic and social development. Given the social and political nature of the process of exclusion which is disability, research into this area is moving toward showcasing experiences of people with disability (Katsui, 2005; Knox et. al., 2000). This research 
complements this work by seeking experiences of community members, some of whom are parents and siblings of people with disability, but all of whom have an equal role to play in societal change towards an inclusive community. 


\section{Chapter Four: Tokelau}

\section{Introduction}

This chapter sets the local context, Tokelau, where the fieldwork component of this thesis was undertaken. It gives a political, economic, historical, cultural and social profile of Tokelau within which to consider international and regional ideas and understand local ideas about disability, development and education. This chapter starts by looking at the geography and history of Tokelau. It then goes on to outline the government and political structures, including Tokelau's relationship with New Zealand and its stance on decolonisation. The chapter concludes by looking at the education system and recent disability initiatives.

\section{Maps}

Figure 5: Map One: The Pacific Region

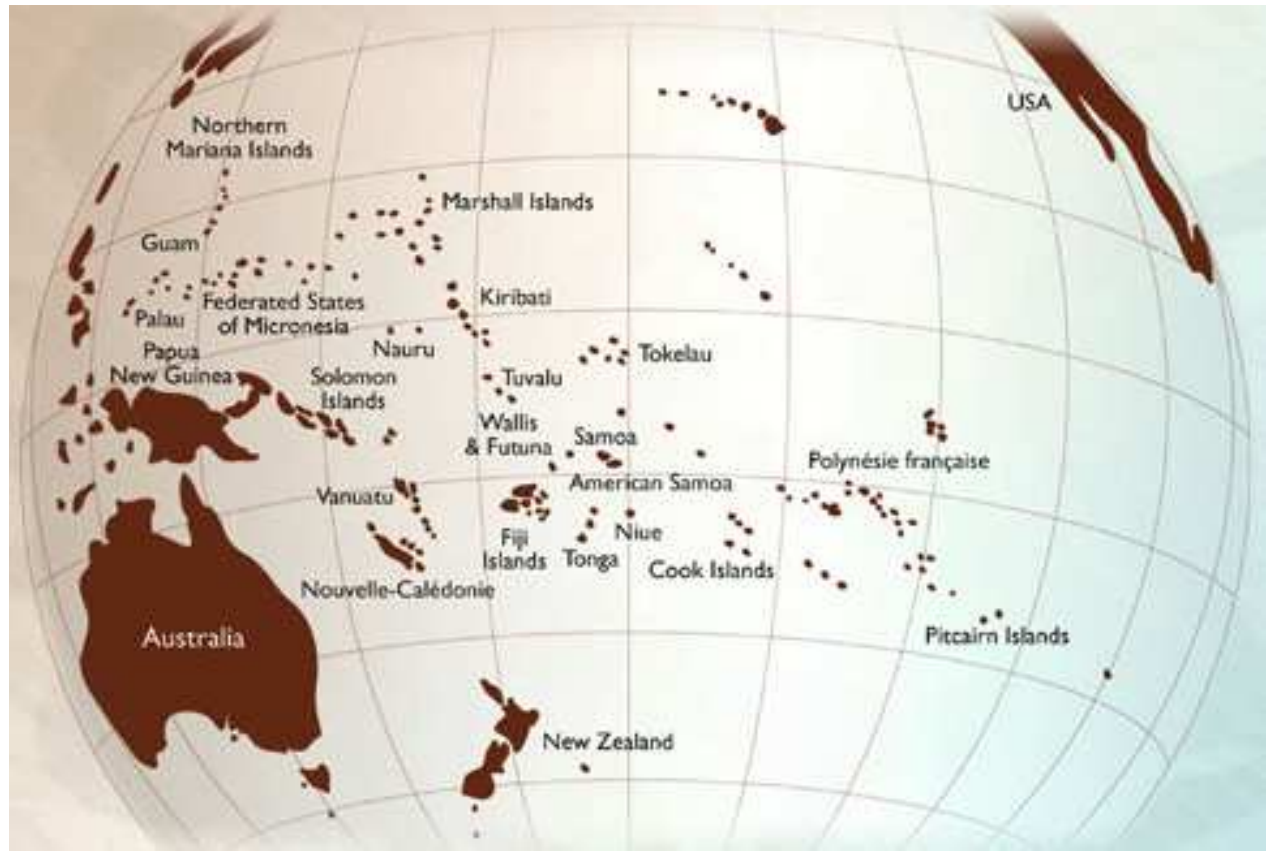

(Source: Retrieved $23^{\text {rd }}$ February 2009, from www.spc.int/corp/index.php?option=com content\&task=view\&id=15\&ltemid=41 ) 


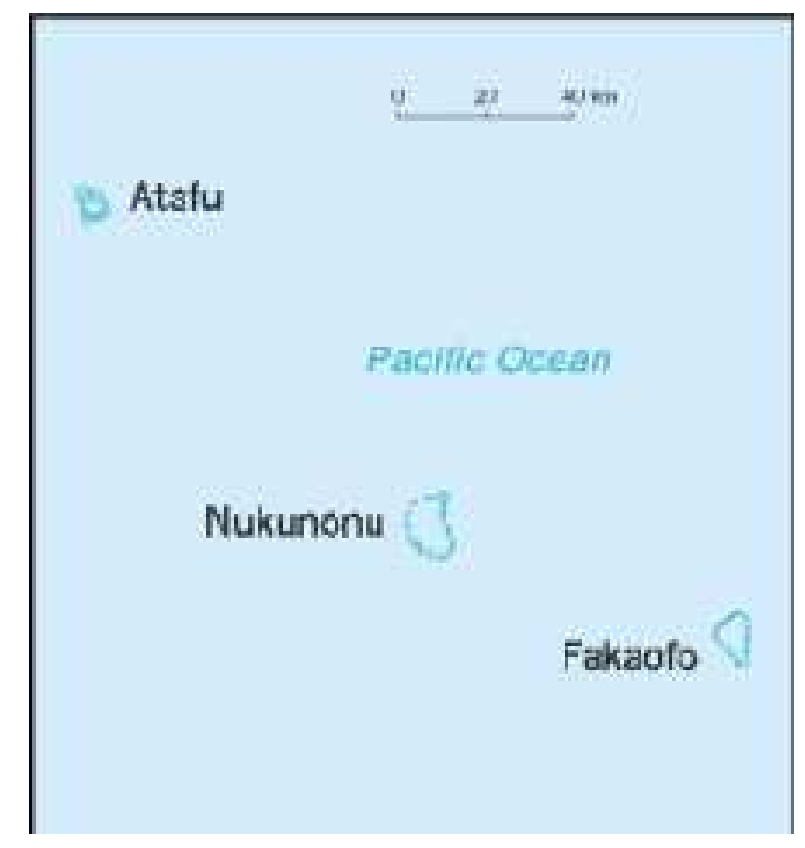

(Source: Retrieved on $23^{\text {rd }}$ February 2009, from www.tokelau.org.nz)

\section{Population}

Tokelauans are ethnically close to Tuvaluan people. The Tokelauan ethnic background changed suddenly and significantly after the kidnapping of almost half the population (253 people) in 1863 by Peruvian slave ships. Following this, immigrants from Tuvalu, Uvea, Java, Scotland, France, Germany, Portugal and New Zealand arrived and were included in Tokelauan society (McQuarrie, 2007).

\section{Table 5: Tokelau 2006 / 2007 Population Data}

\begin{tabular}{|l|l|}
\hline Total Population & 1,446 \\
\hline Atafu & 524 \\
\hline Fakaofo & 483 \\
\hline Nukunonu & 426 \\
\hline Tokelau Population outside Tokelau & Approx 8,000 \\
\hline Tokelau Population In New Zealand & Approx 6,000 \\
\hline
\end{tabular}

(Source: Kelokolio, 2006, as cited in Buchanan, 2007; McQuarrie, 2007; Statistics NZ, 2007)

In the 2006 census, the "usually resident" population was counted at 1,446, which includes people on the atolls on census night and those usually there but temporarily absent for health, education or official purposes (Kelekolio, 2006, as cited in Buchanan, 2007). This system of counting residents for census purposes differs from previous years and for this reason Tokelau's historical population trends are difficult to depict accurately and clearly (Kelekolio, 2006, p. vii, as cited in Buchanan, 2007). 
Tokelau's population holds fairly stable because migration occurs to alleviate overcrowding of the atolls thereby countering what would otherwise be a population increase (McQuarrie, 2007).

There are relatively small Tokelauan settlements in Samoa, American Samoa, Australia and Hawaii as well as approximately 5,000 Tokelauans living in New Zealand (McQuarrie, 2007). The largest Tokelauan settlement is based in the Greater Wellington area (encompassing Wellington city to the Upper Hutt Valley). The earliest migrants to New Zealand from Tokelau usually lived in Samoa first. From New Zealand they instigated chain migration by paying for the fares of their family members who wished to join them (Huntsman \& Kalolo, 2007). The New Zealand government operated a Tokelauan Resettlement Scheme from 1966 - 1976 during which 528 people were brought from the islands to New Zealand (McQuarrie, 2007).

\section{Geography}

Tokelau is made up of three small, isolated coral atolls in the Pacific Ocean, and lies 483 kilometres north of Samoa. Atafu the northernmost atoll is 92 kilometres north of Nukunonu, which in turn lies 64 kilometres north of Fakaofo, so each of the atolls is isolated from each other and other Pacific nations (MFAT, 2005). The three atolls have a total combined land area of 12 square kilometres in 290, 000 square kilometres of surrounding water (McQuarrie, 2007, p. 26). From Atafu in the north to Fakaofo in the south, the group extends for just under 200 kilometres (MFAT, 2005).

Tokelau's own vessel, the MV Tokelau is both a cargo and passenger ship. It travels from Apia to Tokelau fortnightly; a round trip takes five days (MFAT, 2005). There are no deep water passages in any of the atolls which means that ships must drift or anchor out in deep water while passengers and cargo travel between the large ship and atolls on a small boat over the surf and over the reefs (McQuarrie, 2007). There is no alternate way to access Tokelau.

Each atoll consists of a number of reef-bound motu (islets) encircling a lagoon. The motu vary in size from 90 metres to 6 kilometres in length and from a few metres to 200 metres in width. Nukunonu is the largest atoll at 4.7 square kilometres (MFAT, 2005). Fakaofo and Atafu are 4 square kilometres and 3.5 square kilometres respectively. The highest point above sea level of the atolls is 3-5 metres so the atolls 
are vulnerable to threats such as damage from tropical cyclones and global warming; any significant rise in sea level could make the atolls completely uninhabitable (McQuarrie, 2007).

On the outer motu of each atoll dense vegetation is seen in the form of coconut plantations, which have been purposefully cultivated as the dominant plant for copra and food production. There are also some sections of coconut plantations on the inhabited islands (Huntsman \& Hooper, 1996). Because it is predominantly coral debris, the ground is mostly infertile; there are no fresh water sources and rain typically washes away through the porous coral (Huntsman \& Hooper, 1996, p. 21). Tokelau remains reliant on cargo ships regularly bringing non-perishable goods, although it has an abundant supply of coconut and fish and gardening initiatives have recently begun on each atoll so fresh fruit and vegetables can now be grown.

Each atoll has a single village; one motu is inhabited in Nukunonu and Atafu, and two in Fakaofo where expansion was eventually a physical necessity (the village is still united and operates from the main atoll). The villages are located on the western side of the atolls for two reasons. Firstly, this means that there is a down wind on the return trip across the lagoons from the coconut plantations on the outer motu, and secondly, fishermen have sheltered access to the ocean on the lee side of the island (Huntsman \& Hooper, 1996, p. 28).

\section{History}

There is no historical concept of nationhood or unity of identity between the three atolls of Tokelau. In fact, the atolls have a history of hostility against each other and were first joined by force after Fakaofo's victories in war led to the colonisation of Atafu and Nukunonu and their introduction to the rule of the god Tui Tokelau (McQuarrie, 2007).

Throughout the early 1800s many ships came into contact with the atolls of Tokelau but it was not until 1835 that Western sailors' nautical maps and charts recognised the existence of three rather than two atolls (McQuarrie, 2007).

Tokelau has a long political history of relationships with colonial powers. In 1887 Tokelau (then called the Union Islands and consisting of Atafu, Nukunonu, Fakaofo 
and Olohega or Swains Island) become a protectorate of Britain. In 1889 Britain officially annexed the three atolls of Tokelau because they were in the proposed path of the first trans-Pacific telegraph cable and therefore of significant strategic value (McQuarrie, 2007). Tokelau was included as part of the Gilbert and Ellis Islands Crown colony (now known as Kirabati and Tuvalu) in 1916 after Britain relinquished control of Tokelau and Western Samoa to Germany. America asserted sovereignty over Olohega in 1925. New Zealand and Tokelau officially relinquished any claim over Olohega in 1980 in a reciprocal agreement with America who relinquished any claim over the other three atolls (Giese \& Perez, 1983). Olohega is now administered as part of American Samoa, however there is an international dispute over Olohega because Tokelau included it in the draft constitution in 2005 (CIA, 2009; McQuarrie, 2007). New Zealand forces took Western Samoa back from the Germans in the First World War and in 1926 in accordance with the wishes of Britain, New Zealand took responsibility for administration of both Western Samoa and Tokelau. Tokelau was considered a British territory until 1947 when it officially became part of New Zealand (McQuarrie, 2007).

Political unity is new to Tokelau. Each atoll was administered separately until 1963, when representatives from all three atolls were first brought together for policy and planning purposes (Angelo, 1999).

\section{New Zealand's relationship with Tokelau}

Today, Tokelau is New Zealand's last remaining dependent colonial territory. Tokelauans are New Zealand citizens; they hold New Zealand passports and are able to enter in and out of New Zealand freely.

Tokelau has never had a resident colonial administration. The Administrator of Tokelau and other staff comprising the 'Tokelau Unit' are based at the New Zealand Ministry of Foreign Affairs and Trade (MFAT) in Wellington. The unit manages New Zealand's relationship with Tokelau and functions in an advice and guidance capacity, particularly with regard to the process of working toward independent status (discussed below), but also with respect to education, transport, health, financial and public sector management, and constitutional and legislative development (Buchanan, 2007, p. 17). 
In accordance with the UN Special Committee on Decolonisation, and in accordance with the will of the Tokelauan government, New Zealand is supporting Tokelau's political autonomy. Support to Tokelau is provided in accordance with New Zealand's constitutional obligations outlined in the 2003 Joint Statement of the Principles of Partnership between New Zealand and Tokelau (NZAID, 2007). The options of becoming independent, self-governing in free association with an independent state, or integrated with an independent state were first offered to Tokelau in 1976 by a visiting United Nations team, in accordance with their policy on decolonisation (Kalolo, 2007). However, Tokelau declined to consider selfgovernment until 1994 when it began working towards independent status in free association with New Zealand (Buchanan, 2007).

In 2003, a committee drafted the Constitution of Tokelau which covers the topics of the General Fono (Tokelau's Parliament), the Council for Ongoing Government, the Courts, Law Making, Land, Public Service, Finance, Citizenship and Human Rights $^{28}$ (MFAT, 2005). Although included in Tokelau's constitution and thereby in line with many international treaties and covenants, Kalolo (2007) speculates that the terminology and concepts regarding human rights are unfamiliar and not well understood to the majority of the population (p.21). ${ }^{29}$ Certainly, the issue of including human rights in the Constitution at all was debated during its formation; the minutes of one of the discussions about human rights in 1995 show a comment that "human rights cannot have precedence in small places like Tokelau" (Constitution Committee Meeting Minutes, 1995, as cited in Huntsman \& Kalolo, 2007, p. 175).

A Treaty of Free Association with New Zealand was drafted in 2005. This document outlays that Tokelauans will retain New Zealand citizenship, and that Tokelau and New Zealand will continue to act together in a spirit of partnership. Under this agreement, New Zealand undertakes to work with Tokelau to ensure the retention

\footnotetext{
${ }^{28}$ Tokelau is signatory to the following UN Treaties: Convention Against Torture; International Convention on Civil and Political Rights; Convention on the Elimination of Discrimination against Women; International Convention on the Elimination of all forms of Racial Discrimination; International Covenant on Economic Social and Cultural Rights. (ACYA, 2009)

${ }^{29}$ In Chris McMurray's (2006) work in Tokelau a group of women attributed the rise of adolescent problems to the fact that many parents and teachers had adopted the UNCROC's prohibition of corporal punishment (p. 17).
} 
and development of its language and culture, to continue administrative, technical and specialist support in all areas of government activity at Tokelau's request, and to provide ongoing economic support, and contribute to infrastructure development (MFAT, 2005). New Zealand's continued total responsibilities towards Tokelau are in defence, security, maritime surveillance and emergency and disaster relief (MFAT, 2005). The draft treaty states that Tokelau has the right and legal capacity to undertake its own international relations and enter treaties in its own right, but the practical capacity to do so is limited, and as such, international relations will be one of the areas that are supported in consultation with New Zealand (MFAT, 2005).

Both the draft constitution and draft treaty were approved by the Tokelau General Fono in 2005, and together form the basis for an act of self-determination (MFAT, 2005). From the Secretary of the UNGA's Special Committee on Decolonisation's perspective Tokelau is seen as a "shining example" of commitment to selfgovernance through strengthening of its economic, political and social well-being (UNGA, 2007). However, there was a history of contention about the question of independence from Tokelau (quoted here at length):

“Tokelau's perspective toward self-determination has not changed. To us, while we may work on intangibles such as pride of the people, pride of being self-determined, we've always asked the question, what's it for? We've said this to the UN and to New Zealand..., why do you want to do this?...Why do we want to do this? Is it to satisfy you or to satisfy us? Why would we want to declare to the international community we have self-determination? Is it going to feed our mouths, is it going to feed our children? What good is it for future generations?"

(Тари, 2004 as quoted in Huntsman \& Kalolo, 2007, p. 239).

Objections were also stated by politicians in Wellington: "The decolonisation process is being driven by experts in international law who have clearly lost their grip on reality" (Hayes, 2005 as quoted in Huntsman \& Kalolo, 2007, p. 248), and some of the members of the Tokelau population of New Zealand: "some people think they will lose the connection with New Zealand" (Field, 2007a). 
Despite pressure from the UN and New Zealand ${ }^{30}$ in its 'eradication of colonialism' movements, in referendums held in 2006 and 2007, Tokelauans supported remaining a dependant territory of New Zealand; in both elections a majority voted for independent status but did not reach the required threshhold (Huntsman \& Kalolo, 2007). Only Tokelauans resident in Tokelau were able to participate in political decisions affecting Tokelau despite many overseas-based Tokelauans expressing desire to be involved (Kalolo, 2007). In her thesis exploring the reasons why Tokelauans chose to remain a dependency of New Zealand during the 2006 referendum, Buchanan found three main interwoven contributing themes for this decision; political divisions and rivalries which influenced both leaders' and voters' behaviour, a lack of public education about the self-government package and a resulting lack of understanding by many constituents, and a feeling from groups in all three atolls that Tokelau is not ready to self-govern (Buchanan, 2007). Tokelauans raised concerns about issues regarding good governance such as accountability, transparency, human resource capacity, and public participation in decision making (Buchanan, 2007). Some felt these issues needed to be resolved before Tokelau ceased to be a dependency of New Zealand (Buchanan, 2007). Buchanan (2007) relays another contributing factor, the 'Tokelau mindset', as explained to her by Tokelauan participants in her research, as "comprising a narrow world view, resistance to change, and a sense of dependency" (p. 135).

In June 2008, the Ulu (head) of Tokelau gave a speech to the UN Committee on the Eradication of Colonialism indicating that Tokelauans would continue to seek independent status. He suggested that because the two referenda results had countered the position of the General Fono and Taupulega (council of elders) who had instigated the move toward independent status they "questioned the fabric of our traditional and decision-making institutions that has sustained our way of life for generations" (COG, 2008: Para 6). It is not expected that another referendum will be held for at least the next five years (Field, 2007b).

So few territories were delisted during the United Nations General Assembly (UNGA) “Decade for the Eradication of Colonialism' between 1990-2000 and so far

\footnotetext{
${ }^{30}$ New Zealand was reportedly embarrassed by its status as one of only four imperial nations and being lobbied by Syria and Cuba to free Tokelau (Field, 2007c; Hunstman \& Kalolo, 2007).
} 
from the second consecutive Decade (which began from 2000) that the idea arose that self-determination need not be derived solely from independent nationhood and the UN changed its stance by acknowledging that some territories do not wish to recognise their right to self-determination (Hunstman \& Kalolo, 2007).

\section{Tokelauan Government Structures}

Tokelau has national and village organisations of government including a local public service. Traditionally each island was governed individually by its own chief and a council of elders made up of the most senior male in each family. The Taupulega are the main authority on each atoll, and each is headed by the local Faipule (elected village leader) (Kalolo, 1995; Huntsman \& Hooper, 1996). The Taupulega are responsible for local public service provision including employment of public servants, and they delegate responsibility to the General Fono for national matters such as international relations, trade, communications, fisheries and transport (MFAT, 2005).

Every three years, each atoll elects a Faipule and a Pulenuku. The Faipule is the main official link between the village and New Zealand. Nominations for position of Faipule are open to people who are not necessarily members of the Taupulega but women rarely stand for the position (Kalolo, 1995). The Pulenuku's position is more concerned with daily matters of the atoll and Pulenuku is sometimes translated as mayor (Kalolo, 1995, p. 14). The Pulenuku chairs the Taupulega meetings, and is always elected from the Taupulega body (Kalolo, 1995).

The General Fono, which is also elected every three years, and meets three or four times a year for approximately three days, is Tokelau's parliament, or national representative body. The General Fono meetings began in 1963 as a forum to discuss national issues to present a united voice to the administrative power (Angelo, 1999). The role of the General Fono has expanded over time. In the 1980s the General Fono began to take responsibility for policy formation, and in the 1990 s began to hold some legislative capacity (Angelo, 1999). The General Fono is made up of representatives from each atoll, relative to the population size of the atoll. Originally, 
the General Fono constituents were male elders but now women and youth can be included (Angelo, 1999).

The Council for the Ongoing Government of Tokelau (henceforth known as the Council for Ongoing Government) is the national executive and is made up of the Faipule and Pulenuku from each atoll. Each Faipule holds several ministerial portfolios. The position of Ulu (head) of Tokelau rotates between the three Faipule, as does the location of the general fono, so that during every three year term each Faipule holds responsibility for the national government of Tokelau (MFAT, 2005).

\section{Tokelau Public Service \& the Modern House of Tokelau}

In 1967, following the Tokelau Amendment Act, the Tokelau Public Service (TPS) was established (Huntsman \& Kalolo, 2007). There are four units in the TPS; three village units which provide health, education and other public services and a national unit which houses the Council for Ongoing Development, and the Tokelau Apia Liaison Office (TALO). The TPS was developed to provide acceptable levels of social services such as health care and education, which was seen to be beyond the capability of the village. The TPS was originally based in Apia, but this was unpopular with many Tokelauans and the TPS is now localised within each atoll and under the control of the Taupulega (Buchanan, 2007; Huntsman \& Kalolo, 2007).

There were strong feelings that the capability of Tokelau was being weakened, not strengthened by the TPS because its employees essentially reported to New Zealand, thereby disregarding local systems of governance and authority (Buchanan, 2007). This feeling, combined with a sense of a lack of preparedness to cope with administrative responsibilities of self-governance was a factor leading to the Modern House of Tokelau Project (MHT) initiative in the 1990s. The MHT started from the basis that the Taupulega must be the starting point for development of any new governance structures in Tokelau, to protect existing village authority and sociocultural structures, but must also incorporate modern Western systems of governance (MFAT, 2005). At the core of the MHT project was the introduction of public discussions about governance; the United Nations Development Programme (UNDP) supported the General Fono to run workshops on each atoll on concepts such as self- 
determination, democracy, good governance, sustainability, capacity building, accountability and transparency (Kalolo, 2007, p. 258).

In 2004, New Zealand officially transferred full control of the TPS to the Taupulega, a process known as 'devolution'. The MHT ceased to exist, and its principles have been included into the general public sector and constitutional development of Tokelau (Buchanan, 2007).

\section{Tokelau and the International Community}

Tokelau is increasing its participation in certain regional organisations such as the Conference of the Pacific Community, the South Pacific Regional Environmental Programme, the Forum Fisheries Agency, and the Council of the University of the South Pacific, but does not have its own international representation (MFAT, 2005). In 2006 Tokelau had its first representative at the Pacific Islands Forum meeting after being granted observer status in 2005; previously Tokelau was represented by the New Zealand government at these and other international and regional forums (MFAT, 2005; McQuarrie, 2007). Tokelau is an associate member of the World Health Organisation (WHO) and United Nations Educational Scientific and Cultural Organisation (UNESCO).

\section{Development in Tokelau}

Atiakega (to build upon) is the indigenous concept of development in Tokelau (Kalolo, 1995:). Atiakega involves aspects of dependency, which over time has transferred from dependency ${ }^{31}$ on God to political dependence on the colonial power (Kalolo, 1995, p. 104). Traditional Tokelauan social structural systems such as 'inati' (sharing of resources) are not aligned to Western developed world practices such as decentralised governance and democracy (Vandersyp, Fairbairn-Dunlop \& Sulu, 1998). Kalolo (2002) states that development in Tokelau is anchored in the idea of empowering each of the villages to be involved in political, social and economical decisions and processes. Unlike other Pacific countries, there are no NonGovernment Organisations in Tokelau, other than the Aumaga and Fatupaepae (discussed further on page 68).

\footnotetext{
${ }^{31}$ This idea was supported in Buchanan's (2007) thesis when participants in her research relayed the Tokelau mindset, as discussed on page 64.
} 
Tokelau is not included in the UNDP's Human Development Index (HDI) because its Gross Domestic Product (GDP), the measure on which the HDI is calculated, comes mostly from donors and is not considered income (Buchanan, 2007). The figure given on the Tokelau government's website for GDP per capita is $\$ 478$ Australian dollars. However, this figure was estimated in 1980 and the website states that "there are no recent figures" (Tokelau Government, 2009). In 2000 the UNFPA reported on its website that Tokelau is on target to meet the Millennium Development Goals by 2015; however in 2008, the UNDP noted that Tokelau is yet to submit a report regarding its progress towards the MDGs (UNDP, 2008; UNFPA, 2000).

It is difficult to find data for Tokelau on Human Development Indicators, but the following information has been amalgamated from the 2006 Census, the United Nations Population Fund (UNFPA) whose data are dated approximately ca 2000; SPC Pacific Region Information System Management (PRISM) whose data are dated ca 2004 (cited in Lameta, 2005); and Action for Children and Youth Aotearoa (ACYA) Preparation for Next Report to the UN Committee on the Rights of the Child, dated 2007. The source of the data is signalled in brackets.

Table 6: Human Development Indicators for Tokelau

\begin{tabular}{|c|c|c|}
\hline \multicolumn{3}{|l|}{ Reproductive health } \\
\hline Adolescent fertility rate (births per 1,000 women aged 15 - 19) (UNFPA) (2000) & \multicolumn{2}{|l|}{45} \\
\hline Infant mortality rate (per 1,000 live births) $\quad$ (ACYA) (2007) & \multicolumn{2}{|l|}{38} \\
\hline Contraceptive prevalence rate (modern methods) \% (UNFPA) (2000) & \multicolumn{2}{|l|}{13.4} \\
\hline \multicolumn{3}{|l|}{ Population and development } \\
\hline Life expectancy at birth (UNFPA) (2000) & M 68.4 & $\mathbf{F} 71.3$ \\
\hline Age Dependency ratio (UNFPA) (2000) & \multicolumn{2}{|l|}{89} \\
\hline Population under 20 years of age (Kelekolio, 2006, p. 1) & \multicolumn{2}{|l|}{$47 \%$} \\
\hline \multicolumn{3}{|l|}{ Education \& Gender equality and empowerment of women } \\
\hline Ratio of girls to boys in primary/secondary education (UNFPA) (2000) & \multicolumn{2}{|c|}{0.96 to 1.12} \\
\hline Proportion of seats held by women in parliament (\%) (UNFPA) (2000) & \multicolumn{2}{|c|}{14} \\
\hline Literacy rate of people aged 15-24 (SPC) (2004) & \multicolumn{2}{|l|}{$86.5 \%$} \\
\hline
\end{tabular}

(Sources indicated in brackets). 


\section{Economy}

Table 7: Financial Data for Tokelau

\begin{tabular}{|l|l|}
\hline Source of Income & Amount \\
\hline New Zealand Aid & $\$ 13$ million (NZD) (NZAID, 2008) \\
\hline International Trust Fund (established 2000) & \$28.3 million (NZD) (MFAT, 2005) \\
\hline \\
(Sources indicated in brackets.)
\end{tabular}

Tokelau was predominantly a subsistence economy until the 1970s when cash was introduced. Tokelau is economically dependent on financial assistance from outside sources, particularly New Zealand. Tokelau has administered its own budget since 1994, of which New Zealand provides $80 \%$ in the form of 13 million dollars of annual aid money (NZAID, 2008). Tokelau's other main source of income comes from selling licences to the United States for the fishing of tuna (MFAT, 2005). Remittances in the form of cash and goods are another source of income, as is the selling of handicrafts, stamps, coins and copra (MFAT, 2005; UNDP, 2005).

As Tokelau has moved towards political independence, working towards economic independence has become increasingly important (NZAID, 2007; Vandersyp et al., 1998). An International Trust Fund was established by Tokelau and New Zealand in 2000 which now stands at $\$ 28.3$ million; New Zealand and Tokelau are the main contributors but the fund is open to global donors (MFAT, 2005). A review of New Zealand's aid to Tokelau conducted in 1998 stressed that "economic development must be set within the context of political, social and cultural development" (Vandersyp et. al., 1998, p. 5).

\section{Language}

The Tokelau language is a synthesis of two Polynesian dialects which are closely related to dialects spoken in Tuvalu and the northern Cook Islands (Giese \& Perez, 1983). The languages of Samoa and the Solomon Islands are also influences (Hoem, 1995). There is no dialectical variation between atolls. English is also spoken in Tokelau. 


\section{Religion}

Table 8: Religious Affiliation in Tokelau by Atoll

\begin{tabular}{|l|l|}
\hline Atoll & Religion \\
\hline Atafu & Protestant \\
\hline Fakaofo & Protestant and Roman Catholic \\
\hline Nukunonu & Roman Catholic \\
\hline
\end{tabular}

Source: (McQuarrie, 2007).

Table 9: Religious Affiliation in Tokelau by Percentage

\begin{tabular}{|l|l|}
\hline Religion & $\begin{array}{l}\text { Percentage of Population who follow this } \\
\text { religion. }\end{array}$ \\
\hline Protestant & $62 \%$ \\
\hline Roman Catholic & $34 \%$ \\
\hline
\end{tabular}

(Source: Kelekolio, 2006 as cited in Buchanan, 2007).

The religion practised on each atoll is largely due to the external influences of visitors; the London Missionary Society first visited Atafu and Fakaofo from their base in Samoa while Nukunonu was first visited by Roman Catholics visiting from the already converted Uvea (Wallis) Island (McQuarrie, 2007; Giese and Perez, 1983). People are permitted to discreetly follow other Christian denominations of faith (McQuarrie, 2007).

The structure of the church's seating plan on all atolls reflects the stratifications of Tokelauan society. Men and women sit separately and the congregation sit in order of youngest at the front to eldest at the back. The elders in the back row watch over the entire congregation; people move progressively backward as they become more responsible and disciplined and have positions of responsibility over others (Huntsman \& Hooper, 1996).

Churches are very important and powerful in Tokelau but church life is formally separated from politics (Buchanan, 2007).

\section{Culture}

A spirit of community and a group ethic prevails throughout Tokelauan beliefs, traditions and daily life (Huntsman \& Hooper, 1996). Tokelau is guided by elders, but operates communally and decisions are reached by consensus (Kalolo, 2007). 
Lemihio (2003) explains that three central values construct the fakaTokelau (Tokelau way); alofa (love and caring), va fealoaki (sharing and helping) and fakaaloalo (respect). The heart of the fakaTokelau is kainga (kinship). The Draft Constitution of Tokelau puts it thus:

"The Tokelau way ... includes a commitment to a life of interdependence where the less fortunate are cared for, the inati system of sharing resources, equal opportunity to participate in the life of the community, and the right to live happily" (MFAT, 2005).

Community life is supported by working groups. The formation of Aumaga was inherited from Samoan culture and is essentially a men's working group tasked with carrying out the Taupulega's suggestions about what needs to be done on the atoll (Huntsman \& Hooper, 1996; Huntsman \& Kalolo, 2007).

In Atafu, all men are members of the Aumaga and it is an autonomous body with its own leadership structure (Huntsman \& Hooper, 1996). In Fakaofo, the Aumaga functions more as a subsidiary workforce under the control and directive of the Taupulega, although it does have its own leadership structure (Buchanan, 2007). Nukunonu has no Aumaga external to the Taupulega as the elders consider it antithetical to Tokelauan custom and resist creating an alternate locus of power (Buchanan, 2007).

The Fatupaepae (women's group) was established by the New Zealand administration in the 1920s in order to maintain hygiene and cleanliness. There is some evidence of the role of this group changing to include more political pursuits, as representatives from the Fatupaepae sit on the Taupulega in Nukunonu and Fakaofo.

Village life in Tokelau still operates on traditional systems such as lakehe and inati. Lakehe is a system of preferential sharing designed to encourage individuals' equal development within communities by supporting the needy and those without survival skills of their own (Toloa, 1996 as cited by Vandersyp et al., 1998). Inati is a village system of equitably sharing the day's catch of fish, as well as other resources.

One of the most highly regarded traditions and a pervasive concept in Tokelauan life is maopopo which is a feeling of unity of people, both physically and in spirit 
(Huntsman \& Hooper, 1996; Huntsman \& Kalolo, 2007). Huntsman \& Kalolo (2007) describe it as "both an ideology and a morality" (p. 65). Fono (meetings) and discussions are an integral part of life in Tokelau; those who attend are praised for being maopopo and those who do not but should are considered not fully committed and their absence is lamented. Maopopo is compromised if people are absent who ought to be there. Maopopo needs to be nurtured and cultivated; it cannot be decreed. It is not limited to meetings; work can be maopopo if all are united for the successful outcome of the activity. In Tokelauan culture, communal gatherings and priorities take precedence over personal concerns; when people act as one, maopopo is felt and leads to well-being and prosperity for all. The Taupulega are responsible for the maintenance and promotion of maopopo; successful maopopo is euphoric and a lack of maopopo results in feelings of despair. A fono is judged as successful more by the maopopo felt than the decisions reached and it is preferred to delay a decision rather than threaten maopopo (Huntsman \& Hooper, 1996).

\section{The Place of Children in Society}

Children are treasured in Tokelau - "the strength of our nation in the future is in the health and well-being of the children" (Tokelau Department of Education, 2007, p. 9). However, it has been suggested that children and young people typically have little opportunity to voice their opinions and needs in Tokelau society because of their position at the bottom of the social hierarchy; when they are given an opportunity to express themselves, they are likely to agree with their elders by reinforcing conservative viewpoints, for the sake of acceptance (McMurray, 2006). As a consequence of their low status in the social hierarchy of Tokelau, some youth feel disempowered and discriminated against and exposure to external ideas with little authority to pursue a self-determined future has resulted in a sense of disenfranchisement (McMurray, 2006). However, there are examples of youth being invited to participate in community discussions such as the devolution of government (McMurray, 2006).

\section{Modernisation}

Traditional systems and beliefs are still prevalent in Tokelau. However, the mobility and youthful structure of Tokelau's population and developing communication with the outside world means that Tokelau is rapidly modernising (MFAT, 2005). Since 
Tokelau negotiated free wireless broadband internet in selling their internet domain DOT TK the internet has had a major influence on culture (Field, 2008). In 2001 there were 12 computers in Tokelau, in 2007 there were over 200 (Field, 2008). Many homes have satellite TV and the multichannel Sky Fiji is available (Field, 2007c). The impact of isolation is diminished by the rapid increase of telecommunications and global influences.

An example of some of the tension between modern and traditional justice authorities was seen in one of the most divisive events in Tokelau society. Field (2007c) refers to 'the Pastor situation' in Atafu when the Pastor admitted to sexually abusing a young girl in 1992. The Pastor was never charged but the international church council requested that he not be re-appointed as Pastor when he returned to Tokelau, a decision overruled by the Atafu village council which reinstated his position (Buchanan, 2007; Field, 2007c). The Atafu community is polarised by this event into church-going and non-church factions, who agree or disagree with the council's decision respectively (Buchanan, 2007). It was reported that the nonchurch group were asked to stay away from community events and nine individuals were ejected from the village council for not complying with council decisions (Buchanan, 2007; Field, 2007c). An implication of the community's rift was that in the referenda the church-going and non-church groups took the opposite position to each other (Field, 2007c).

\section{Health System}

Tokelau faces many barriers in providing healthcare to its population. There is a basically equipped hospital with an operating theatre on each atoll, but there are frequent shortages of medical staff. Doctors from overseas are offered 18 month locum positions in an effort to ensure continuity of treatment for patients and the community. Two dentists serve the three atolls. Any serious cases of medical illness are transferred to Samoa or New Zealand; a quarter of the health budget is spent on transferring patients. The incidence of preventable diseases such as diabetes, dental decay, high blood pressure, obesity and gout is rising due to lifestyle changes and the increase in imported foods (MFAT, 2005). Other public health concerns include youth suicide, unplanned pregnancy and sexually transmitted infections which are all increasingly common health issues in the Tokelau community (McMurray, 2006). 


\section{Education System}

The vision for Tokelau stated in the National Curriculum Policy Framework is

"our people improving the quality of their lives living on Tokelau"

(Tokelau Education Department, 2007, p. 4).

Table 10: Number of Students on each Atoll in Tokelau

\begin{tabular}{|l|l|l|}
\hline Atoll & School & $\begin{array}{l}\text { Number of Students in Early Childhood, Primary } \\
\text { and Secondary Education }\end{array}$ \\
\hline Atafu & Matauala & 164 \\
\hline Fakaofo & Tialeniu & 137 \\
\hline Nukunonu & Matiti & 96 \\
\hline
\end{tabular}

(Source: Tessa Kirifi, Tokelau Director of Education, personal communication, November $12^{\text {th }} 2007$ )

Tokelau's formal education system has been influenced and supported by external sources. In the 1950s New Zealand introduced school buildings and formal secular education to Tokelau. The first language of education was Samoan; educational radio programmes were broadcast into classrooms from Samoa in the early 1950s (McQuarrie, 2007). In 1969 the first education advisory couples from New Zealand were invited to Tokelau to give advice, guidance and resources to the Tokelauan teachers who had usually been trained in Fiji and Samoa (Huntsman \& Kalolo, 2007).

Education remains highly valued in Tokelau; early childhood education, primary and secondary schooling are compulsory and free and there is a high attendance rate $^{32}$ (MFAT, 2005). All schools first introduced year 12 in 2008; prior to this, in order to complete secondary schooling, students had to obtain one of 10 scholarships to Samoa. Schools are also beginning to encompass vocational training through programmes such as TVET (Technical Vocational Education Training). There is an office of the University of the South Pacific (USP) in Tokelau allowing tertiary education to be conducted by distance. The Tokelau curriculum advocates for a bilingual language of instruction (English and Tokelau), but resources are typically in English (MFAT, 2005).

\section{Critiques of the Education System}

Tokelau is developing and reforming its education system which is hindered by outdated teaching practices such as rote learning, and a lack of qualified teachers

\footnotetext{
${ }^{32}$ Except students excluded from school because of their physical impairment and truants.
} 
(MFAT, 2005). Kalolo offers some criticisms of Tokelau education, particularly in terms of its classroom and teacher centred practice (2002). He says that in Tokelau, learning traditionally took place through oral means such as storytelling, song, demonstration, dance and drama, but classroom learning has been removed from traditional learning in Tokelau (Kalolo, 2002). Most concepts and subjects taught at schools are rote learnt in order to pass exams which are written externally to Tokelau. The learnt knowledge is not applied to the known and lived everyday experiences of the students (Kalolo, 2002). Kalolo (2002) advocates for education developments in Tokelau to combine Western and traditional knowledge in the school.

Kalolo (2002) also suggests that difficulties arise from using both English and Tokelau as a language of instruction. The education language is Tokelauan at preschool levels and gradually English is introduced at upper primary and secondary levels (Tokelau Education Department, 2007). This presents many problems for older Tokelauan students as they are being asked to develop language skills like critical thinking and problem solving in their second language (Kalolo, 2002). Due to the prevalence of rote learning many of these students' difficulties are not picked up until they do not pass an examination which asks a question in a way they have not memorised (Kalolo, 2002).

Individual reading and writing skills are favoured over co-operative and oral skills for students which is a remnant of imported $19^{\text {th }}$ century British education models (Kalolo, 2002).

Kalolo (2002) writes that the narrow choices for students force many of them into failing in the academic system in which they are either not capable of success or not interested. He states that schools in Tokelau often do not recognise the diverse talent of the students because they do not provide a balanced holistic education (Kalolo, 2002).

\section{Education Reform}

It must be noted that many of Kalolo's critiques of the education system are from 2002 and are in the process of being addressed. As mentioned, the Tokelau Department of Education has recently started working towards broadening the educational options for students who may have either dropped out or been unable to 
progress, by extending secondary education to Year 12 and introducing non-formal vocational education. The Year 12 programme includes literacy, numeracy, and computer, environmental and vocational modules. Technical Drawing is the first vocational module to have been offered, and the Tokelau Department of Education plans to establish expressive arts, small business studies, design and technology, and food and textiles technology modules as well as some community public health education initiatives (Tokelau Education Department, 2007).

\section{Disability in Tokelau}

\section{Inclusion International / NZAID Survey 2002}

In 2002 a Disability Identification Survey was conducted in Tokelau as part of a Pacific region wide initiative to gather information through Inclusion International, in conjunction with the NZAID Regional Pacific Health Programme. Inclusion International worked with a volunteer from Volunteer Services Abroad (VSA) in Tokelau to coordinate the survey. During this survey, 17 people $(1.2 \%$ of the population) were identified as having one or more type of disability. The results from the survey were shown like this:

Table 11: Tokelau Disability Identification Survey 2002

\begin{tabular}{|c|c|c|c|c|c|}
\hline & $0-14$ & $15-25$ & $25-35$ & $35-50$ & $50+$ \\
\hline Slow learners & 4 & & & & \\
\hline Behaviour Problems & 1 & 1 & & & \\
\hline Visual Impairment & & 2 & & 1 & \\
\hline Intellectual Disability & 1 & & & 1 & \\
\hline Hearing Impairment & & 1 & & & \\
\hline Physical Disability & & 1 & & 2 & 2 \\
\hline Multi-disabled & 3 & & & & \\
\hline Total & 9 & 5 & 0 & 4 & 2 \\
\hline
\end{tabular}

(Source: Tokelau Disability Identification Survey, 2002)

The survey commented that although people with disability are generally accepted, in that everyone knows everyone because of the population size, expectations for people with disability are low because of a lack of information and support available to develop practices which enhance the potential of people with disability (McCullough, 2002). For example the local nurses were trying to support children with muscular dystrophy but were unfamiliar with the condition (McCullough, 2002). 
In terms of education, the survey found that children identified as "slow learners" typically were included in school but children in the other categories were excluded; the reasons given for exclusion was the teachers' lack of experience in special education and because the children were generally seen as "not suitable for a regular classroom environment". It went on to comment that children with disabilities are frequently sent to New Zealand for schooling. This scoping survey concluded that knowledge and information about disability and support is "very much needed" in Tokelau (McCullough, 2002).

\section{Group Special Education}

In 2007, a multi-disciplinary team from Group Special Education, Ministry of Education, New Zealand visited Tokelau at the request of the Tokelau government. This project focused on the pre-school, primary and secondary school aged population. The objectives of the visit were to contribute to raising public awareness about disability; to create a database that can be used by both the health and education departments with a register of students who were identified with having any impairment and disability which impedes their ability to access education, and to provide some individualised assessments, advice and guidance to students and excluded school aged children identified by schools, parents and the community.

This team identified that approximately $60 \%$ of the population they assessed (131 students across all three atolls) had an additional need at the time of the assessment which without consideration and management within the regular education setting likely limits their learning potential (Tokelau Special Education Team Report). The discrepancy between the figures in this report and the Inclusion International survey can be explained by several factors. Firstly, the GSE team had expertise in specific disciplines: Audiology, Speech and Language Therapy, Physiotherapy, and teaching children with behavioural and learning difficulties, so they could be very specific in identifying children at risk of difficulty learning in the present education environment. Secondly, the use of specialised audiological equipment meant that children with temporary conductive hearing impairment due to otitis media and otitis media with effusion (glue ear) were identified. This accounted for the majority of students included in the statistics. Thirdly, confusion between English and Tokelau languages meant that students who demonstrated confusion between the two 
alphabets in written form to the extent that they were at least 2 years behind their chronological age in literacy competence in English were included in the figures, a practice which follows New Zealand Special Education guidelines and practice. GSE thus recognised the systemic barriers to learning and education from a social model perspective.

The GSE work continued in 2008 and is an ongoing initiative with a sustainable design; there are plans to include community members in the next phases, to continue strategic collaboration between health and education, as well as to target the education system to be more responsive to a diverse population and to develop functional and academic goals in IEPs for some students.

\section{Disability in the Tokelau Education Curriculum}

The Tokelau National Curriculum Policy Framework states that the education system will treat all individuals fairly in the provision of educational opportunity, and that policies and practices which advantage some and disadvantage others will be avoided (Tokelau Department of Education, 2007, p. 10). It promotes equity in access to education, treatment within the education system, and outcomes for all groups by providing quality education irrespective of gender, abilities and nuku (Tokelau Department of Education, 2007). The Tokelau National Curriculum Policy Framework advocates for using IEPs for children who require additional or alternative resources and support (Tokelau Department of Education, 2007). It is "designed to be inclusive and appropriate for all children" and does explicitly refer to children with special needs (Tokelau Department of Education, 2007, p. 20).

Policy documents are critical to the guidance and implementation of practices, but at this stage it could be said that the framework addresses equity in an 'aspirational policy' since as noted earlier by Kalolo (2002) the reality is that many students are disadvantaged by an inflexible teaching system and a curriculum which is not related to lived experiences, and it was observed during the fieldwork that a small number with significant impairments are excluded completely. However, the new Tokelau National Curriculum Policy Framework addresses these concerns and the education system is currently changing. 


\section{Chapter Summary}

This chapter has shown some of the historical, political, social and cultural elements of life in Tokelau. The rapid modernisation of Tokelau means there is a balance between managing changing global aspirations and preserving local culture (Vandersyp et. al., 1998). Tokelau's complex political structure comprises facets of traditional authority such as the rule of the Taupulega which prevails in the modern context, as well as new components influenced by globalisation such as the General Fono and the TPS. Tokelau's relationship with New Zealand adds a further complexity to its makeup and the relationship is unlikely to change soon since Tokelau has twice recently elected to remain a dependent territory.

Traditional and modern ideas also exist alongside each other in education. Tokelau is seeking to broaden the opportunities afforded through education in its current educational reforms such as the introduction of non-formal education and through offering a full course of secondary school on the islands. Tokelau has recently also begun to pursue including children with disability in meaningful education with support from the New Zealand MOE and NZAID. Certainly, the Tokelau National Curriculum Policy Framework advocates for equity of opportunity in experiencing meaningful education for all children, irrespective of gender, abilities, special needs and $n u k u$ and thus reflects current international rhetoric. 


\section{Chapter Five: Findings}

This chapter presents the opinions and experiences of the participants thematically. As discussed in the research principles and design chapter, the questions ${ }^{33}$ served as a guideline; not all questions were asked in each instance and during the course of the interviews other topics were explored that were raised either by the interviewer or participants and these are presented here also. Findings are presented in three parts, under the broad headings of 'Knowledge and Attitudes about Disability', 'Resources and Support', and 'Regional and International Movements'. Quotes have been included from participants to illustrate particular themes and salient points. Unless otherwise indicated (e.g. by an $(S)$ for Samoa) quotes are from Tokelauan people; quotes are also indicated by gender (e.g. /f/ for female and $/ \mathrm{m} /$ for male).

\section{Part One: Knowledge and Understanding, Attitudes and Beliefs}

The first part of this chapter presents data about traditional and modern attitudes, opinions, hopes and knowledge about disability issues, interacting with people with disability, and including people with disability in education and society.

\section{Knowledge about Disability and Education}

\section{Special Needs and Special Education}

It was found that the concept of Special Education was familiar and understood by the participants:

"Special Education deals with special needs students so setting up the right programmes of education so these students will not be disadvantaged in the education system - they will be having some form of formal education." (m)

Collectively, the participants could name many of the varying needs that are typically included under the broader term 'special needs'. Most participants included physical, mental, behavioural and learning impairments or difficulties; some gave specific populations like hearing and vision impaired, and some participants included gifted children.

\footnotetext{
${ }^{33}$ See Appendix Seven for the full question guide.
} 
The term 'Special Needs' is already used in Tokelau, and the visiting GSE team from New Zealand were often referred to as the 'Special Needs Team'. However, many participants stated that it is a term that is used and understood in a limited sense in Tokelau:

"...even just that the term Special Needs is not limited to physical disability, I'm not sure that's clear to parents." (m)

One participant reported that his understanding of the terminology had increased since interacting with the team from New Zealand, which indicates achievement towards the goal of raising awareness about disability:

"I didn't know before but now I know there are ... different kinds of special needs." (m)

Although there is awareness that there may be different kinds of impairments, it was found amongst the general public of Tokelau that 'special needs' refers only, or usually, to children with physical disabilities. Clearly, this could lead to confusion when discussing disability issues if the term is being used in either sense without first establishing a common understanding of its definition.

Beyond potential confusion, comments were made that indicated the term 'special needs' also connotes a pre-existing negative assumption and was exclusionary, as seen here:

"I don't actually like the term Special Needs because it labels people and as soon as you say special needs it's been my experience that people go on the negative rather than the positive so people refuse to work with people with special needs, sort of like really hard work whereas I tend to think that it doesn't matter who you are, at some point in time we all need help and we're all special. We're great at labelling and boxing people, our systems are set up for that. Whereas if you look at the person as a human being it changes your focus and you work with them differently, you don't put limitations on them, but that happens a lot. Just work with them, without labels but because that is what they need at that particular moment in time, on that particular day." (m)

"People have come up with terms to rationalise things like 'you're Polynesian because there are many of you, Micronesian because you're small, Melanesian because you're black". Like 'Special Needs', yeah you're special, but not different. Inclusive Education 
would be a cool term to use in Tokelau because it's small... I think we should start changing the terminology, its important." (m)

One participant commented about the importance of people-first language and emotions:

"It's worse when parents or someone says 'oh that deaf boy'...it makes your heart cry when they do that - refer to them by their disability not their strengths." (m)

\section{Inclusive Education}

As noted, the concept of Inclusive Education is becoming a strong movement in the Pacific, and particularly in nearby Samoa which Tokelau has links to. When asked their understanding of Inclusive Education, participants gave answers reflecting beliefs that education should be made available for all children, regardless of their ability, or level of need for support to access education:

"Inclusive education is the opportunity for looking at all children and students, no matter what their background is, for them to have some opportunity to experience some form of education." (f)

The term also evoked answers demonstrating an understanding of the systemic changes which Inclusive Education aims towards:

"Inclusive education is about ... ensuring equal equity and access for all to education. It's making sure everyone, regardless of their level of ability, no matter what capacity whether or not they do have a mental or physical disability - it's making sure they do not feel excluded from education. Every education system should have the capacity to include them." (f)

The international move towards an Inclusive Education approach, and the associated rationale was expressed succinctly by a Tokelau Department of Education employee:

"Inclusive education has come later as the macro concept within which special needs has become part of. Inclusive education is more inclusive, covering a whole range of marginalised groups from education so it takes into consideration gender, students with special needs - physical, intellectually impaired, learning difficulties, for various reasons, not able to access language - for Pacific students this has been a big area that has excluded people from learning when 
they've been unable to access the language in which education has been provided." (f, S)

It may also be that participants were familiar with Inclusive Education philosophy through exposure to systems in Samoa:

"I have seen a few small institutions you know like in Samoa ... I think they're doing really well ... It's creating an environment for them. It's not that difficult for the government to provide the necessary resources for these children." (m)

It may be that the term inclusive education is inherently a more comprehensive term which without too much analysis can mean including all children in education, rather than the term special education which is automatically divisive of any education system into non-special or regular education, and special education.

Participants spoke about how current educational reform in Tokelau is targeted at broadening the system to be more inclusive of the diverse range of abilities within the schools by encompassing non-formal education such as vocational training, because, as one participant put it:

"We can see some kids are not so good at writing but they're very useful with practical learning." (m)

As noted, Tokelau is in the process of introducing Technical and Vocational Education and Training (TVET) and Year 12 in its schools in order to offer more opportunities to students.

"The priorities are to build capacity and be able to develop offering students another path besides the mainstream system. Some kids are better off doing practical hands on work than academic ... we're hoping to see people who drop out as having a chance to have another go. So these kids can give something back to the atolls and help their community." (m)

"One of the major changes is that last year there were 10 scholarship students out of 60 and the rest were excluded from that point. 2008 is the first year of change because now all are included, they can move into different pathways." (f)

These reforms and goals fit well with the Inclusive Education philosophy and the overarching aim of the Tokelau curriculum which is to "improve the quality of life living on Tokelau". These comments show that there is an opportunity to capitalise 
on the current broadening of the education system to include providing education for all children with disability.

\section{Language used to discuss Disability issues}

When asked whether there is a Tokelauan word for disability, or people with special needs, some participants reported that it is not a topic often discussed in Tokelau and many thought there is not any specific terminology:

"I don't remember having a name for them, they were just different." (m)

The participants who worked in education and government gave the general and literally translated term of "manakoga fakapitoa" (special needs) or "na tino mana manakoga fakapitoa" (people with special needs).

Some of the colloquial language used to refer to people with impairments in the Tokelau community indicates that attitudes are aligned to a medical and deficit model of disability:

"I've heard a literal translation of weak child, or sick child, not well child. There is babango that also means naughty; it's quite a negative word." (f)

"They are usually called kids with illness, that they are disabled Tamaiti Tamale." (m)

Other words which occurred with high frequency throughout the discussions such as 'burden' and 'pity' indicate the prevalence of a care and charity model of disability, in which it is considered an act of kindness to care for people with impairments.

\section{Attitudes to People with Disability and their Family}

\section{Shame / Superstition}

The Tokelauan participants had varying perspectives about shame attached to people and families of people with impairments, and the causes of disability. Most felt that there has been a historical attribution of stigma to the family of people with impairments, because of the belief that disability is caused by a curse because of sins or mistakes. 
"Some people honestly think the mother must have stood on a grave and that's why the child has special needs. There is a real religious and spiritual side to it." (f)

"There are superstitions here that if you do something wrong your child will suffer. E kai e na matua te vine moto kae maniania ai ia mifo o fanau. The parents will eat the unripe vine and the children will feel it in their teeth. They are blaming. If the children suffer hardships old people look at the parents - it's their fault, they did something wrong." (m)

To a degree this is in line with a religious or moral model of disability, where disability is seen as a punishment or curse from an ancestor, God, or evil spirit.

"A very important cultural aspect is how important aunties and uncles are because there is a very special relationship in Tokelauan culture of how children are related to their aunties, especially their aunts, they call Matua Tauaitu or Matua Lea. They are the worse ones. While the parents have their rules, she is the person you shouldn't be really mucking around with, the sacred mother. They hold special powers that they could curse." (m)

Two participants discussed the issue of shame from personal experience, and observation:

"I think it's all around the Pacific region that if you're looking at physical or mental disability people think you've been cursed. So there has been superstition attached and ... so they look at those with disabilities with pity for the family for something that's been done in the past that's why they've been cursed, so it's a burden they all have to carry. In my family the first born son died so that was our curse, our whole extended family, not just my immediate family was cursed. We used to have family gatherings and praying and stuff. Every year we got together and prayed. Only when we got together that's when I thought there was something wrong with our family but not now since growing up and moving away. I was too young at the time but I sort of sensed at the time when we were having those prayers and stuff that other people felt for us because we were afflicted. On the other side I thought it was pretty cool that whatever was happening didn't happen to me. I wasn't worried, I was just grateful that whatever happened stopped. (m)

"Certainly there is shame [associated with having a child with special needs]. A couple of cases that I remember that children were banished 
from the immediate household - they went and stayed with other uncles which was certainly associated with embarrassment." (m)

One young participant felt that impairment is usually explained by genetics, but stated that:

"Sometimes people think disability is due to something bad that has happened - the consequence of that action. That's Malaia, that's strong in Samoa but it's not as strong here." (m)

These comments indicate that there may be a difference in attitudes and perspectives in the younger generation. Some participants noted this themselves:

"Younger people probably don't feel like that, they have been caught up by modern education." (m)

"They [the traditional beliefs] are fading. Now it is quietly accepted that a defect must be a mishap, a constructed course for that to happen." (m)

However, there were contrasting viewpoints about whether or not there was a difference in superstitious beliefs about causes of disability between younger and older generations:

"It depends if young people have had the opportunity to travel... but not really, no, because they're entrenched in the community and unless you have the ability to look in from outside you don't know what you don't know." (m)

One participant explained the conflict between the viewpoints he was raised with and modern viewpoints. This participant felt that other community members of his own generation were likely to share the same beliefs, because they were raised the same way:

"It's half half. I know the reasons but with what I was brought up I believe the superstitious one. If I did something wrong like steal, it would come back to haunt me. If a couple has an affair and they have a baby the child will always suffer, it always happens over here." (m)

Many people talked about a change in their own perceptions, understanding and comfort levels after personal experiences.

"My beliefs have shifted away from seeing it as a deficit because I have a close friend whose background is in special education. I always 
thought 'poor child'. Now I've had some insight...I'm personally comfortable to be around children with special needs." (f)

"Back in high school they had disabled students boarding at the hostel and students could volunteer to share a room with one of the students. I was privileged to have the opportunity to share a room. At first I was a bit scared because I had the perception they might be violent but after that experience I became more accepting." (f)

The participants living in Samoa, who are all professionals working in the field of education, presented the traditional Samoan views about disability and its ramifications. These views are suggestive of the moral or religious model of disability:

"There is often a lot of blaming and the belief that you have been cursed by God or you did something wrong like stayed out late at night or ate a pig's ear, that sort of thing. So a lot of these parents feel guilty. A lot of parents don't know what causes a disability. Usually they would hide the child away. Lots of children with disabilities aren't included socially in their villages." (f)

"People believe children born with conditions are an abhorration; it's a form of punishment, pay back for sins committed by the parents. So traditionally there has been shame attached to the individuals and their families and the treatment is that they are isolated, excluded, hidden away." (f)

It was emphasised that attitudes in Samoa were changing, largely due to Inclusive Education and disability rights initiatives, as discussed earlier.

\section{Teasing, Harassment}

One of the prevalent concerns discussed was teasing.

"People tend to make fun [of people with impairments] due to a lack of understanding." (f)

"Some, even older people, but especially children, they mocked them, they imitated how they walk, - it's terrible, it's really terrible. They learn to cope over time but I think it's a terrible thing you can do to somebody." (m)

One man commented that parents feel a responsibility to keep their children safe from teasing and that they keep them from attending school to avoid it. Therefore, 
rationale for establishing a separate special class rather than inclusion in a regular class was based in part on the desire to keep the children from being teased:

"Slow learners need some special school to educate them. [Parents] know he or she can be cared for but are scared to send them to school for teasing ...currently they're not incorporated into the education system because parents ... fear they will be hassled, harassed and further demoralised." (m)

One participant talked about a kind of teasing in her family:

"In my family if you do something stupid you get attached to my aunty (who had special needs)". (f)

The head of SENESE School in Apia, an education facility with an Inclusive Education philosophy reported a different experience when asked about the reaction by students to the inclusion of children with disability in their school:

"The children are never a problem. If the school sets the tone it's great. You need to get the principals on board and show them how it can happen. We've created lots of video clips and pictures to show people this is how inclusion might look." (f)

\section{Personal perceptions and experiences}

All participants felt that they did not discriminate against people with disabilities or special needs, and viewed all people as equals.

"My personal belief is that there is not much difference between people who are termed "normal" and those with special needs or disabilities because what they don't have they make up in another way." (m)

"They should be treated like any other human being. They are part of any society and they should be made to feel like they are included. They need some compassion and respect. You should treat others as you want to be treated." (f)

One participant put forward the sentiment that disability can be experienced by any member of the population depending on where you are in the life cycle and your health and well-being:

"I see it as a fluid concept; even I have special needs every now and then." (m) 


\section{Community perceptions}

Participants shared the wider views about disability and consequent behaviours of the community. Some had positive perceptions of the community's willingness to include people with impairments in daily life:

"From my experiences everybody gives them moral support. It's traditional not to discourage them from joining in and taking part e.g. in cricket and island community work. When someone with special needs comes in they will let them do the small jobs they will be able to do." (m)

One participant believed that the attitudes of the community may be exclusionary due to a lack of public awareness:

"Because it's rare for people with disabilities to be seen in Tokelau at first people are scared. There is a lack of understanding. Generally they know that people need more care than so called normal people so people will be more sensitive. It depends on the individual...but generally they pity them." (f)

Another man explained the traditional Tokelauan beliefs about how to treat people:

"Fakaaloalo (Respect), Alofa (Love), Poupouaki (Support), Fakataumuna (Communication), Talitonuga (Faith) - the list goes on. These are foundations of how we treat any person ... [including] ... people with special needs; everyone is the same, we're all part of one kaiga (family)." (m)

\section{Education}

When asked about traditional views about educating children with special needs, participants agreed that in the past most children with impairments, and particularly physical impairments did not attend school:

"In the past people tended not to send their children to school, to keep them at home because parents feel it will be a burden to the teacher and they feel sorry for their own child." (m)

"They didn't get any education because they're different. I don't know why but I just remember growing up and in my classes there were no kids with disabilities, they just were left home, didn't go to school. I don't think they really understood. There could be a whole range of reasons - it's too hard work, parents of that child probably think it's 
too much of a hassle, teasing/bullying too much, teachers not being able to adapt curriculum, resources, getting to school. It seemed like if you were different you were exempt." (m)

Other comments pointed to a change in people's expectations of schools in Tokelau to educate children with impairments. As one of the participants put it, "schools have the responsibility to provide education and they have to be held accountable for that service." The increased expectations could be due to the impact of travel and exposure to other countries' services and models and partly seen as an extension of the benefits of citizenship of New Zealand:

"For those who lived here their whole lives they don't know and they think it is the family's sole responsibility. As people travel and see what services are provided in other countries they come back here and ask why can't they get that here? More and more people are becoming aware that they need to be catered for." (f)

"If we are New Zealand citizens we should be getting access to schools like in New Zealand. Why isn't that happening? ... Tokelau is New Zealand's aid dependent nation but as a territory of New Zealand there's nothing over there." (f)

There has been acknowledgement of this from the New Zealand government; in his 2006 report to Tokelau, the Administrator stated that schools and hospitals ought to be brought to a standard suitable for citizens of New Zealand (ACYA, 2009).

Comments indicated there has also been an increasing willingness of schools to welcome all students, and changes in policy and capability to include all students:

"Lately teachers at school encourage parents to send their children to school, the teachers will be there to guide them and teach them the right stuff, and include them." (m)

“At school we're talking about policy and we've chosen someone who will run the [Special Education] programme, so those are the first steps." (m)

One man discussed his perception of children with impairments as being competent and enthusiastic learners, albeit behind their chronological age:

"They are not up to par mentally so they have special treatment in academic work but they have to join in, do sports like everyone else. 
The main thing is that they're able to learn and very passionate and show they're willing to learn; they're very energetic in trying to learn something even though they won't be able to do it as easily. And when they do accomplish it its good because it encourages you, they're motivating." (m)

All but one participant thought that if they had a child with an impairment, they would like him or her to be included in school.

"No matter what I'd love my child to be included in school. Because I don't want kids and parents thinking he's any different. No matter what barriers exist they can be overcome. I would be there though because that support is important. But gradually I would draw back because I don't want him to feel like a baby being watched by Dad. I'd like him to feel independent in that sense. And if it didn't go well I wouldn't just say 'oh well off to the next school', I'd work through the process, talk to the teacher." (m)

When asked whether they would prefer their child to be included in school with their same aged peers, many participants felt that inclusion with same age peers would be preferential but were concerned that their child may be vulnerable to teasing:

"Start off with being with the so called normal kids and if there were any adverse effects on my child then I would change. But I'd still like them to have some experiences to play with other children." (f)

The participant who speculated he would not want a child of his with a high level of need included in school supposed that he would feel too overprotective, which he based on his experiences with his own children:

"I have a child whose one leg is shorter than the other. He's fine even in competing in sports but in my heart I think, no he's sick. I have a tendency to hold him back." (m)

The parent of a child with disability stated that his child does experience education in Tokelau:

"I send my daughter to school but because of her slow progress she's still in preschool. Her younger brother has gone ahead of her (to school) but she's stayed behind. I don't mind. There's no point going to primary school when she can't speak properly and can't write properly." (m)

He shared positive accounts from his daughter's experiences at pre-school: 
"She likes going to school, she's the first one ready. At home she sings songs from preschool and even though her pronunciation is not sufficient and the tune is a bit out, she would never have learnt it if she didn't go to school, her speech wouldn't have improved. Now she learns a new word every day." (m)

Later he talked about the reluctance for children to be included in the school in general due to the lack of programmes available and lack of teachers trained to cater for children with impairments.

\section{Right to Education}

Several participants used the language of human rights to emphasise the importance of including children with impairments in education; for example:

"Everyone has the right to be on the same level. I felt that one before, like common sense." (m)

"Even though they are a bit afflicted with a disability they have the same rights as everybody else and they deserve the chance to attend a mainstream school. I don't see a reason why they should be treated differently. If they're in separate schools then it's going to be hard for them to get into mainstream schools but with a bit of modification like handrails, people with special needs can access these rooms. They deserve to be treated like everybody else. We might think we're doing them good but we're actually hurting them - just let them be themselves." (m, S)

One participant stated that human rights systems are in place in Tokelau, under the auspices of the Taupulega:

"I'm happy people of Tokelau are seeing this as an important aspect of education, the children's right to go to school. If you see a child not at school the Taupulega will say 'you have to send your child to school'; the way they do that shows they want kids at school. Nobody should be treated as poor, abused; nobody should go without food, that's the inati system. The Taupulega want kids to go to school so I'm sure they want special needs children to go to school. But for the ones who can't move...nothing is being done to get education to their home". (m)

\section{Inclusion in Society}

There were differing viewpoints about the level to which people with impairments are currently included in society. One participant felt that the community tended to 
be quite welcoming and happy to include people in the daily life of Tokelau, such as community sports and the work done by the Aumaga and Fatupaepae:

"At the community level, they're welcome and they can get their education through the community work." (m)

Whereas another commented that any community tendency toward inclusion tends to be quite ad hoc:

"What is happening right now is that the family takes the whole responsibility. There are no special arrangements or special provisions that the community as a whole or departments to assist with those children with special needs." (m)

It was reported that in general, people with disabilities and particularly physical disabilities are typically left out even when they indicate they would like to be included:

"It depends on the activity. They're marginalised a lot. But see it saddens me that the urge for those children, especially those with physical disabilities, they really want to participate but they're restricted." (m)

Two adult males with physical impairments in Tokelau are included in employment in the men's gangs, and are fully paid despite their limited workload. The long term options in Tokelau for females with a disability are not equitable:

'It's a different story if you're a girl with a disability. People wouldn't consider that you don't have the option to get a pay cheque. They might let you join in with the Fatupaepae but you wouldn't be paid." (f)

\section{Aspirations / Ideal Scenario}

When asked about their vision for the ideal scenario for children with impairments and their families in Tokelau many considerations emerged.

Participants talked about the desire to have all children attending school with adequate support, and collaborative goal setting in their educational plan:

"Those children who are not included in school for various reasons will be attending with the right support; families will be involved in 
setting up the programmes; all stakeholders will have an equal role in deciding what is best." $(\mathrm{m})$

"The ideal that the Department of Education is moving towards is bringing children to learning environments at school in the mainstream." (f, S)

Hope for a change in negative attitudes toward people with disability was often mentioned:

"All the negative connotations that have been associated with people with special needs are put to rest." (m)

"People can see people with special needs for who they are not what they don't have." (m)

"We need to change from the deficit model so what does a strengthsbased model look like in Tokelau?" (f)

The hope for a change in negative attitudes was linked to a hope for greater understanding amongst the community of disability, and many called for public education campaigns. As one man put it:

"We need assistance and help; we need understanding of why - not the fixing of the problem but understanding of the cause. [Community] education is the main one." (m)

Some people prioritised training, professional development and positive role modelling specifically for teachers, so that teachers would be up-skilled and parents would be more confident in leaving their children at school:

"Teachers in Tokelau would be uncomfortable. They are only used to children who can come to school. You need someone who is a positive role as a Special Ed teacher." (f)

"People know teachers are not trained to cater for special needs kids." (m)

A form of respite care, and financial relief was sought, which follows the theme of a shared community response to disability:

"I'd like parents to be supported financially by the government. I'd like the community to support the parents to give them time to rest." (f) 
Physical adaptations to the environment to make it accessible were mentioned by one participant:

"I'd like to see a community service and health care and school to have easily accessible facilities." (f)

A whole of government and community response was frequently considered to be part of the ideal scenario:

"Definitely education led but a system wide government commitment, with education health and finances. Like the New Zealand Disability Strategy. That's at a high level and then public education; I think the Bronfenbrenner34 ecological model would suit Tokelau because it's all about the environment and breaking barriers. I think it will require building capability at the technical level but also changing the thinking and the cultural elements." (f)

"Every initiative will be community oriented not just ... school; the Taupulega needs to be on the same boat and then they can take ownership." (m)

"Everyone has ownership, if the onus is on them they can't fail to provide. Hopefully one day the $n u k u$ is equipped." (m)

One participant shared the hope that the whole of the community could respond collectively to include people with disability in society, and stated the importance of the community staying child-focused and committed to benefitting the child:

"Not to make a big fuss out of it. For the community and parents not to make a big deal and not to look at their own gain but to look at the child." (m)

Positive discrimination in the creation of opportunities was discussed:

"Make sure they get the best resources in terms of education, create the opportunities for them to come up with the equal opportunities to those who do not have any special needs." (m)

\footnotetext{
${ }^{34}$ Bronfenbrenner's model of child development is similar to the ideas presented earlier by Sara Smidt in her image of a global child in the twenty first century; both models emphasise the essential factors of communication, interaction and relationships in child development and consider the child an active learner and social constructivist. For a depiction and brief synopsis of Bronfenbrenner's ecological model of development see Appendix Six.
} 
Two participants looked toward following other models of service delivery in education for children with impairments:

"We should move towards what New Zealand does for its students." (f)

"If there is a model in the South Pacific, use it, especially if the New Zealand model is not being followed." (f)

The importance of a directional policy, and research in Tokelau in order to monitor and develop services was raised by two participants:

"That the policy is based on the premise that children are included in learning environments with all children where physically able to." (f)

"What does research, policy and practice look like in the Tokelau Public Service?" (f)

\section{Summary of Part One}

A significant finding was that the connotation of the term 'Special needs' is synonymous with 'physical impairment' in colloquial use in Tokelau. Although there was a broader understanding that there are different types of impairments, the use of the terminology is likely to be confusing and misleading unless a common understanding is established prior to discussion. The term and philosophy of Inclusive Education was understood to encompass all students.

Another finding was that the historical attribution of shame accorded persons with disability and their family is changing, and may no longer be as prevalent, particularly amongst younger generations. There were a range of views and perceptions about the prevalence of superstition and shame attached to disability in the Tokelau and Samoan communities, but both groups suggested that traditional beliefs are being replaced by modern explanations. Most participants tended to attribute superstitious beliefs to other members of the community not themselves. Although there is a perception that shame and stigma remain attached to the families of people with special needs, at an individual level, most participants believe that disability is neither the product of a curse, nor shameful.

At the same time, there is a growing expectation and willingness of schools in Tokelau to include all students in meaningful education. All participants commented that their personal experiences of interacting with people with impairments increased 
their comfort and understanding of disability issues, which forms its own justification for including all members of society in Tokelau.

Although the data revealed some assertions of a lack of discrimination towards people with impairments, it also revealed a lack of provision of the extra support needed for people with impairments to enjoy equal opportunities. Referring back to Minnow's 'Paradox of Difference' (in Chapter 3) it seems that for people with disability, Tokelau falls on the side of being insensitive to difference and hindering people on that basis. The small size of Tokelau is such that it would not strictly be accurate to refer to the disabled contingent as a 'hidden' population, but the lack of advocacy and discussion of disability issues makes it so in a sense. Participants recommended increased public awareness of disability issues, including the causes of disability, and a forum for support groups for disabled persons and their parents and families. Although concerns were raised that shared advocacy is an elusive goal in a small population due to the unlikely incidence of the same specific impairment between any two people, once disability is understood as a social practice of exclusion it provides a shared experience as a basis of support. Participants view people with impairments as being equal in society, and yet exclusionary practices, negative connotations associated with disability, and teasing prevail. A public awareness campaign on the social model of disability could raise awareness of the collective responsibility to actively include all members of society.

\section{Part Two: Resources \& Provision of Support}

This section presents the main discussion points about resources and provision of support including the current situation, who participants feel should take responsibility for driving services and supporting people with disability and their families, and some of the challenges faced and constructive suggestions given about how to approach them.

\section{Current Situation}

One participant commented that all families are provided for by the existing structures of the community through centralised systems:

"Families [of people with disability] are supported on the island the same as the rest of the families in Tokelau by the government with benefits. Other support comes from the relatives and communities 
asking after your child, sending their regards, telling you they care." (m)

Another gave examples of cases where specific material assistance has been given by individuals and the TPS:

"Individuals have been involved in helping the families here. In Nukunonu the priest has contributed. We (Tokelau Department of Education) put in extra assistance for the wheelchairs for one family. In Fakaofo we paid a mother to care for her son who was very disabled, even his nappies were paid for by the $n u k u . "$ (f)

All participants answered that there are currently no groups, or people in Tokelau who meet to discuss issues such as how to include people with impairments in education and the community, or how to support families. Ownership always falls to the parents.

At the community level:

“It doesn't exist. Until you guys [GSE] came over everybody knew but nobody was doing anything about it, it's just part of life like "oh you've got that [impairment] ... too bad". We won't do anything about it, we won't help but we won't kick you out either. It's always the parents who cater for their child's needs." (m)

"There is training for people to support children. I know of a specific family who have had provision of wheelchairs and there has been awareness raising within the political structure of the village in terms of that the family needs support." (f, S)

At the household level:

"Mum and Dad might say something like be nice to them...just the caring stuff, but not actually talk about their needs and how to overcome them, how to provide assistance." (m)

At the government and public service level:

"The Health Department, the hospital meet and visit ... kids to check on their condition." (m)

“There isn't any organised meetings on the island. Sometimes at staff meetings teachers talk about it." (m) 
Acknowledging that the schools and the hospitals do take responsibility for meeting some educational and health needs in individual cases, there has nonetheless been a lack of systematic information sharing and partnership between the two departments:

"When I was teaching in Tokelau I could see a couple of children needed glasses and had hearing problems. You could tell because they were squinting or always saying 'what?' I realised there was no formal collaboration between health and education." (f)

Partnership between the two departments has been itemised on the agenda as part of the current GSE work. Some participants discussed some specific changes which have occurred as a result of current initiatives:

"Just recently one family is beginning to get support - their children will gradually be included in school." (m)

\section{Who should take ownership and responsibility of disability issues in Tokelau?}

When discussing which agency should be the driving force for including children with impairments in education in Tokelau, participants acknowledged that there is "not a specific role for that" at a high level, in terms of a minister of disability or equivalent. Most stated that the local government needed to take a more directive role. Comments were made that the Taupulega and Pulenuku are responsible for driving all community initiatives, but also that there are a few passionate individuals who are eager to take responsibility for including all children in education in Tokelau.

It was suggested that sometimes progressive and creative ideas are raised but thwarted because they have been suggested by a community member without much authority.

"Like [if someone] is young and ideas flow from him ... he is not taken seriously because he's not part of the driving force of [the village]. It's a close knitted family thing." (m)

One man felt that because ultimately the Taupulega have the final say on what happens and how, they need to be able to make specific informed judgements and to monitor their requests: 
"The Taupulega. The buck stops. The Taupulega have to make the request, they need to be able to recognise there are people with special needs. There's stuff they need to do that, like they need to be able to ask for assistance, be very specific about what they're asking for and because they've asked for it they have to be able to assess it, look at what they've asked for, see what they actually got and review whether it actually met their needs. Rather than just a blanket ask and getting whatever and being happy with it." (m)

He added that work needs to be done to address underlying governance issues before it is possible to make progress in any specific community initiatives:

"Within the Taupulega there needs to be work done on up skilling them, there needs to be some understanding of power relations, understanding what power is, governance, roles and responsibilities before we even start addressing education and other things." (m)

As noted, the role of the Taupulega is increasing as Tokelau modernises. The tension between forces of globalisation and the traditional hierarchical power structures and systems of civic society was put forward by another participant who framed the question:

"We understand looking after people with fish and day to day life. But what does something like inati mean in a free market economy and a capitalist society?" (f)

The broader implication of this question for children with disability was raised by another participant:

"I think the traditional way of thinking with the community is that if they look after what they see, so people are comfortable and fed, they've fulfilled their obligations as a community. For children with physical needs that's about it. But then they're just left sitting all day in a corner and not engaged in the community. They don't actually think about the other side, like their mind might be quite strong or they might want to be with their peers. For children who aren't physically disabled but have other needs they just lump them in with everybody else. There's either something wrong with you or there's not, it's pretty black and white eh, that's how they see it. Gifted children are lumped in with the same group too." (m)

This comment demonstrates the need for positive discrimination to ensure people have equal opportunities. It also points to the idea that although people's basic needs 
are met, there is a lack of equality in the greater human freedoms of participation and opportunity, and highlights a tendency in education toward group teaching rather than individualising learning.

One participant felt that the parents of children with disability and the community are doing their best, but that there is a need for the government to make changes to the education system to ensure schools are able to cater for all students. This was echoed by another participant:

"Initially the government should take on the responsibility in terms of funding and policy and to ensure that departments and villages in each community set money aside for these people to support the students and the schools." (f)

A school staff member felt that the main impetus ought to be with the schools, but that the community also needed to be involved:

"School are the main drivers of this initiative and other groups can be informed by school and health. It'd be good if these two can work together and inform other groups to make sure everyone is informed and knows what the plan is. That includes the Fatupaepae and men's group, and we should let parents know they can come in and they shouldn't feel discouraged." (m)

\section{Collaboration}

All participants felt that collaboration in the community is important in order to achieve appropriate services and supports for people with impairments and their families in Tokelau. Illustrative comments include:

"At every level there is some role for parents, school, health department, community, the general fono - Tokelau's parliament, the department of education. New Zealand has a commitment in terms of providing funding and assistance in the form of expertise. Even the region has an involvement. Each of these groups has different goals and they need to figure out some common ground instead of coming with their own agendas and losing sight of the child who is at the centre." (m)

"What should be happening is that it is not one institution but a community approach with the health department and education department, Fatupaepae and the youth group. You see where everyone fits in, all of them. Even the church has a role to play. While those 
departments should be taking the leading roles, other social sectors should be equally involved." (m)

From the comments of one participant, collaborative approaches have been instigated previously within other education and health initiatives, but have abated:

"There should be collaboration all the way. This has been on and off, this is an on and off relationship and there is no reason why it should be. Like they started the dental checks but then all of a sudden they stopped and the health checks in schools have stopped." (m)

\section{Challenges}

Participants varied in their ideas about what the challenges of implementing inclusive education in Tokelau might be. Answers incorporated themes of resources, attitudes and mindsets, systems and policies, and initiating then maintaining impetus for the ideal. As one participant put it:

"Current beliefs about what special needs is about. People think students are included but they don't realise it means everybody. Infrastructure, facilities, specialists, expertise, if you want to do it right, to be fully equipped. Funding - is the Taupulega willing to put up money, is the department of education - who is holding the purse strings? It all comes to whether they value all children. Children are the future but I believe the future is now - we can't keep saying tomorrow tomorrow, tomorrow. Politics could be a huge barrier because of the lack of consensus between the atolls; everything has to be divided by three equally even though we have different needs." (m)

The idea that absolute division of resources by three may result in extra expenditure was reinforced by another participant:

"Right now there has to be everything on each island so a challenge will be cost related, the cost of training teachers, equipment and facilities and setting up the programme on each island." (m)

Throughout the interviews, there was a recurrent theme of the lack of training for the teachers of the schools which dominated discussions about why it is difficult for all children to be included in education. Most participants stated that teachers are often unqualified and not confident to cater for diverse populations. The need for specialist teachers for different disability groups is seen as an extra necessary requirement, 
both in terms of creating meaningful learning programmes for students with impairments and in up-skilling the teachers:

"The teachers try to cope the best they could but ... if you don't have the skill you don't have the confidence to teach."

"Some of the [children with impairments] that I know have the opportunity to go to school but in terms of them receiving special attention for their disability there is nothing for them. They probably enjoy the play." (m)

As noted earlier, Inclusive Education philosophy suggests that all children can be educated under the same pedagogy regardless of ability or impairment, although this does not discount the need for specialists (Florian, 2009). The school and wider community in Tokelau would need to be made aware that specialist teachers are not a minimum prerequisite, as discussed by the principal of SENESE school in Samoa:

"You may need to reassure the teachers that they can include children with disabilities in their class. They might say 'oh I'm not trained' and not want to have a child with special needs in their class even if they agree with the child's right to education in principle because they are not confident." (f)

Further lessons from the Samoan experience show how an Inclusive Education approach has benefited the school at a systemic level by improving its teaching practices:

"The great thing about an inclusive education approach is that it supports change throughout the entire school system which is sometimes what is needed in a regular school. It enhances teacher's skills in things like conducting group work and individualising learning." (f)

The population size of Tokelau seems to be both a challenge and strength with regard to establishing an inclusive education system. To one participant, the small population size meant that each individual with a particular impairment was quite unique, making it difficult to form a specific support group, or to garner expertise about any specific impairment:

"Right now it's hard to develop those programmes because there are not so many...the numbers are insignificant." (m)

However, two participants felt that the small population was an asset: 
"We should move towards what New Zealand does for its students. There are not a big number of students with these needs here so it won't cost a lot." (f)

"We have equal opportunities to teach our students here in Tokelau. I don't want kids with disabilities to be the problem now. I think our advantage is only 1500 people here and if we can do it we can set the stage for doing it completely and no child will be marginalised." (m)

The frequent population migration to New Zealand creates its own challenges in terms of human resource capacity and maintaining a skill base:

"Human capacity - personnel with skills and knowledge and the right frame of thinking to advocate for children with special needs. You need to get the right people on board and then there is the challenge of keeping them there - the population is very mobile. Tokelau is very committed to putting resources in but the barrier is having the capacity to do the work. There is a lot of empathy and awareness at the governance structures but its having the people." (f, S)

Infrastructure was also cited as a major challenge; in addition to the impact of geographical isolation making it difficult to access resources on the atolls, the coral makes difficult pathways for wheelchairs to access schools and the physical school buildings need to be accessible for the entire population. This challenge is currently being met during the rebuilding of Tokelau's schools:

"We have the room to deal with that now because we're rebuilding the schools so it's important to factor in access ways, furniture and do it now not as an afterthought." (f)

One participant seemed to imply that a lack of resources is used as an excuse for not taking any actions to support students with disability in education. In his words:

"It's easy to say resources but I've always said that's just another reason for not doing anything new and keeping doing what they're doing. So probably the best way to look at it if it were up to me given the resources and personnel on the island now and what they know, like they knew what they had to do...Like we were talking about how inclusive programmes providing for all different types of kids - they all knew the answers and came up with different learning styles, providing activities that are hands on, listening et cetera. But there's no integrity in the work they do because they say it but they don't actually do it." (m) 
Another participant furthered the viewpoint that the knowledge and strategies already known on the islands have not been implemented:

"Put your right leg in front of the other leg. Once you get going, no one can stop you. Get up and do it, make the first move. Coz everyone's been talking about it, our minds are ahead of us but we're not standing up to do it". (m)

Participants suggested ways in which some of the challenges could be overcome such as public awareness campaigns (as mentioned previously) and the formation of support groups for parents and family members of people with disability:

"There needs to be more public awareness and a support group of forum where the needs of children with special needs are discussed. It could include all the parents and relatives of children with special needs." (f)

"Work with the families as much as you can because they're the ones who will be able to support children at home. Build on the culture. The people who are best to become advocates and teachers for these children are the ones who are experienced with children themselves. It is more meaningful for parents to engage with another parent with a similar experience than someone young without children.” (f, S)

"Inclusive education needs to start from the top. The Taupulega need to take an interest in the school. I'd be surprised if any of them have read the curriculum. I'd make one of them actively take part in school life - every aspect in the school. And it's all about accountability you know - holding the principal accountable for what's happening in the school." (m)

Bilateral collaboration with Samoa to gain knowledge and insight into an existing Pacific model was also suggested:

"In terms of disabled people I'd rather that we were proactive in developing a strategy that's meaningful. We can learn lessons from Samoa and other countries that are close to us and acquire human and material resources. Then we can have a plan.” (m)

One participant suggested documenting the feelings of a child with disability in order to show the community the detrimental effects of exclusion on the psyche of the child, and also to give the child an opportunity to advocate for him or herself, which he felt would be a catalyst for change in attitudes to inclusion: 
"It's gauging the real and inner feeling of a handicapped child given the limitations they have and circumstances of homes who don't take care of them. It must be a terrible experience for them. The dilemma they face and there are unheard and unsaid feelings. It's that aspect I wish could be documented honestly and privately as a teaching tool. I really want the community to wake up to this. Not only the older people but also the children because they cannot understand how a child with a disability thinks, the deeper feelings, if they're marginalised with resources, in the community all the things we talk about, unless they say so. The honest documentation of how they feel would be a catalyst for us to address those issues honestly." (m)

\section{Summary of Part Two}

The second section of this chapter has addressed subjects such as ownership of the roles and responsibilities in developing and providing disability services in Tokelau. One of the key points raised was the lack of systems in place for strategic collaboration between stakeholders at all levels. Collaboration between all stakeholders was highly valued by participants and all declared personal commitment to developing disability support services. Having a catalyst for action was suggested by several participants. Some participants suggested that the lack of community action could be linked to the existing hierarchical political and bureaucratic structures. It was suggested that since the Taupulega have ultimate control of daily life in Tokelau, they need to have thorough ownership and authority to drive any disability initiatives or alternatively to relinquish some autonomy over decision making. One participant suggested a Taupulega member on each atoll be involved in the daily operations of the schools. The desire for a collaborative process at all levels of community reinforces the current initiatives being instigated by the NZ \& Tokelau MOE which have characteristics of a CBR model and participatory approach. Some participants called for the chance to design a plan for disability in Tokelau before adopting international plans, but comparing the data from this research to current international directions, it is likely that the two could be aligned to occur simultaneously. Challenges presented by the participants in establishing disability services in Tokelau, and particularly Inclusive Education included barriers of resources, population and isolation, systems, and attitudes. These challenges mirror the five barriers outlined by SENESE School in Samoa in their work in implementing Inclusive Education; environmental, attitudinal, policy, teaching 
practice and resourcing. That the issues identified are similar provides further support for the suggestion that Tokelau build on the experiences of Samoa.

\section{Part Three: The Human Rights Framework \& Tokelau's participation in regional and international movements}

This section provides the analysis of the answers to questions and discussion points about regional and international movements. Although specific international frameworks and initiatives were mentioned as examples during discussions, the intention was not to critique any specific movement or initiative. Rather, the purpose was to Talanoa about the universalism of international frameworks and their applicability to Tokelau, and Tokelau's participation in and commitment to regional and international movements. Tokelau is in a unique position in the Pacific as New Zealand's last dependent territory, and the theme of the relationship between New Zealand and Tokelau was often raised in the discussions about Tokelau's participation in the activities of the international community.

\section{Human Rights}

As already noted, the Convention on the Rights of Persons with Disabilities (CRPD) is the most recent document to frame disabilities rights specifically within the framework of human rights. The Draft Constitution of Free Association between Tokelau and New Zealand includes language of human rights, so the rhetoric of rights is familiar in the governing documents of Tokelau, although as noted in Chapter Four the language and concepts may not necessarily be as familiar at the village level.

Discussions showed that several participants did not have any personal awareness about the existence of the CRPD in Tokelau. Nevertheless, some participants felt that inclusion of disability within a human rights framework would not be unfamiliar for Tokelau and that at a high level the documents are meaningful and important. One Samoan participant, working for the Tokelau Department of Education, stated the synchronicity between the rhetoric of rights-based approaches and the governing documents of Tokelau: 
"I don't think it's seen as anything new because care and rights are extended to all individuals in the constitution so it sits consistently with Tokelauan frameworks." (f, S)

This view of policy and theory is in contrast to the developing understanding of human rights at the village level, which is relatively new:

"Now that it's a human rights approach that will impact a lot. It was quite recently that people were informed that people and children have rights, which was quite foreign in a way. People took it as a joke but are starting to become open minded. If you have the rights of disabled people in a framework people will take notice because they hold the $\mathrm{UN}$ in high esteem. We're not as closely involved with the UN as other countries and we do want a voice. If Tokelau ratifies things themselves it depends what the country prioritises at the general fono." (m)

"It is meaningful at this point in time. There is lots of understanding from people about children's and human's rights. It's really important". (m)

A criticism about the signing and ratifying of the CRPD was the lack of public awareness and information about the convention:

"It's the same as any other convention framework in the past. We don't know about them." (m)

"It's been similar to the process we had for UNCROC. It's easy for Tokelau to sign but hard to implement. It's just another document that's been signed." (f)

It was interesting to note Samoa's approach to the CRPD, as relayed by the principal of SENESE school in Apia:

"Samoa hasn't ratified the convention yet. We're trying to get a disability desk in a government agency. It looks like it is going to sit with the Ministry of Women and Youth Development. They don't want to ratify it without a process of public awareness so that it is more meaningful for people when it is signed than something like CEDAW which was just signed by a Minister. They want to make sure the policy side of things won't precede the public awareness and grass roots side of things." (f) 
Two people felt that the language of human rights frameworks did not sit comfortably in the context of the Pacific and Tokelau:

"It's hard to accept the concept because of the terminology; it can be seen as an imposition." (f, S)

"I don't think it's a right. It's a responsibility for parents, community, leaders, the Aumaga, Fatupaepae and everyone to do their part. The word 'right' is not accepted in many Pacific cultures. If it's gonna be a 'right' it's quite demanding. Maybe it's an abuse of the rights has been done before maybe something like that. That's where UNCROC comes in. It does not fall comfortably with the Taupulega, it's too demanding. Maybe for other countries without our values in terms of the responsibility parents and community have for their children it will be right for them to say that word but for us it's a prime responsibility to do our part. I suppose there will be reasons why the convention has been put together by the UN." (m)

Some participants anticipated that the impact of the Convention would be fairly limited:

"The Convention probably won't make a difference to the average person in Tokelau but it might for someone who goes in and out of Tokelau ... or it might not." (f)

"I think the problem with Tokelau is the isolation. You can have all sorts of strategies but it would be slow to filter through, slow to implement. A lot of people wouldn't be receptive to being told what to do. So it would depend if they had input into it, otherwise they'd probably see it like all the other projects, just talk talk talk. It depends whether it's relevant to how they see life in Tokelau." (m)

\section{Children's Rights}

The idea of children's rights can be contentious in the Tokelau community and the Samoan community; one participant reported that UNCROC almost redefines the relationship between parents and children. Another participant echoed this sentiment:

"The concept of [children's] rights is difficult in Tokelau because of the cultural thing that children should listen and show respect. People are listening to younger children at a family level, there it's accepted that children have a right to have a voice but not yet at the general level." (f) 
One participant attributed the contention which surrounds the idea of children's rights to religion:

"It's probably a biblical thing that children should be seen and never heard, because they're so strong on the bible. Children are not encouraged to voice their opinions and ideas, just to do what they're told". (m)

The community discussions about disability and education held as part of the project work undertaken by the NZ Ministry of Education GSE was credited by one participant with re-introducing and re-consolidating the idea of children's rights:

"Children's rights ... just introducing the idea of children having a contribution to education - some people are talking about it and saying 'yeah that's right' ... it's like a seed, something to start thinking about. There would be many young people who've gone to New Zealand or Australia have come back with those ideas and having [GSE] there rekindled them to start to have a conversation about it again." (m)

\section{Individual vs Group Rights}

The idea of communal and individual human rights was discussed briefly with two participants. It appeared that human rights are secondary to the local system of authority (i.e. the rule of the Taupulega) in Tokelau, as suggested by one participant:

"The first time Human Rights stuff came out was when [one man] stopped going to community things, that's the first we heard about "freedom of choice". That was about 20 years ago. High people can go against the flow." (m)

"I think Tokelau is like a communist thing. Every day has been planned by our elders or Pulenuku. We're not allowed to go here and there. If we have to go somewhere, everyone is expected to be there and if we don't go we don't get paid. We can't do our own thing. They're saying we're democratic but can I do what I want, hop on a dinghy and get some coconuts - no ... I can't do anything without the nod from the elders." (m)

A Samoan participant reported some of the conflict that has arisen by individuals advocating for their rights at the expense of respect for existing cultural structures in Samoa: 
"I think it's really interesting the issue of communal vs. individual rights. Individual rights don't hold up if they disturb the communal rights ... people have choices but it's not appropriate given the small size. There are tensions here in Samoa ... there have been people banished from their homes and burning of houses." (f)

\section{Tokelau's participation in Regional and International Movements}

When discussing participation and cooperation with regional and international movements, there were a range of views. Two participants felt that Tokelau has the opportunity to participate in regional movements:

"Tokelau has a role in driving regional initiatives through the PRIDE project which currently funds five projects here. If we had a special needs programme PRIDE would probably support us. There is not yet much impact from the others but we expect a bigger impact in future." (f)

"Tokelau comes under New Zealand for international relations but is a full participant at regional level at everything ... Tokelau is there as an observer because it's under New Zealand but that hasn't excluded Tokelau from the benefits of participating at regional forums." (f)

A Samoan participant working for the Tokelau Education Department commented that sometimes the time commitment it takes to implement suggestions from the frameworks is too short before another framework is put up for consideration:

"We're still developing EFA (Education For All) and they roll out another one, ESD - Education for Sustainable Development. Countries are asked every year to consider a new global framework." (f)

Others felt that Tokelau is frequently overlooked in regional and international movements and that that regional and international frameworks are imposed on Tokelau at the detriment of local priorities:

"It's been beautiful to see them written in papers and be quoted by leaders for Tokelau to claim they are involved. I've seen the draft of the Pacific Plan and the Biwako but they're very generic and I try to reflect of how they fit into Tokelau. I'm a bit sarcastic when I say that because it should not be this way. It should be what we want then translate. Although they're very general with the way they put it but we have priorities that we believe should be first, and then second. How I personally feel about those things I want to close my eyes and 
forget them. We're currently developing our national strategy and then if we have a blueprint in terms of knowing that we're here, what do we want, and where do we want to go, how're we going to do it, - if we're clear of those things then we can set our own priorities and come up with something that is more realistic, more national and more Tokelauan. Then we can look at the Pacific Plan. Then it will be more real and sustainable that we don't just put down things for the sake of it. Not only for the ownership issue but so that we come up with things that are achievable and can be implemented. We don't want to come up with a huge plan." (m)

\section{New Zealand and Tokelau's relationship}

Participants who commented about the relationship between New Zealand and Tokelau all leaned towards the position that Tokelau wishes and needs to be more included in the formulation of international plans and initiatives, and the signing and ratifying of international conventions:

"Whatever New Zealand sign they always ask how Tokelau feels about it and they normally do legislation for Tokelau to sign or agree but the process should be more consultative and we should be given the privilege to either say yes or no because New Zealand is different from here although we are citizens. It seems these things are obligatory - the UN conventions. Its good New Zealand leads the way as the mother nation - they have the resource and understanding and all of this - but Tokelau should sign on its own right." (m)

Two participants felt that in the current relationship as it exists now, ultimate responsibility lies with New Zealand, including the responsibility to be more consultative with Tokelau:

"Because of the political bond to New Zealand the Human Rights issues need to be addressed in New Zealand. The policy needs to be clearer. The UN/New Zealand and Tokelau governments need to discuss these things and then at the village level people need to feel empowered too." (f)

"It depends if New Zealand will initiate that initiative [CRPD] in Tokelau. They tend to focus on New Zealand first. Honestly we've been getting an unfair deal in education. As New Zealander citizens we're entitled but we're last on the list, if we're on it. On the other side, New Zealand might not know and on our end we can take responsibility but New Zealand has a responsibility to do that too. 
Sometimes we feel shunted. Over here every programme doesn't last." (m)

"It's an interesting position because it's called a special relationship between New Zealand and Tokelau. That's bureaucracy speak. I don't know how they build capabilities for Tokelau. New Zealand has a supporting role in this. It's a grey area how far MFAT goes and how far they extend it to the MOE. There's no clear indication for any strategy from MFATs end but I don't know what the administrator thinks. Tokelau is a really interesting situation. Tokelau is crippled by dependency. The work ethic there is different to NZ, there's no urgency." (f)

\section{Summary of Part Three}

As noted earlier, the language and concept of human rights is familiar in Tokelau at a political level, and many participants comfortably used the rhetoric of human rights. At the village level, there were recent public awareness campaigns to introduce the idea of human rights. Examples from the data showed that while human rights conventions are becoming more familiar in society, they are secondary to existing political village structures which may potentially limit their impact. Some participants suggested the need for a clearer policy between New Zealand and Tokelau with regards to the international human rights framework; some participants suggested Tokelau ought to participate and sign in their own right, with guidance from New Zealand.

As with other Pacific cultures, the concept of rights in the spirit in which they are intended in international conventions is not necessarily contested. However, the language of human rights is sometimes seen as confrontational and antithetical to the culture. This was raised by participants who gave examples about children's rights and the tension between group and individual rights. When looking at the right of a child with any form of impairment to education, there are exponential factors of exclusion to consider in the form of disability, youth and gender (as raised earlier in section one by one participant who noted the discrepancy of opportunity for males compared to females). The reality is that there has not been enough positive action taken for disabled citizens to have the same educational opportunities as all members of the community. 
In terms of regional and international initiatives and movements, the participants often stated a preference for a locally developed plan which could then be tailored to international and regional objectives. 


\section{Chapter Six: Discussion and Implications of Findings}

This chapter discusses the implications of the findings presented in the previous chapter.

The findings showed that Tokelauan beliefs about how to treat people call for equality and respect. Traditional systems, such as inati which ensures no person goes without food, and lakehe - a philosophy of providing for the "needy", prevail in Tokelau's contemporary society which maintains its communal values (Huntsman \& Hooper, 1996; Vandersyp et al., 1998). The gap in traditional provision of support into which people with impairments currently fall is characterised by a lack of positive discrimination and a deficit model perspective. This is not to say that the view of people with disability in Tokelau is not compassionate, but just that it could be developed into perceptions that people with disability are competent, and focused on strengths. Relating participants' comments back to paradigms of disability shows parallels to the medical and religious models; people with disability may be seen as afflicted or cursed. This possibly explains the seemingly contradictory responses given that people feel both "pity" and "blame" toward people with disability and their extended family.

However, the deficit, medical and religious models of disability are not the only paradigms of disability in Tokelau. Throughout the responses, participants used concepts of equality and participation, reflective of the social and rights-based models of disability. There is an opportunity to take advantage of the customary consciousness of social responsibility, evidenced by the strong calls for collaborative programming at all levels seen in the data, as well as the traditional cultural beliefs discussed above, and the growing knowledge and acceptance of human rights-based approaches (if not yet the rhetoric of rights). Public education and awareness campaigns about the social model of disability could build on traditional beliefs and introduce new ideas such as positive discrimination to enable people with disability to participate more in society.

Disability issues are now explicitly and firmly grounded in the international human rights framework and consequently in the rhetoric of the rights movement. It was suggested in the responses that the word "rights" is resisted by some people as "too 
demanding", yet responsibilities are accepted. Conceptually, they are two sides of the same coin - if you have a social responsibility to act toward me in a certain manner, I have the right to expect that you will not act toward me in a socially irresponsible manner. Given that policy in Tokelau reflects international practice by using the language of human rights, it might be helpful to increase people's comfort levels with the rhetoric to ensure that the connotations of the terminology do not become a barrier to the concepts and intentions, which as we have seen are overall compatible.

Community education about human rights in general, and the principles of indivisibility of human rights and participation in particular, may be useful. There are programmes developed in the Pacific, such as those offered by the Pacific Rights Regional Resources Team, which provide training in human rights, technical support and policy and advocacy services specifically for the Pacific region (RRRT, 2009) ${ }^{35}$. A community education programme can emphasise the importance of human rights, and dispel any concerns that human rights approaches are neo-imperialistic and threatening to culture. It could illustrate how traditional values are aligned with current international understandings of human rights including the idea that human rights can be both universal and contextual. Nevertheless, a lack of acceptance of the terminology of human rights need not preclude advances in supporting people with disability to access education and participate in society from a human rights-based perspective.

The relationship between New Zealand and Tokelau adds a complexity to the considerations about the relevance of international human rights and education conventions to a small island Pacific state in terms of their ability to participate in the formation of international covenants, and the issue of legal accountability. Now that Tokelau has twice voted against independent status in free association with New Zealand in favour of remaining a dependency of New Zealand, does this indicate a need for more direct involvement from New Zealand in the governance of Tokelau in terms of obligations of the State to rights-holders?

There seems to be no discernable difference in opinions between participants from certain atolls, or between male and female participants which means a collaborative community approach is probably feasible. However, the findings did suggest that the

\footnotetext{
${ }^{35}$ For more information about the RRRT see http://www.rrrt.org/default.asp
} 
younger generation lack superstitious beliefs about the cause of disability. The diminishing prevalence of feelings of shame toward people with disability amongst the younger members of the population suggests a rationale for initiatives which support community participation, and particularly youth participation in developing Inclusive Education systems in Tokelau. The findings also showed that people who have had personal experiences in interacting with people with impairments tend to have more understanding about disability, and inclusive dispositions, which provides its own justification for forming inclusive societies and enabling participation of people with impairments in daily life.

It can be said that in education, Tokelau is moving toward a twin-track approach. The Tokelau National Curriculum Policy Framework is one document which specifically includes people with disability in its programming, and the Tokelau Department of Education are working towards a disability-specific plan and the deliberate and strategic implementation of existing education policies.

While the Tokelau National Curriculum Policy framework does state that it is inclusive of all students, I would suggest that it may benefit Tokelau to specifically and fully adopt an Inclusive Education philosophy and approach, including terminology. In addition to Inclusive Education being strongly advocated for in international literature, there are several other key reasons to move towards this. Firstly, it will create an opportunity for clarity of purpose so the public can be made aware that any work done in the area of disability, development and education is not intended to benefit only physically impaired students. Also, the Inclusive Education model encompasses current education reform initiatives in Tokelau such as the introduction of non-formal vocational education, designed to make education more accessible for more students. Tokelau would benefit from its close proximity to Samoa where there are Pacific models of operational Inclusive Education systems, and Samoa and the greater regional body would benefit from Tokelau's experience of implementing an Inclusive Education system. For example, while Samoa's experiences of setting up Special Education units in schools had limited success in terms of inclusion "because the children stayed in their special needs units", Tokelau has the vantage point of observing these experiences and learning from them. As noted earlier, Tokelau's education system stands to benefit from an Inclusive Education approach, through the enhancement of teaching skills such as conducting 
group and individualised (this does not mean exclusively individual) learning. Lastly, adopting an Inclusive Education approach from the outset would frame inclusion in education for children with impairments within the contemporary rights-based framework, and help shift attitudinal barriers borne out of the existing deficit, medical and religious models of disability. 


\section{Chapter Seven: Conclusion}

By examining people's opinions, experiences, attitudes, aspirations, perceptions, knowledge, and understanding about disability, education and development, this thesis sought to identify the challenges of including people with disability in education and society in the context of a small Pacific Island developng nation, and the ways in which these challenges can be addressed.

One of the main findings of this thesis is that some of the attitudinal barriers to inclusion of people with impairments in Tokelau (such as shame) are reducing as people become better informed about disability, whether through education, personal experience, exposure to scientific ideas about the causes of disability, observations of people with disability participating in other societies such as Samoa, or a growing understanding of human rights. For example, the findings suggested that younger members of the population are unlikely to believe that disability may be caused by a curse. Although change is evident, it cannot yet be said that people with disability are fully included and welcomed at all levels of society. Participants called for public education campaigns about the causes of disability and disability issues so that disability issues can be better understood and people with disability better supported.

There is certainly confusion and misinformation about disability in Tokelau. For example, it was reported that many people use the term 'special needs' to refer to people with physical impairments; suggesting a narrow use and understanding of terminology. The data also showed there is some opposition to the term 'special needs', although not all participants expressed this view.

The terminology of 'inclusive education' was better understood and one participant stated a preference for using that term in Tokelau. Some understanding of the broader philosophy of Inclusive Education was demonstrated, and almost all participants stated a preference for educating children with impairments in the regular education system rather than establishing segregated classes.

Employees of the Tokelau Department of Education stated how the education system is broadening to create more opportunities for students in both academic and vocational education. These reforms show a recognition of the diversity of students' needs and suggests that it would be timely to further develop these concepts so that schools are increasingly able to also cater for students with impairments. 
Another finding of the research was the strong call for a collaborative, community wide approach. This is in line with international ideas about how best to include people with disability in societies, such as the Community Based Rehabilitation (CBR) model. However, participants talked about a lack of strategic collaboration between groups in society about disability issues. One participant suggested involving a member of the Taupulega at the grass roots level to address this.

There is variation in the acceptance and comfort of human rights rhetoric, some resistance to the language exists. Particularly contentious is the language of children's rights and individual rights. The findings showed that although the community is increasingly aware and accepting of human rights ideas, and human rights are seen in the draft constitution and education policies of Tokelau, human rights are often considered as secondary to the rule of local authority.

Nevertheless, throughout the discussions, human rights concepts were alluded to in both the acceptance of responsibility towards people, and in the statements of beliefs of equality amongst people and non-discrimination. The research also shows that traditional beliefs and values, and systems, such as lakehe, are aligned with human rights ideals. For example the central idea in lakehe - preferential sharing toward the needy, is similar to the idea that positive discrimination is necessary to enable people with disability to be included in society.

However, I would suggest that one of the significant incompatibilities between traditional Tokelauan perceptions about disability and a social and political (rightsbased) model is the way in which 'needy' people are viewed. The view of disability as a social process of exclusion was not explicitly raised, nor the idea of empowering people with disability to advocate for themselves. The choice of the words 'pity' and 'burden' and other phrases such as 'not up to par' in discussions suggests a combination of a medical, religious and deficit model of viewing people with disability. As put by one participant, people with disability are seen for what they don't have rather than what they do, and another stated how terrible it is when people with disability are referred to "by their disability not their strengths".

The results showed varying perspectives about the significance of regional and international initiatives and movements. Although several people felt that the international human rights framework is held in high esteem, it was also stated that 
people in Tokelau are often unaware of the conventions New Zealand has signed, including the CRPD (except the participants who worked for the Tokelau Department of Education), and felt that most of the community would also not be aware of it. Some participants stated the desire for more involvement in the development of international and regional plans, but one participant felt that for disability issues a locally developed plan, with some observation of Samoa's progress, would be more meaningful to meet local priorities and set achievable goals. The frequency with which international and regional frameworks are introduced appears to create a barrier to implementation. One participant raised the question about whether human rights obligations can be met within Tokelau and suggested that New Zealand should have more direct involvement. I would suggest that the question of increased bilateral (or multilateral) involvement in enabling people with disability to access human rights in developing countries goes beyond the relationship of New Zealand and Tokelau because of the CRPDs stipulation of transnational obligations. Nevertheless, New Zealand and Tokelau are in a unique relationship which must be considered when exploring political issues like adherence to international human rights law.

The research showed that current theories and ideas about disability, development, and education are inextricably linked and parallel one another in their tendency toward a human rights-based perspective. Contemporary definitions of disability and poverty both refer to the limitation of social, cultural, political and economic participation in daily life. The recognition that poverty and disability are linked in a cyclic, mutually reinforcing relationship has led to specific inclusion of disability in the international human rights framework through the UN 2006 Convention on the Rights of Persons with Disabilities. Consequently, if development is to be successful, it must address disability in a twin-track manner: as a separate targeted issue, and included into all mainstream development programming, planning, policies and research. Unless disability is included in development, the large population of already marginalised people with impairments will continue to face discrimination, and be denied equal participation in social, cultural, economic, and political life.

The right to education is frequently denied to most people with disability, which further perpetuates the cycle of poverty and disability. Conversely, including people with disability in education has been shown to yield economic and social benefits for 
people with disability and their society. The current prevailing perspective on how to best support people with disability to access education is through Inclusive Education philosophies and approaches in both non-formal and formal education. Inclusive Education approaches are characterised by taking a holistic view of students, a principle of non-segregation and of viewing disability within a social-model paradigm.

These contemporary global ideas about disability are reflected in the regional Pacific context. At a policy level, mainstreaming disability in development is endorsed by bilateral donors such as AusAID and NZAID, and a commitment to Inclusive Education is seen by Education Ministers at the Pacific Islands Forum meetings. Some practical applications of these regional and international ideas were shown in the context of Samoa (chosen because of its geographical and political links to Tokelau) at both national and grass roots levels. The experiences of Samoa showed that human rights approaches are being used by people with disability for advocacy and empowerment, and that Inclusive Education schools have contributed to Samoa's ability to provide education for all its citizens and therefore its progress towards international development targets, as well as changing negative attitudes toward people with disability and increasing people's comfort with diversity.

To my knowledge this is the first study which explores opinions, experiences, attitudes, aspirations, perceptions, knowledge, and understanding about disability, education and development in Tokelau. As such, it provides a starting point for further research into disability in Tokelau from a social and rights-based model perspective. Some suggestions for future research directions are:

- Action research in implementing an Inclusive Education system pilot school in Tokelau.

- Emancipatory research looking in more detail at the experiences of people with disability and their family in Tokelau. (This was also suggested by a participant who felt that there would be a strong community response and commitment to social change towards inclusive philosophies if the feelings of a person with disability were documented.)

- Research with children and youth in Tokelau to explore their perspectives on disability and education. This research could capitalise on the suggestions 
found in this study that younger people tend not to attribute shame to people with disability and their family, and on the findings from Samoa that children and young people are "never a problem" in including people with disability in school if an inclusive tone is set by the school.

- Action research with children and youth (with and without impairments) as co-researchers encouraging them to explore the issues faced by people with impairments or educational difficulties in their community and create advocacy campaigns to respond to their findings.

- Undertaking analysis of all government policies in Tokelau to examine whether they can be considered disability inclusive, or can be adapted to the recommended "twin-track" approach.

Given its small size and communal values, Tokelau has an exciting opportunity to create a truly inclusive and enabling society. Further analysis of disability and education issues are necessary in Tokelau if current education initiatives are to be sustained and further developed, if the Tokelau National Curriculum Policy Framework Guidelines are to be implemented, and if New Zealand and Tokelau are to create equality of opportunity and access to meaningful quality education for all their citizens. 


\section{References}

ACYA. (2009). Children in Tokelau; New Zealand's Citizens: What will it mean to these children's future as the country seeks self-government. August 2007. Provisional Working Paper by Peter Shuttleworth for the next ACYA report to the UN Committee on Children's Rights. Action for Children and Youth Aotearoa. Retrieved February 19, 2009, from www.acya.org.nz/site_resources/library/Documents.pts_2009/Children_in_T okelau_New_Zealand_Citizens.pdf

ADB. (2005). Disability brief: Identifying and addressing the needs of disabled people. Retrieved March 31, 2008, from www.adb.org/Documents/Reports/Disabled-People-Development/disabilitybrief.pdf

Alice, L. (2003). Power, experience, and process in feminist research. In C. Davidson \& M. Tolich (Eds.), Social science research in New Zealand. Auckland: Pearson Education NZ Ltd.

Alston, P. (2005). Ships passing in the night: The current state of the human rights and development debate seen through the lens of the millennium development goals. Human Rights Quarterly, 27, 755-829.

Angelo, A. (1992). Lo bilong yumi yet. In A. Angelo (Ed.), Essays and documents on human rights in the pacific (pp. 33-47). Wellington: Victoria University Press.

Angelo, T. (1999). Establishing a nation: Kikilaga nenefu. Retrieved August 29, 2008, from http://www.austlii.edu.au/nz/journals/VUWLRev/1999/28.html

AusAID. (2008). Development for all: Towards a disability-inclusive Australian aid program 2009 - 2014. Retrieved January 18, 2009, from www.ausaid.gov.au/publications

Baba, T. (2004). Pacific and indigenous research: Beyond bondage and patronage. In T. Baba, O. Mahina, N. Williams \& U. Nabobo-Baba (Eds.), Researching the pacific and indigneous peoples: Issues and perspectives (pp. 95-104). Auckland: Centre for Pacific Studies: University of Auckland.

Barnes, C., \& Mercer, G. (1995). Disability: Emancipation, community participation and disabled people. In G. Craig \& M. Mayo (Eds.), Community empowerment: A reader in participation and development. London: Zed Books.

Bartlett, K.T. (1992). Minnow's social-relations approach to difference: Unanswering the unasked. Law and Social Inquiry, 437-470.

Bell, L.S., Nathan, A.J., \& Peleg, I. (Eds.). (2001). Negotiating culture and human rights. New York Chichester: Colombia University Press.

Briggs, J. (2005). The use of indigenous knowledge in development: problems and challenges. Progress in Development Studies, 5(2), 99-114. 
Buchanan, T. (2007). Decolonisation of Tokelau: Why was the proposal to become self-governing unsuccessful in the 2006 referendum? Unpublished Thesis toward Master of Philosophy, Massey University.

CIA. (2009). Field Listing Disputes International Tokelau. Retrieved February 10, 2009, from www.cia.gov/library/publications/the-worldfactbook/fields/2070.html

Chambers, R. (1995). Paradigm shifts and the practice of participatory research and development. In N. Nelson \& S. Wright (Eds.), Power and participatory development ( pp 30-42). London: Intermediate Technology Publications.

Chambers, R. (2005). Notes for participants in PRA-PLA familiarisation workshops in 2005. Retrieved August 14, 2005, from www.ids.ac.uk/ids/particip/research/pra/pranotes05.pdf

Charmez, K. (2006). Constructing grounded theory: A practical guide through qualitative analysis. London: SAGE Publications.

COG. (2008). Question of Tokelau Statement by Faipule Pio Iosefa Tuia Ulu O Tokelau. Retrieved February 10, 2009, from www.tokelau.org.nz

DFID. (2000). Disability, Poverty and Development. Retrieved January 10, 2009, from

www.addc.org.au/webdocs/disability\%20\&\%20Poverty/Reports/DFID_PAP ER_Disability\%20Poverty\%20\&\%20Development_Feb2005.pdf

Dick, B. (2005). Grounded theory: A thumbnail sketch. Retrieved March 31, 2008, from www.scu.ed.au/schools/gcm/ar/arp/grounded.html

Eklindh, K., \& Brule-Balescut, K.V.D. (2005). The right to education for persons with disability: Reflecting on UNESCO's role from salamanca to the convention on the rights of persons with disability. In M. Farrell (Ed.), Key issues in special education: Raising standards of pupil's attainment and achievement. Canada: Routeledge.

Farer, T.J. (2003) The ethics of intervention in self-determination struggles. Human Rights Quarterly, 25(2), 382-408.

Field, M. (2007a, October 24). Tiny atoll has its say on the future. Dominion Post, p. A2.

Field, M. (2007b, October 25). Tokelau to stay NZ dependency. Retrieved 10 February 2009, from www.stuff.co.nz/4250377a12.html

Field, M. (2007c, November 2). Tokelau ponders pastor's dark past. Retrieved 10 February 2009, from www.stuff.co.nz/42588253a12.html

Field, M. (2008). Bebo-ing the south seas: from tin cans to the internet in the Pacific. Retrieved $10^{\text {th }}$ February 2009, from www.michaelfield.org/digital.htm

Florian, L. (2009). Towards an inclusive pedagogy. In P. Hick, R. Kershner \& P.T. Farrell (Eds.), Psychology for inclusive education: New directions in theory and practice (pp. 38-51). New York: Routeledge. 
Freire, P. (1970). Pedagogy of the oppressed. $\left(30^{\text {th }}\right.$ anniversary ed.) New York: The Continuum International Publishing Group Ltd.

Giese, C., \& Perez, C. (1983). Tokelau: Micro-politics. In R. Crocombe \& A. Ali (Eds.), Politics in Polynesia. Suva: USP.

Griffen, V. (2006). Gender relations in Pacific cultures and their impact on the growth and development of children. Paper prepared for a seminar on "Children's Rights and Culture in the Pacific". Retrieved February 1, 2009, from www.unicef.org/eapro/Gender_Relations_in_Pacific_cultures.pdf

Hamill, L., \& Everington, C. (2002). Teaching students with moderate to severe disabilities: An applied approach for inclusive environments. New Jersey: Pearson Education, Inc.

Hayward, C., Simpson, L., \& Wood, L. (2004). Still left out in the cold: Problematising participatory research and development. Sociologia Ruralis, 44(1), 95-108.

Hick, P., Kershner, R., \& Farrell, P.T. (Eds.). (2009). Psychology for inclusive education: New directions in theory and practice. New York: Routeledge.

Hick, P. (2009). Reframing psychology for inclusive learning within social justice agendas. In P. Hick, R. Kershner \& P.T. Farrell (Eds.), Psychology for inclusive education: New directions in theory and practice. New York: Routeledge.

Hoem, I. (1995). A way with words: language and culture in Tokelau society. Bangkok: Orchid Press

Huffer, E. (2006). Cultural rights in the Pacific: What they mean for children. Paper prepared for a seminar on "Children's Rights and Culture in the Pacific". Retrieved February 1, 2009, from www.unicef.org/eapro/Cultural_rights_in_the_Pacific__what_this_means_for_children.pdf

Hunt, R. (2008). Disability, human rights and development in the Pacific. Just Change, 12(July), 22.

Huntsman, J., \& Hooper, A. (1996). Tokelau: A historical ethnography. Auckland: Auckland University Press.

Huntsman, J., \& Kalolo, K. (2007). The future of Tokelau: Decolonising agendas 1975 - 2006. Auckland: Auckland University Press.

Jennings, R. (2000). Participatory development as new paradigm: The transition of development professionalism. Paper prepared for the "Community Based Reintegration and Rehabilitation in Post-Conflict Settings" conference, Washington DC.

Jonsson, T., \& Wiman, R. (2001). Education, poverty and disability in developing countries: A technical note prepared for the Poverty Reduction Sourcebook. Retrieved September 8, 2008, from www.siteresources.worldbank.org/disability/resources 
Kalolo, K. (2002). A Tokelau perspective. In F. Pene, A. M. Taufe'ulungaki \& C. Benson (Eds.), Tree of opportunity: Rethinking pacific education (pp. 104106). Suva: Bluebird Printery Limited, University of the South Pacific.

Kalolo, K. (2007). Tokelau. The Contemporary Pacific, 19(1), 256-262.

Katsui, H. (2008). Downside to the human rights-based approach to disability in development. Working Paper. Institute of Development Studies. University of Helsinki: Finland. Retrieved February 10, 2009, from http://disabilityuganda.blogspot.com/2008_11_01_archive.html

Katsui, H. (2005). Towards equality: Creation of the disability movement in Central Asia. Academic Dissertation. Faculty of Social Science, University of Helsinki. Retrieved February 10, 2009, from www.ethesis.helsinki.fi

Katsui, H., \& Kumpuvuori, J. (2008). Human rights-based approach to disability in Development in Uganda: A way to fill the gap between political and social spaces? Scandinavian Journal of Disability Research, 10(4), 227-236.

Kershner, R. (2009). Learning in inclusive classrooms. In P. Hick, R. Kershner \& P.T. Farrell (Eds.), Psychology for inclusive education: New directions in theory and practice (pp. 52-65). New York: Routeledge.

Knox, M., Mok, M., \& Parmenter, T.R. (2000). Working with the experts: Collaborative research with people with an intellectual disability. Disability \& Society, 15(1), 49-61.

Kuipers, P., Kendall, E., \& Hancock, T. (2001). Developing a rural communitybased disability service: (1) service framework and implementation strategy. Australian Journal of Rural Health, 9, 22-28.

Kumar, S., \& Corbridge, S. (2002). Programmed to fail? Development projects and the politics of participation. The Journal of Development Studies, 39(2), 73103.

Lameta, E. (2005). Pacific regional overview of progress towards EFA since Dakar. Retrieved February 10, 2009, from www.portal.unesco.org/education/en/files/43618/1131582071/Lameta_E.doc

Lemihio, P. K. (2003). He fatele ke hiva te afafine Tokelau: A song for a Tokelauan daughter to dance. In P. Fairbairn-Dunlop \& G. Makisi (Eds.), Making our place: Growing up PI in New Zealand (pp. 151-170). Palmerston North: Dunmore Press Ltd.

Lene, D. (2004). The status of women with disability in Samoa. Report produced jointly for Inclusion International and UNESCO, Samoa.

Lene, D. (2005). The development of policy planning and support and services for people with disabilities (15 years +) in Samoa. Minor Thesis presented in partial fulfilment of the requirements of the degree of master of Educational Leadership and Management: The University of Newcastle. 
Ljungman, C.M. (2005). Applying a rights-based approach to development: Concepts and principles. Paper presented at The Winners and Losers from Rights-Based Approaches to Development, Manchester University.

Lynch, J. (1994). Provision for children with special education needs in the Asia region. World Bank Technical Paper number 261. Asia Technical Series. Retrieved September 8, 2008, from www.worldbank.org.sp

Mahina, O. (2004). Issues and challenges in pacific research: Some critical comments. In T. Baba, O. Mahina, N. Williams \& U. Nabobo-Baba (Eds.), Researching the pacific and indigneous peoples: Issues and perspectives (pp. 186-200). Auckland: Centre for Pacific Studies: University of Auckland.

McCullough, R. (2002). Tokelau Disability Identification Survey. Report produced jointly for Inclusion International and NZAID.

McKinstry, G., Price, P., \& Macanawai, S. (2004). Review of disability legislation in the South Pacific. Pacific Islands Forum Secretariat. Retrieved March 31, 2008, from www.forumsec.org.fj/userfiles/file/regional_doc_on_review_of_policy_and_1 egislation_on_disability.pdf

McMurray, C. (2006). Young people's participation in the Pacific-facilitating factors and lessons learned. Paper prepared for a seminar on "Children's Rights and Culture in the Pacific". Retrieved February 1, 2009, from www.unicef.org/eapro/Young_people's_participation_in_the_Pacifc.pdf

McQuarrie, P. (2007). Tokelau: People, atolls and history. Wellington: First Edition Ltd.

Merry, S.E. (2001). Changing rights, changing culture. In J.K. Cowan, M.B. Dembour \& R.A. Wilson (Eds.), Culture and rights: Anthropological perspectives (pp. 31-55). Cambridge: Cambridge University Press.

MFAT. (2005). Draft Constitution of Tokelau - English. Retrieved February 13, 2008, from www.mfat.govt.nz/Foreign-Relations/Pacific/Tokelau/TokelauConsitution-(English)

MFAT. (2005). Draft treaty of free association between New Zealand and Tokelau. Retrieved February 13, 2008, from www.mfat.govt.nz/Foreign-Relations/Pacific/Tokelau/Treaty-Treaty$\underline{\text { (English) }}$

MFAT. (2005). Information bulletin on Tokelau. Retrieved August 29, 2008, from www.mfat.govt.nz/Foreign-Relations/Pacific/Tokelau/0-tokelaubooklet.php

MFAT. (2003). New Zealand handbook on human rights. Wellington: author.

Miles, M. (2003). International strategies for disability-related work in developing countries: Historical and critical reflections. Disability in the Third World: The Newspaper for the Network of People with Disability in a Unified World, p. $96-106$. 
Minnow, M. (1990). Making all the difference: Inclusion, exclusion, and American law. New York: Cornell University Press.

Mikkelsen, B. (2005). Methods for development work and research: A new guide for practitioners. New Delhi: Sage Publications.

MOE. (1996). Special education policy guidelines. New Zealand: author.

MOE. (1999). Individual education programme (IEP) guidelines. New Zealand: author.

MOE. (2001) Pasifika Education Research Guidelines. Prepared for Ministry of Education by Anae, M., Coxon, E., Mara, D., Wendt-Samu, T., \&Finau, C. Auckland Uniservices Limited: The University of Auckland.

Nowland-Foreman, G., \& Stubbs, D. (2005). Free and equal: A review of NZAID Pacific Regional Disability Programme for New Zealand Agency for International Development. Pacific Forum Islands Secretariat. Retrieved March 31, 2008, from www.forumsec.org/userfiles/file/regional_doc review of the NZaid_Pacific _Health_Sector_program.pdf

NZAID. (2007). Tokelau programme. New Zealand Agency for International Development. Retrieved April 25, 2008, from http://www.nzaid.govt.nz/programmes/c-tokelau.html

Otsuka, S. (2006). Talanoa research: Culturally appropriate research design in Fiji.

PDF. (2009). Pacific Disability Forum. Retrieved February $12^{\text {th }}, 2009$, from www.pacificdisability.org

PIFS. (2001; 2002; 2004; 2005; 2006; 2007). Forum Basic Education Action Plan: Forum Education Ministers Meetings and Forum Basic Action Plan Review Minutes. Retrieved March 31, 2008, at www.forumsec.org.fj/resources/article/files/FBEAP\%20complete\%202007.pdf

PIFS. (2002). Agenda Item 6(d): Issues in basic education for children and youth with disabilities. Forum Education Ministers Meeting: Suva.

PIFS. (2007). Samoa disability country profile. Retrieved February 12, 2009, from www.forumsec.org/pages.cfm/sustainable-development/socialpolicy/disability/country-profiles/samoa-disability-country-profile

PIFS. (2008). Disability in the Pacific. Retrieved March 31, 2008, from www.forumsec.org./pages.cfm/sustainable-development/socialpolicy/disability

Pfeiffer, D. (2001). The conceptualzation of disability. In S. Barnartt \& B. Altman (Eds.), Exploring theories and expanding methodologies: Where are we now and where do we need to go (pp. 29-52). New York: Elsevier Science. 
Pfeiffer, D., Sam, A. A., Guinan, M., Ratcliffe, K. T., Robinson, N. B., \& Stodden, N. J. (2004). Ethnic and religious perspectives on disability and the helping professions. The Social Science Journal, 41, 683-687.

Platteau, J-P., \& Abraham, A. (2002). Participatory development in the presence of endogenous community imperfections. The Journal of Development Studies, $39(2), 104-136$.

Price, P. (1994). Early intervention in the South Pacific: Issues in program development. International Journal of Disability, Development and Education, 41(3), 223-230.

Price, P., Radio, L., \& Toga, J. (1999). Global trends in disability issues: A south pacific perspective. Developmental Articles. Retrieved March 28, 2008, from http://www.dinf.ne.jp/doc/english/asia/resource/apdrj/z13jo0400/z13jo0404.h $\underline{\mathrm{tml}}$

Price, P. (2003). Education for all (EFA): An elusive goal for children with disabilities in developing countries in the Asian and Pacific region. Asia Pacific Disability Rehabilitation Journal, 41(1), 3-9.

PRIDE. (2004). The Pacific Regional Initiatives for the Delivery of (basic) Education (PRIDE) Project. Retrieved March 31, 2008, from www.usp.ac.fj/index.php?id=pride

Reinsich, A. (2002). The changing international legal framework for dealing with non-state actors. In P. Alston (Ed.), Non-state actors and human rights (pp. 37 - 89). Oxford: Oxford University Press.

Rieber, R.W \& Carton, A.S. (1993). Vygotsky, L.S., Collected Works, Vol.2: The Fundamentals of Defectology (Abnormal Psychology and Learning Disability). London: Plenum Press

RRRT. (2009). The Pacific Regional Rights Resource Team. Retrieved March $15^{\text {th }}$ 2009, from www.rrrt.org

Sanga, K. F. (2004). Making philosophical sense of indigenous pacific research. In T. Baba, O. Mahina, N. Williams \& U. Nabobo-Baba (Eds.), Researching the pacific and indigneous peoples: Issues and perspectives (pp. 41-52).

Auckland: Centre for Pacific Studies: University of Auckland.

Sanga, K. F. (2002). Beyond access and participation: Challenges facing pacific education. In F. Pene, A. M. Taufe'ulungaki \& C. Benson (Eds.), Tree of opportunity: Rethinking pacific education (pp. 52-58). Suva: University of South Pacific: Bluebird Publishing Limited.

Sen, A. (1998). Universal truths: Human rights and the westernising illusion. The Harvard International Review, 20(3), 40-43.

Sen, A. (1999). Development as freedom. New York: Oxford University Press.

Sen, A., \& Wolfensohn, J. (2004). Helping disabled people out of the shadows. Retrieved February 10, 2009, from www.addc.org.au/disabilityadvocacy.html 
SENESE. (2008). Senese School: 3 year strategic plan 2008 - 2010. Samoa.

Shakespeare, T.,\& Watson, N. (2002). The social model of disability: An outdated ideology? Research in Social Sciences and Disability, 2, 9-28.

Smidt, S. (2006). The developing child in the $21^{\text {st }}$ century: A global perspective on child development. New York: Routeledge.

Smith, L. T. (1999). Decolonizing methodologies: Research and indigenous peoples. Dunedin: University of Otago Press.

Smith, L. T. (2004). Building research capability in the pacific, for the pacific and by pacific peoples. In T. Baba, O. Mahina, N. Williams \& U. Nabobo-Baba (Eds.), Researching the pacific and indigenous peoples: Issues and perspectives (pp. 4-16). Auckland: Centre for Pacific Studies: University of Auckland.

Smith, J.D. (2004) The historical contexts of special education: Framing our understanding of comtemporary issues. In A.M. Sorrells, H.J. Rieth \& P.T. Sindelar (Eds.), Critical issues in special education: Access, diversity and accountability (pp. 1-15). USA: Pearson Education Ltd.

Snow, K. (2008). Disability is natural: A new way of thinking. Retrieved March 31, 2008, from www.disabilityisnatural.com

Spedding, S. (2005). The role of teachers in successful inclusion. In P. Foreman (Ed.), Inclusion in action (pp. 404-444). Australia: Thomson.

Statistics New Zealand. (2007). Tokelauan People in New Zealand: 2006. Statistics New Zealand. Wellington: Tatauranga Aotearoa.

Steiner, H.J. \& Alston, P. (2000). International human rights in context: Law, politics, morals $\left(2^{\text {nd }}\right.$ ed.). Oxford: Oxford University Press.

Taafaki, I. J. (2000). Cultural rights: A curriculum and pedagogy for praxis. In P. Hunt \& M. Wilson (Eds.), Culture, rights and cultural rights: A south pacific perspective (pp. 103-106). Wellington: Huia Publishers.

Taufe'ulungaki, A. M. (2002). Pacific education at the crossroads: Are there alternatives? In A. M. Taufe'ulungaki \& C. Benson (Eds.), Tree of opportunity: Rethinking pacific education (pp. 5-21). Suva: University of the South Pacific: Bluebird Printery Limited.

Teasedale, G.R. (2000). Education and cultural rights: An Asia-Pacific perspective. In P. Hunt \& M. Wilson (Eds.), Culture, rights and cultural rights: Perspectives from the south pacific (pp. 117 - 128). Wellington: Huia Publishers.

Terzi, L. (2007). A capability approach on impairment, disability and special needs. In R. Curren (Ed.), Philosophy of education: An anthology (pp. 298-313). Oxford: Blackwell Publishing Ltd. 
Thaman, K. H. (2000). Cultural rights: A personal perspective. In P. Hunt \& M. Wilson (Eds.), Culture, rights and cultural rights: Perspectives from the south pacific (pp. 1-11). Wellington: Huia Publishers.

Thomas, P. (2005). Disability, poverty and the Millennium Development Goals: Relevance, challenges and opportunities for the United Kingdom. Department for International Development. Retrieved September 12, 2008, from www.addc.org.au/disabilitypoverty.html

Thomas, D.R. (2006). A general inductive approach for analyzing qualitative data. American Journal of Evaluation, 27(2), 237-246.

Tiroler, G. (2003, August). Nordic projects in the south: Where do people with disability come in? Disability in the Third World: The Newspaper for the Network of People with Disability in a Unified World, pp. 107-112.

Tokelau Department of Education. (2007). National Curriculum Policy Framework 2006 - 2010. Government of Tokelau.

Tokelau Government Website. (2009).Retrieved January 20, 2009, from www.tokelau.org.nz

Tolich, M., \& Davidson, M. (2003). Collecting the data. In C. Davidson \& M. Tolich (Eds.), Social science research in New Zealand. Auckland: Pearson Education NZ Ltd.

UN. (1948). Universal Declaration of Human Rights. Retrieved March 31, 2008, from www.un.org/Overview/rights.html

UN. (1989). Convention on the Rights of the Child. Retrieved March 31, 2008, from www.2ohchr.org/englsh/law/crc.htm

UN. (2006). Convention on the Rights of Persons with Disability. Retrieved March 31, 2008, from www.un.org/disability/documents/convention/convoptprofe.pdf

UN. (2000). Millennium Declaration, 8th plenary meeting. Retrieved September 12, 2008, from www.un.org/millenniumgoals/

UN. (2008) Mainstreaming disability in the development agenda. Note by the secretariat. Commission for Social Development. Retrieved 31st March, 2008, from http://www.un.org./disability/documents/reports/e-cn5-2008$\underline{6 . d o c}$

UNDP. (2005). Practice Note: Human Rights in UNDP. United Nations Development Programme. Accessed on $5^{\text {th }}$ January 2009, from www.undp.org/governance/docs/HRPN_English.pdf

UNDP. (2008). Country Programme Action Plan (CPAP) between the Government of Tokelau and United Nations Development Programme Samoa MultiCountry Office 2008 - 2012. Retrieved January 15, 2009, from http://www.undp.org.ws/Portals/12/pdf/GPRU/CPAP_Tokelau_signed.pdf 
UN Enable. (n.d.). Fact sheet on persons with disability. Retreived March 31,2008, from www.un.org/disability/documents/toolaction/pwdfs.pdf

UNESCO. (n.d.) Towards Inclusive Education: Initiatives from the Pacific Region.

UNESCO. (1994). World conference on special needs education: Access and quality. Salamanca: Spain. Retrieved March 31, 2008, from www.unesco.org/education/pdf/SALAMA_E.pdf

UNESCO. (2003). Overcoming exclusion through inclusive approaches in education: A challenge and a vision. Conceptual Paper. Retrieved August 6, 2008, from www.unesco.org/education/en/ev.php_URL_ID=56261\&URL_DO=DO_TO PIC\&URL_SECTION=201.html

UNFPA. (2000). Tokelau at a glance. UNFPA in the Pacific. Retrieved February 15, 2009, from www.pacific.unfpa.org/countries.tk.htm

UNGA. (2007). Special Committee on Decolonisation, Concluding 2007 Session, Welcomes Tokelau's Decision to Hold another Referendum on Territory's future Status in October. Retrieved January 17, 2008, at www.un.org/news/press/docs/2007/gacol13163.doc.html

UNICEF. (2003). What is child participation? Retrieved January 8, 2009, from http://www.unicef.org/sowc03/contents/childparticipation.html

UNICEF. (2008). The state of Pacific children. Report by Dr. Chris McMurray. Retrieved February 1, 2009, from www.unicef.org/pacificislands/SOPC1_2008.pdf

UNOHCHR. (2006). Frequently asked questions on a human-rights based approach to development cooperation. Geneva: author.

Urquhart, I. (2009). Reframing psychology for inclusive learning within social justice agendas. In P. Hick, R. Kershner \& P.T. Farrell (Eds.), Psychology for inclusive education: New directions in theory and practice (pp. 66-78). New York: Routeledge.

Vandersyp, C.J., Fairbairn-Dunlop, P., \& Vulu, T. (1998). Review of the framework for New Zealand overseas development aid to Tokelau. Prepared for the Government of New Zealand and the Government of Tokelau, April 1998.

Vaioleti, T. M. (2006). Talanoa research methodology: A developing perspective on Pacific research. Waikato Journal of Education, 12, 21-34.

Valdez, M.F., Dowrick, P.W., \& Maynard, A.E. (2007). Cultural misperceptions and goals for Samoan children's education in Hawai'i: Voices from school, home, community. The Urban Review, 39(1), 67-92.

Wickliffe, C. (2000). Cultural rights, culture and human rights education. In M. Wilson \& P. Hunt (Eds.), Culture, rights and cultural rights: A south pacific perspective (pp. 129-143). Wellington: Huia Publishers. 
Williams, N. (2004). On the inside: Narratives from the 'frontline'. In T. Baba, O. Mahina, N. Williams \& U. Nabobo-Baba (Eds.), Researching the pacific and indigneous peoples: Issues and perspectives (pp. 159-169). Auckland: Centre for Pacific Studies: University of Auckland.

Wirz, S., \& Thomas, M. (2002). Evaluation of community-based rehabilitation programmes: A search for appropriate indicators. International Journal of Rehabilitation Research, 25(3), 163-171.

Wong, D., Peason, V., Ip, F., \& Lo, E. (1999). A slippery road to equality: Hong Kong's experience of unplanned integrated education. Disability \& Society, 14(6), 771-789.

WHO. (2001). World Health Organisation International Classification of Functioning, Disability and Health. Retrieved January 3, 2009, from www.who.int/classifications/icf/en/

Yeo, R., \& Moore, K. (2003). Including disabled people in poverty reduction work: "Nothing about us, without us". World Development, 31(3), 571-590. 


\section{Appendix One: Principles which underpin the International Human Rights Framework}

- Universality and inalienability: All people everywhere in the world are entitled to human rights. They cannot be given up or taken away.

- Indivisibility: Human rights are indivisible. Whether of a civil, cultural, economic, political or social nature, they are all inherent to the dignity of every human person. Consequently, they all have equal status as rights, and cannot be ranked in a hierarchical order.

- Inter-dependence and Inter-relatedness. The realisation of one right often depends, wholly or in part, upon the realisation of others. For instance, realisation of the right to health may depend, in certain circumstances, on the realisation of the right to education, or of the right to information.

- Equality and Non-discrimination: All human beings are entitled to their human rights without discrimination of any kind, on the grounds of race, colour, sex, ethnicity, age, language, religion, political or other opinion, national or social origin, disability, property, birth or other status as explained by the human rights treaty bodies.

- Participation and Inclusion: Every person and all peoples are entitled to active, free and meaningful participation in, contribution to, and enjoyment of civil, economic, social, cultural and political development in which human rights and fundamental freedoms can be realised.

- Accountability and Rule of Law: States and other duty-bearers are answerable for the observance of human rights. In this regard, they have to comply with the legal norms and standards enshrined in human rights instruments. Where they fail to do so, aggrieved rights-holders are entitled to initiate proceedings for appropriate redress before a competent court or other adjudicator, in accordance with the rules and procedures provided by law.

(UNDP, 2005, p. 16) 


\section{Appendix Two: Obligations of State Parties to International Human Rights Law}

Human rights law defines three categories of actors - rights-holders (a category to which all humans automatically belong and cannot withdraw from), duty-bearers and others. It is not the responsibility solely of the State to ensure the provision of human rights for each individual citizen; rights holders and others (for example, NGOs, multinational corporations, regional cooperative bodies, aid agencies, and private sector organisations) are all moral duty bearers expected to act in a manner which realises human rights, including their own. The State is, however, the only legally obligated moral duty bearer in the protection and realisation of human rights for its citizens (Mikkelsen, 2005). The obligations of the State in international human rights law are outlined here.

The obligation to respect requires State Parties to refrain from interfering with the enjoyment of rights. It must abstain from carrying out, sponsoring or tolerating any practice, policy or legal measure violating the integrity of individuals or impinging on their freedom to access resources to satisfy their needs. It also requires that legislative and administrative codes take account of guaranteed rights.

The obligation to protect obliges the State Parties to prevent the violation of human rights by third parties such as other individuals or non-state actors. Where violations do occur the State must guarantee access to legal remedies.

The obligation to fulfil involves issues of advocacy, public expenditure, governmental regulation of the economy, the provision of basic services and related infrastructure and redistributive measures. The duty of fulfilment comprises those active measures necessary for guaranteeing opportunities to access entitlements. It requires State Parties to take appropriate legislative, administrative, budgetary, judicial and other measure toward the full realisation of human rights, including the promotion of human rights.

(UNDP, 2005) 


\section{Appendix Three: Outline of International Frameworks relating to Disability, Education and Development}

\section{The Universal Declaration of Human Rights 1948}

The Universal Declaration of Human Rights (UDHR) is the central international document which focuses on the protection, equality and dignity of individuals (UN, 1948). It recognises the equality and inherent worth of all human beings and accords basic rights to all individuals. With respect to education, the UDHR states that

"Everyone has the right to [free and compulsory elementary] education..." Article 26, Paragraph 1

"Education shall be directed to the full development of human personality and to the strengthening of respect for human rights and fundamental freedoms..." Article 26, Paragraph 2

The UDHR applies to, but does not specifically mention people with disability (McKinstry et al., 2004). Since the UDHR, a number of more specific and legally binding international covenants and treaties have evolved in order to realise the human rights of all individuals.

\section{The Convention on the Rights of the Child 1989}

This document lays out the fundamental human rights of children and acknowledges that special care and provisions are necessary in childhood. For children with disability this convention protects their rights to life, support, rehabilitation, education, employment and recreation. It also provides for their fullest possible individual development and integration (UNCROC, 1989).

Specifically it states that:

"State Parties shall respect and ensure the rights set forth in the present convention to each child in their jurisdiction, without discrimination of any kind, irrespective of the child's ...disability...or other status."

(Article 2, Paragraph 1).

"State Parties recognise that a mentally or physically disabled child should enjoy a full and decent life, in conditions which ensure dignity, promote selfreliance and facilitate the child's active participation in the community."

(Article 23, Paragraph 1). 
It reiterates the sentiment in the UDHR that the central aim of education is to encourage the fullest emotional, social, creative and cognitive development of every individual (Eklindh \& Brule-Balescut, 2005).

\section{Education For All - the Jomtien Declaration on Education For All (EFA) 1990\& the Dakar Framework of Action 2000}

The 'Education For All' is one of the most well known movements in the international arena - in 1990, representatives from 155 countries and 150 organizations pledged to provide basic education for all children, youth and adults by the year 2000 at the World Conference on Education for All in Jomtien, Thailand. Originally this initiative did not explicitly mention inclusion of children with disability. However, over time, EFA has adapted to assume inclusive education philosophy at its core (Eklindh \& Brule-Balescut, 2005). The 2000 Dakar Framework of Action, which reinforced the original declaration and set another target for 2015 makes reference to ensuring education of the most disadvantaged children in formal and non-formal approaches and also to early childhood education, literacy and life skills programmes (Eklindh \& Brule-Balescut, 2005).

\section{United Nations Standard Rules on the Equalisation of Opportunities for Persons with Disability 1993}

This international document provides a framework for policy making and legislature change. It suggests ways in which States can take responsibility for removing obstacles which prevent full participation in society for people with disability as well as outlining positive actions which the State can take to ensure full participation in society for people with disability. The rules are not legally binding, but show a strong moral and political commitment to equalising opportunities for persons with disability by governments (UN, 1993). There are 22 rules in four chapters preconditions for equal participation, target areas for participation, implementation measures, and the monitoring mechanism. With regard to education, the rules advocate for equal access to primary, secondary and tertiary education in an integrated setting for children, youth and adults with disability (UN, 1993). 


\section{Millennium Development Goals (MDGs) 2000 - 2015}

The UN Millennium Development Goals were formed at the start of the new millennium to rally the international community by providing focus and direction for aid and development initiatives. The MDGs have been credited with coordinating international development efforts (Alston, 2005). The goal for education is as follows

"By the year 2015, children everywhere, boys and girls alike, will be able to complete a full course of primary schooling, and that boys and girls will have equal access to all levels of education" (UN, 2000).

Reference to inclusion of children, youth and adults with disability is not explicitly stated in this or any of the other MDGs. The Millennium Declaration refers to human rights although the MDGs themselves do not. However, it is generally accepted that the goals follow a human rights approach (Alston, 2005, p. 757).

\section{The Convention on the Rights of Persons with Disability}

The Convention of the Rights of Persons with Disability is discussed in the body of the thesis. 


\section{Appendix Four: UN Asian-Pacific Regional Disability Initiatives}

The first regional disability initiative was instigated by the UN: the Asian-Pacific Decade of Disabled Persons from 1993-2002. The Asian-Pacific Decade of Disabled Persons was intended to build on the public awareness raised by the 1981 International Year of Disabled Persons and the 1982 United Nations Decade of Disabled Persons, and to establish and begin to carry out actions needed to support people with disabilities in the region (McKinstry et al., 2004). The start of the AsianPacific Decade of Disabled Persons saw the signing of the Proclamation on the Full Participation and Equality of People with Disabilities in the Asian and Pacific Region in 1993 by Fiji, Australia and the Federated States of Micronesia. An Agenda for Action was also adopted in 1993 which provided operational guidelines for governments for establishing policies and programmes concerning people with disabilities. The Agenda for Action provided guidelines relevant for the developing country context in 12 major policy areas: national coordination, legislation, public awareness, accessibility and coordination, education, training and employment, prevention of the causes of disability, rehabilitation, assistive devices, self-help organisations and regional cooperation (McKinstry et al., 2004).

Evaluation of these strategies at the conclusion of the Decade revealed that although some progress had occurred, it was variable across the region and there was a significant lack of equitable access to social environments and education for students with disability, as well as a lack of data about people with disability in the region (McKinstry et al 2004). Therefore, a decision was made to continue the initiative, and the $2^{\text {nd }}$ Asian-Pacific Decade of Disabled Persons from 2003-2012 was launched.

The seminal document to begin the $2^{\text {nd }}$ Asian-Pacific Decade of Disabled Persons was the Biwako Millenium Framework of Action towards an Inclusive, Barrier-free and Rights-based society for Persons with Disabilities in Asia and the Pacific (BMF). The BMF is the partner document to the Millennium Development Goals for the Asian and Pacific region and includes specific targeting of children and youth with disabilities in planning initiatives. The BMF provides an operational guideline for governments and civil societies which they need to apply nationally in order to work towards two broad targets: by 2010 at least 75 per cent of children and youth with disabilities will have completed or be in the process of completing primary 
schooling; and by 2012 all infants and young children with disabilities will have received early intervention services including support for their families.

Priority Areas for Action for the Second Asian-Pacific Decade of Disabled

\section{Persons}

\section{$2003-2012$}

- Self-help organisations of persons with disabilities and related family and parent associations;

- Women with disabilities;

- Early detection, early intervention and education;

- Training and employment, including self-employment;

- Access to built environments, and public transport;

- Access to information and communications, including information, communications and assistive technologies;

- Poverty alleviation through capacity-building, social security and sustainable livelihood programmes.

Source: PIFS, 2008 


\section{Appendix Five: The Cycle of Poverty and Impairment}

\section{How Impairment Causes Poverty:}

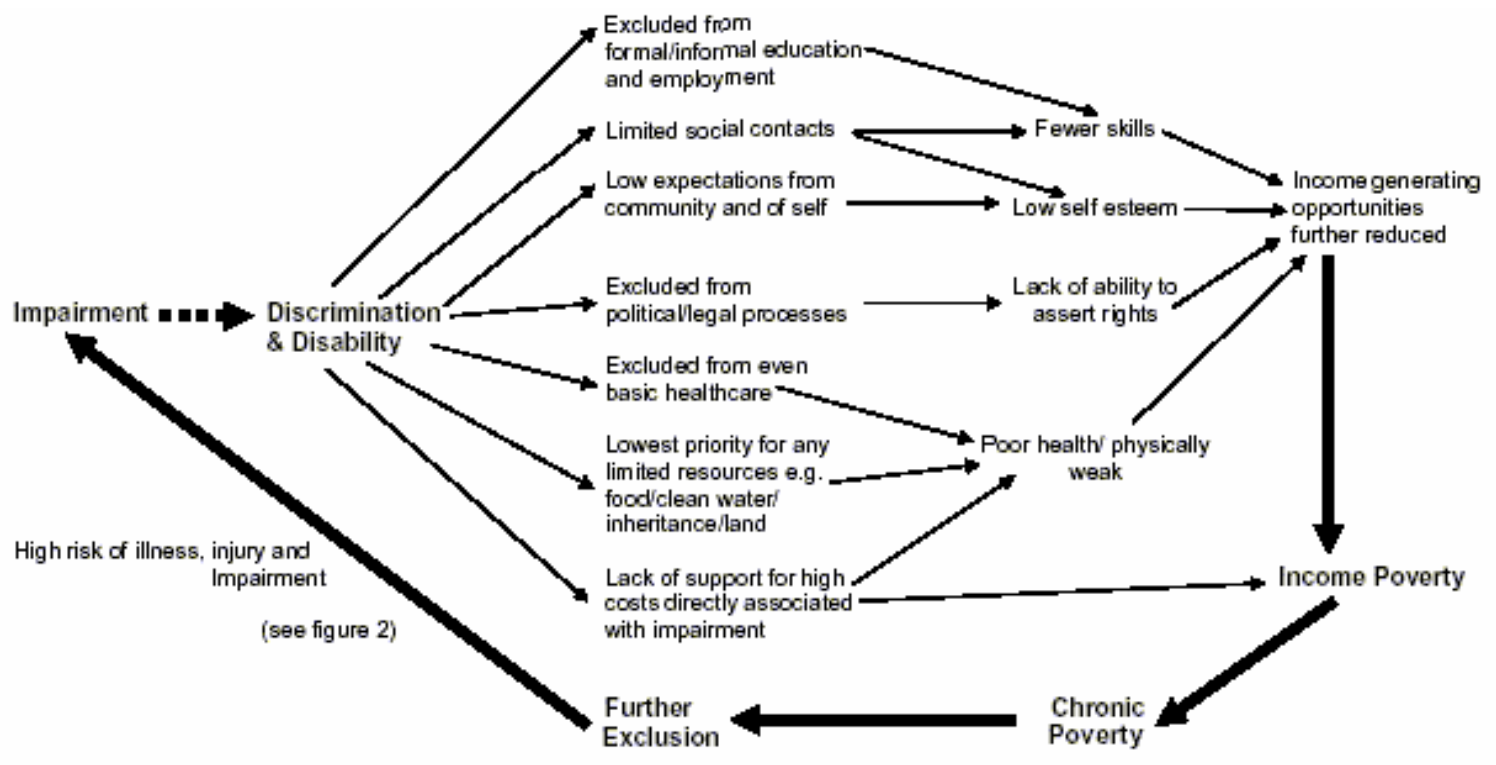

(Source: Yeo \& Moore 2003, p. 572)

How Poverty Causes Impairment:

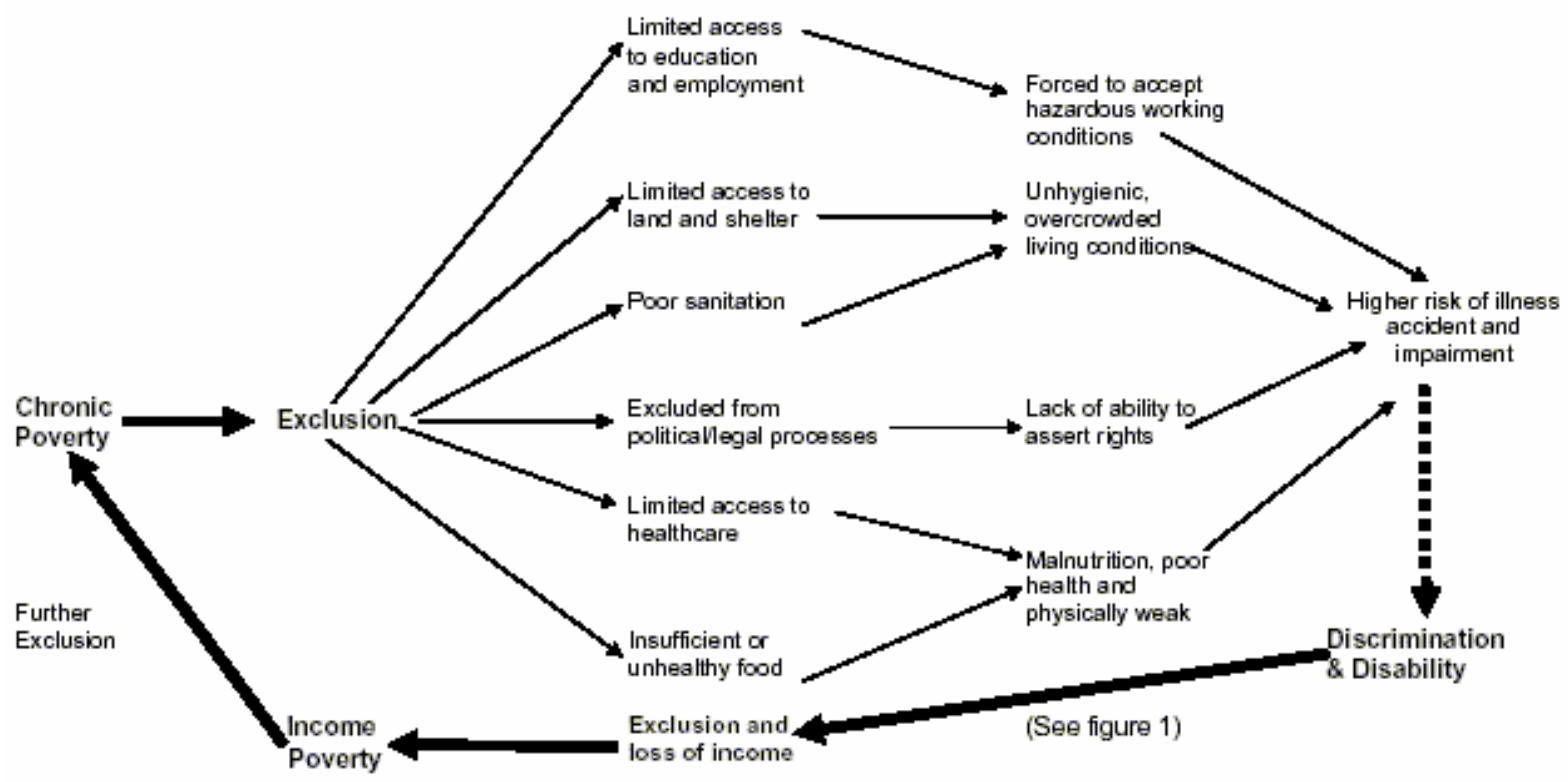

(Source: Yeo \& Moore, 2003, p. 573) 


\section{Appendix Six: Bronfenbrenner's Ecological Model of Child Development}

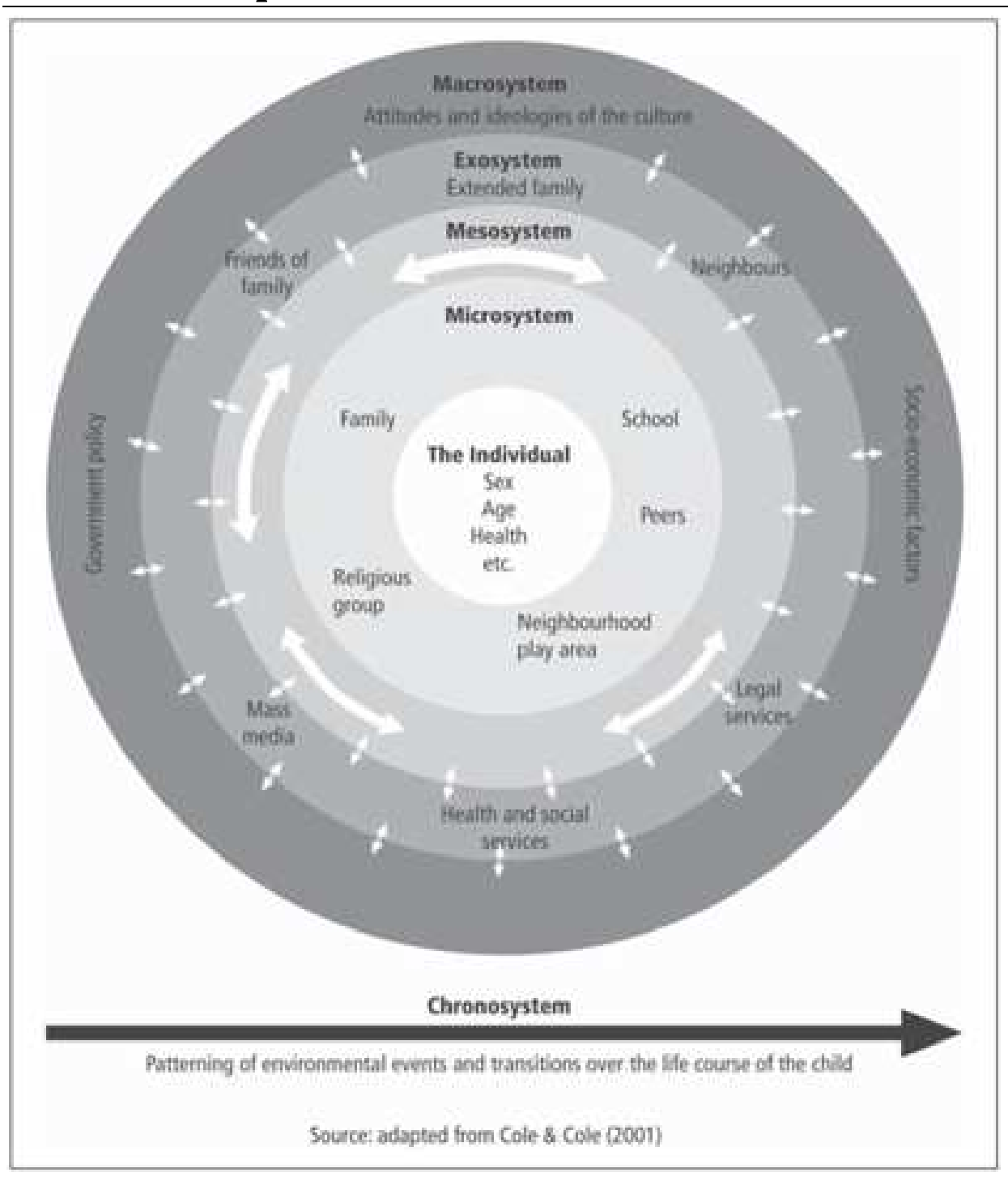

Urie Bronfenbrenner is a psychologist who devised an ecological theory of child development in 1979. Bronfenbrenner emphasizes the importance of the developing child's interactions with the people and institutions closest to her within the microsystem and mesosystem, as well as the effects on her life of a widening array of social and cultural institutions, attitudes, and beliefs within the exosystem and the macrosystem. These systems change over time, which is represented by the chronosystem. Source: Accessed $19^{\text {th }}$ February 2009, from: 


\section{Appendix Seven: Ethics Forms}

\section{Participant Information Sheet}

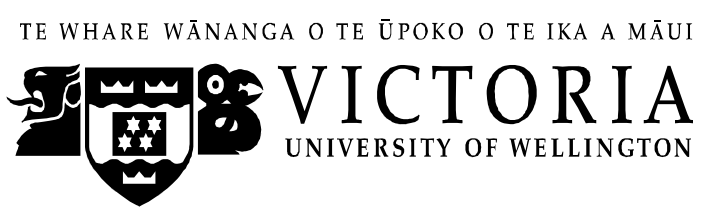

Participant Information Sheet for:

\section{Inclusive Education in Tokelau}

Researcher: Kathryn Meredith, Development Studies Programme, School of Earth Sciences, Victoria University of Wellington, New Zealand

In the South Pacific there are many regional initiatives underway to promote inclusion in schools and communities for children with special needs. Pacific governments are working to bring disability issues to the forefront as an issue of national and regional concern. One of the desired outcomes stated in the Tokelau 2007/08 Education Plan is to "improve learning opportunities for children with special needs". In 2006 the Tokelauan government requested support from the New Zealand government in establishing a database of children with special needs and in raising public awareness about special education.

As part of my degree, I am undertaking research about inclusive education in Tokelau leading to a thesis.

The objectives of this research are to:

1. To document traditional and modern Tokelauan perceptions and understanding about special needs, and aspirations for (children with special needs) inclusive education in Tokelau.

2. Identify the challenges that Tokelau faces in educating children with special needs.

3. Examine New Zealand's role and responsibilities as a state provider in ensuring inclusive education practices in Tokelau and in supporting ongoing capabilities building in order to ensure sustainability in Tokelau's inclusive education initiatives. 
4. Examine Tokelau's participation in and commitment to international and regional initiatives and mandates concerning disability issues such as the Convention on the Rights of People with Disabilities, the Education for All movement, the Pacific Disability Forum and the Biwako Millenium framework.

This research will document the Tokelauan community's perceptions and desires about Inclusive Education, the rights of children with disabilities and service options for children with special needs; it will in itself contribute to raising awareness of some of the issues of equity and access faced by children with disabilities in Tokelau. It will serve as a baseline of existing knowledge and attitudes and be valuable information for planning the next steps in implementing inclusive education in Tokelau. The thesis will also contribute to the growing body of literature on inclusive education and disability initiatives in small Pacific island states.

The University requires that ethics approval is obtained for research involving people, and that I attain your informed consent prior to undertaking the interview. Ethics approval from the University has been granted.

People will be invited to participate in an approximately 60 minute (group or individual) interview where you can describe your experiences, views and aspirations for inclusive education in Tokelau.

Participation is voluntary. Participants may withdraw themselves and their comments at any stage.

With participants' consent, the interviews will be recorded. At any stage during the interview the participant may request that recording is ceased. Any written or electronic material will be confidential and kept securely (in a locked room); it will only be seen by myself and my supervisor. All participant information will remain private and confidential and your responses may be identified in the published thesis by gender, age bracket and usual country of residence only. The information and opinions given during the interview will only be attributed to participants with their permission. 
Upon completion of my thesis, a copy will be available from the Victoria University library. A summary of findings will be distributed to you upon your request. The research may also be published in academic journals and / or disseminated at academic or professional courses as the opportunity arises.

Although I work for Group Special Education, Ministry of Education, I am undertaking this research as a student. If you have any questions or would like any further information about this project please contact me or my supervisor.

This study is being conducted by Kathryn Meredith, Masters of Development Studies student at Victoria University of Wellington, PO Box 600, Wellington, New Zealand (phone 006444395016 ).

kathryn.meredith@minedu.govt.nz or meredith_kathryn@hotmail.com

Supervisor: Dr. P. Fairbairn-Dunlop, Director, Va'aomanu Pasifika, Pacific and Samoan Studies, Victoria University of Wellington, PO Box 600, Wellington, New Zealand (phone 00644463 6867).

peggy.fairbairn-dunlop@vuw.ac.nz 


\section{Participant Consent Sheet}

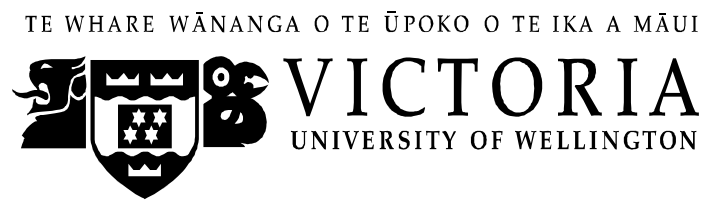

\section{Participant Consent Sheet}

\section{Title of Project: Inclusive Education in Tokelau}

I have been given and have understood an explanation of this research project. I have had an opportunity to ask questions and have them answered to my satisfaction. I understand that I may withdraw myself (and any information I have provided) for this project (before data collection and analysis is complete) without having to give reasons.

I agree to take part in this research

I consent to this interview being recorded

I understand that I will have the opportunity to check the transcripts of the interviews before publication

$\square \quad$ I understand that the data I provide will not be used for any other purposes or be released to others without my consent

I would like to receive a summary of the research when it is completed

$\square$ I only consent to undertaking this interview under the condition that the published results will not use my name, and that no opinions will be attributed to me in any way that will identify me or

I consent to information or opinions which I have given being attributed to me in any reports on this research

Signed:

Name of Participant:

(Please print clearly)

Date: 


\section{Interview Questions Guide}

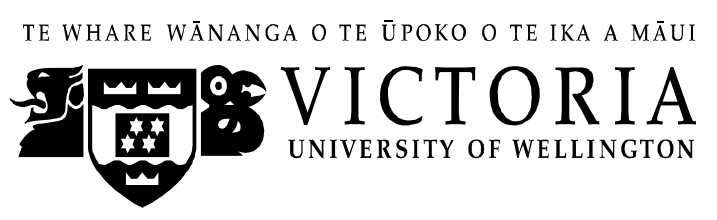

Inclusive Education in Tokelau.

Researcher: Kathryn Meredith, Development Studies Student, Victoria University of Wellington

\section{Interview Questions}

Please note that questions may not be asked in the order presented below nor will every question necessarily be asked given the sensitive nature of the topic. In addition the researcher will further probe any issues raised in the course of the interviews. Bracketed sections are prompts for the interviewer.

\section{Attitudes \& knowledge}

- What do you know about special needs and inclusive education?

- Is there a Tokelauan word for people with special needs?

- Have you had any personal experiences with people who have special needs?

- What are traditional Tokelauan beliefs about people with special needs?

- What are your personal beliefs about people with special needs?

- What are the traditional Tokelauan views about educating children with special needs?

- If you had a child or grandchild with special needs would you like them to be in school? Why / why not? Would you prefer them to be in class with other children their age or in a special class?

- Do you know of any groups or people in Tokelau who meet to discuss these issues?

- Have you seen any or do you know about of the types of programmes, supports and classes for children with special needs and their families in New Zealand? Do Tokelauan families access Special Education? If not, why not?

- What would be the ideal scenario for children with disabilities and their families in Tokelau?

\section{Resources \& Provision of Support}

- What is currently happening to support children with special needs and their families in Tokelau? 
- Who is responsible for providing support and education to children with special needs and their families in Tokelau? (NZ / Tokelau; Education / Health)

- What do you think the challenges of implementing inclusive education in Tokelau would be? (Infrastructure? Politics? Resources? Culture?)

\section{International and Regional Movements}

- Samoa and the Cook Islands have established special classrooms attached to mainstream schools so their students can access special and mainstream education. Do you think that this could work in Tokelau? If not, why not?

- Have you heard of international and regional initiatives like the Education for All, the Pacific Disability Forum, the Biwako Millenium framework and the Millennium Development Goals? How do these impact on people with disabilities in Tokelau?

- The United Nations has recently developed its Convention on the Rights of Persons with Disabilities, which New Zealand has signed. This is a significant document internationally in terms of putting disability issues into the realm of human rights rather that social welfare. What impact do you think this will have in Tokelau?

- There are also many regional initiatives focused on raising awareness and developing strategies to support people with disabilities currently underway in the Asia-Pacific - e.g. Biwako Millennium Framework, Inclusion International, second Asia-Pacific Decade of Disabled Persons and Pacific Disability Forum. What is Tokelau's involvement in these initiatives and what impact have they had (or do you expect to see them have in future) locally? 